University of Louisville

ThinkIR: The University of Louisville's Institutional Repository

Electronic Theses and Dissertations

$5-2018$

\title{
A qualitative approach to examining the rules of a community college and industry partnership.
}

Cara Dimattina-Ryan

University of Louisville

Follow this and additional works at: https://ir.library.louisville.edu/etd

Part of the Adult and Continuing Education Commons, Human Resources Management Commons, and the Organizational Behavior and Theory Commons

\section{Recommended Citation}

Dimattina-Ryan, Cara, "A qualitative approach to examining the rules of a community college and industry partnership." (2018). Electronic Theses and Dissertations. Paper 2897.

https://doi.org/10.18297/etd/2897

This Doctoral Dissertation is brought to you for free and open access by ThinkIR: The University of Louisville's Institutional Repository. It has been accepted for inclusion in Electronic Theses and Dissertations by an authorized administrator of ThinkIR: The University of Louisville's Institutional Repository. This title appears here courtesy of the author, who has retained all other copyrights. For more information, please contact thinkir@louisville.edu. 
A QUALITATIVE APPROACH TO EXAMINING THE RULES OF A COMMUNITY COLLEGE AND INDUSTRY PARTNERSHIP

By

Cara DiMattina-Ryan
B.S., William Paterson University, 2007

A Dissertation

Submitted to the Faculty of the

College of Education and Human Development of the University of Louisville in Partial Fulfillment of the Requirements

for the Degree of

Doctor of Philosophy in Educational Leadership and OrganizationDO HMHRSP HQW

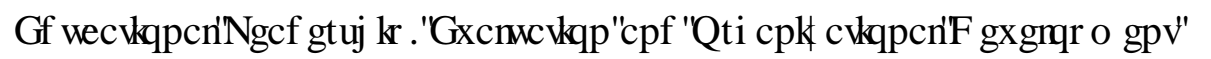

एس山ा山m

Louisville, Kentucky

(

(

May 2018 
Copyright 2017 by Cara DiMattina-Ryan

All rights reserved 



\title{
A QUALITATIVE APPROACH TO EXAMINING THE RULES OF A COMMUNITY COLLEGE AND INDUSTRY PARTNERSHIP
}

\author{
By \\ Cara DiMattina-Ryan \\ B.S., William Paterson University, 2007
}

A Dissertation Approved on

March 8, 2018

by the following Dissertation Committee:

Dr. Meera Alagaraja, Chair (ELEOD)

Dr. Kyle Ingle, (ELEOD)

Dr. Terri Rowland (ELEOD)

Dr. Beth Bukoski 


\section{DEDICATION}

This dissertation is dedicated to my daughter and son, Katherine and Anthony. May you always value the pursuit of knowledge. You can overcome obstacles and achieve anything, if you are willing to put in the time and effort.

To my husband, Mark Ryan - thank you for being supportive throughout this whole endeavor. Thank you for sitting outside of an office building with our newborn so I could collect data. Thank you for proofreading and editing various papers. Thank you for being a study buddy and someone I could bounce ideas off. I promise not to make you call me Doctor (every day).

To Dr. Stone - Thank you for sending me down this path. I started on this journey, because of your passion for the field and your support and encouragement of me. The whole doctoral experience gave me more than just academic lessons and a doctorate. I gained experiences, friendships, and a new data-driven way to problem solve. Without

you, I'm not sure that I would have chosen this path. I can't thank you enough for helping me to choose it (and employing me through most of it). 


\section{ACKNOWLEDGMENTS}

I could never have accomplished completing my doctorate without the support of my dissertation committee. Each of you placed time, energy, and support into my dissertation's final product. Without those resources, I would not have accomplished and learned from the dissertation process.

I, also, have had the great fortune to be surrounded by some of the strongest and most supportive women in our field. Dr. Alagaraja was integral to help me shape my research ideas and strategies early on in my doctoral journey. Dr. Bukoski gave me time, energy, and support during one of the most challenging times I had early on in the dissertation process. I would not be where I am now without their understanding, support, and contributions to my writing and research process. 


\begin{abstract}
A QUALITATIVE APPROACH TO EXAMINING THE RULES OF A COMMUNITY COLLEGE AND INDUSTRY

Cara DiMattina-Ryan
\end{abstract}

March 8, 2018

The purpose of this study was to qualitatively examine the governance structure of a successful community college and industry advisory board that collaborate to improve regional workforce development initiatives. The institutional analysis and development (IAD) framework was used as a lens to describe the partnership. The results determined that there were many informal rules that governed the relationship between the community college and industry partners, which led to successful implementation of decisions. The community college leaders created the informal rules with the purpose of encouraging involvement among industry stakeholders, sharing power among all the participants, and facilitating communication. The findings are consistent with the literature in collaboration. Frequent and open communication, outcomes that benefit all stakeholders, and other positive institutional designs aid in the success of a community college and industry partnership.

Keywords: community college, collaboration, industry, partnerships, industry advisory board, governance, institutional analysis and development framework, rules, cooperation, regional workforce development 


\section{TABLE OF CONTENTS}

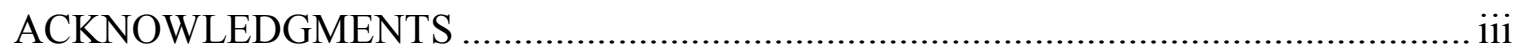

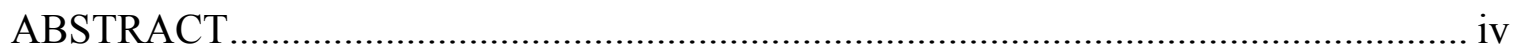

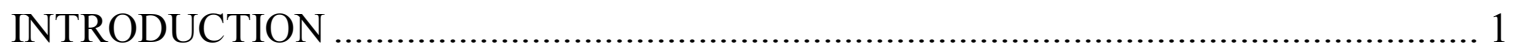

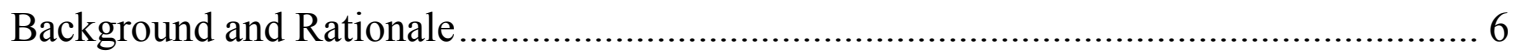

Purpose

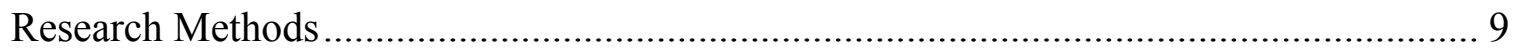

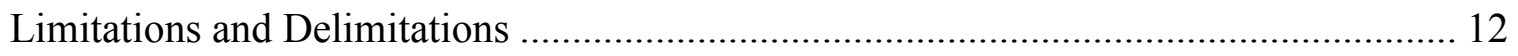

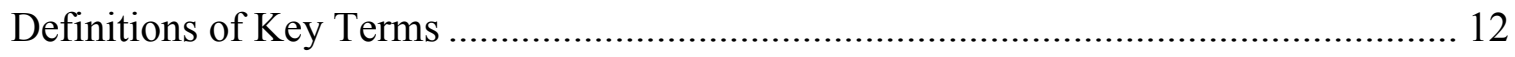

Organization of the Remaining Chapters.................................................................... 14

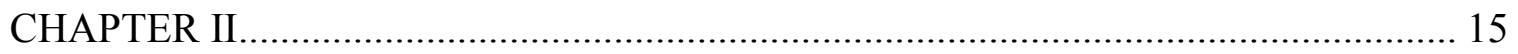

Community College and Industry Collaboration ......................................................... 16

Supply and Demand Problems in Workforce Development......................................... 19

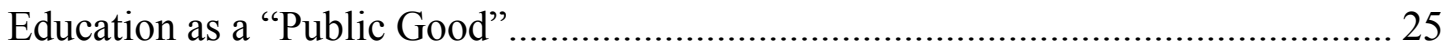

Bureaucratic Incentive Structure...................................................................... 26

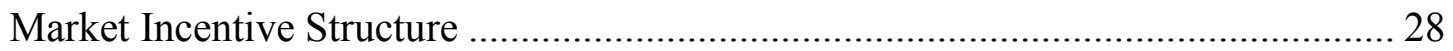

Workforce Development in the Public and Private Sectors .............................................. 30

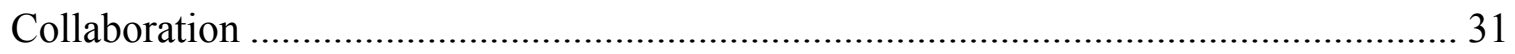

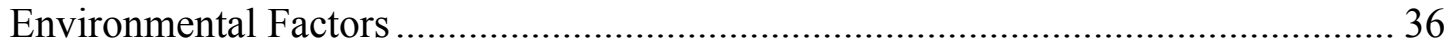

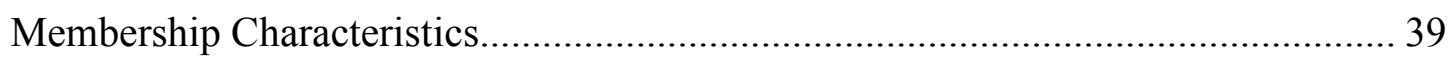

Structure

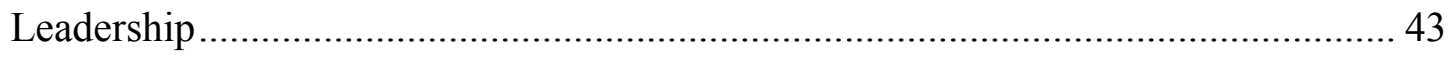




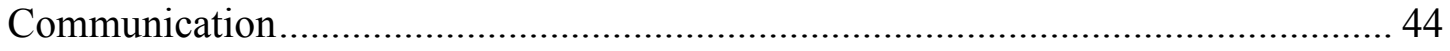

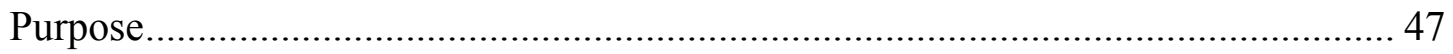

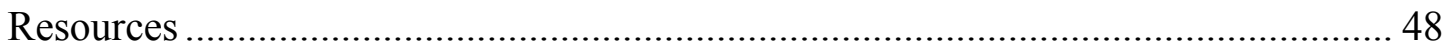

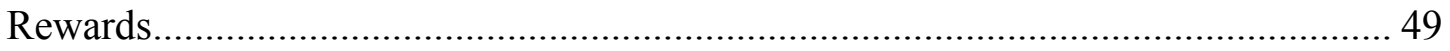

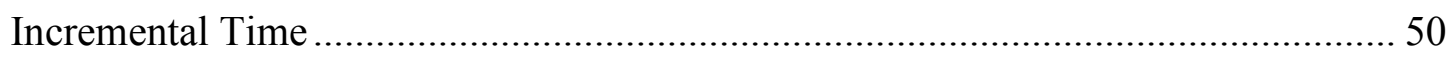

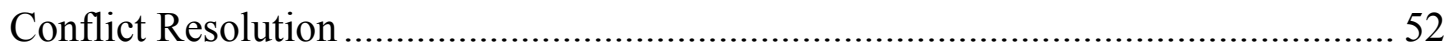

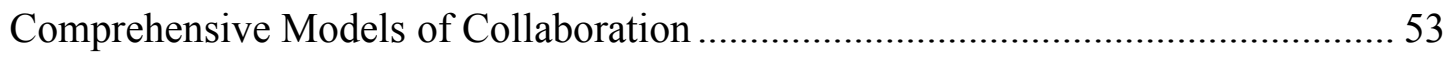

Institutional Analysis and Development Framework …………………....................... 54

Key Components of the Action Situation ................................................................. 59

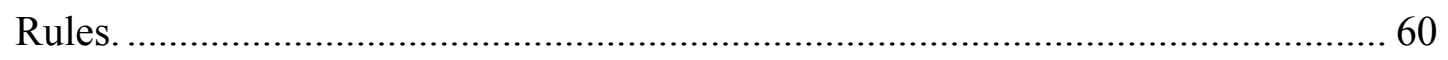

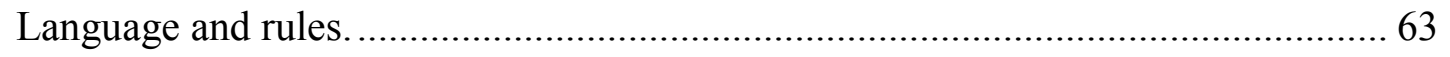

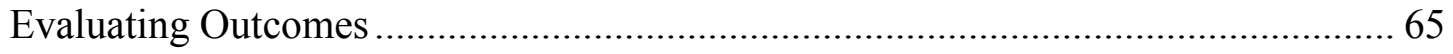

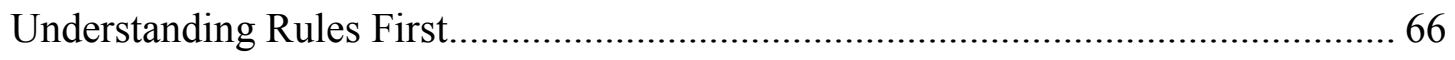

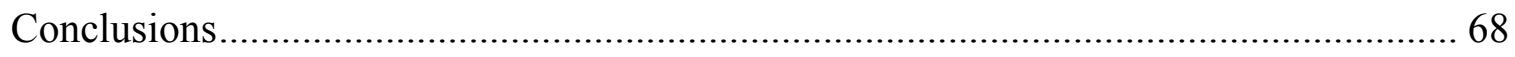

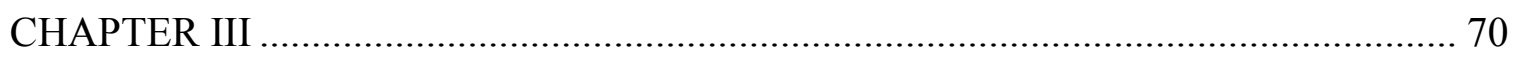

Philosophical Assumptions and the Qualitative Case Study ………………………....... 72

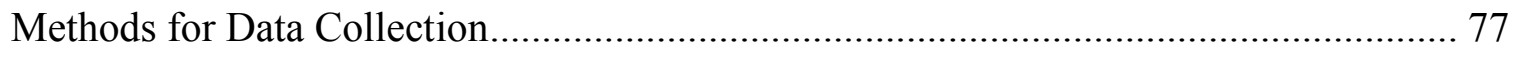

Documentation and Archival Records ................................................................... 78

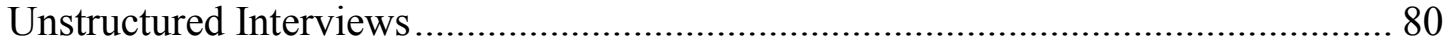

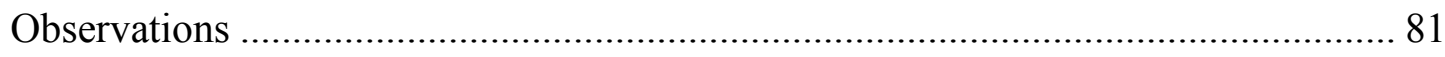

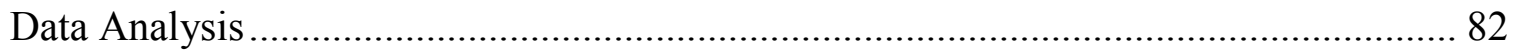

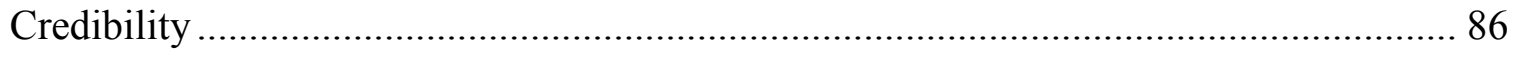

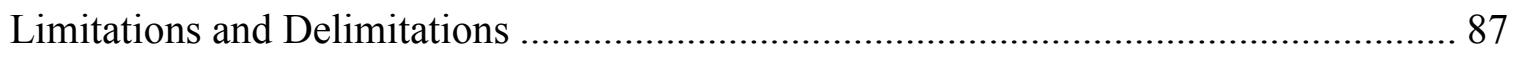




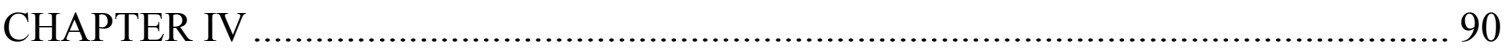

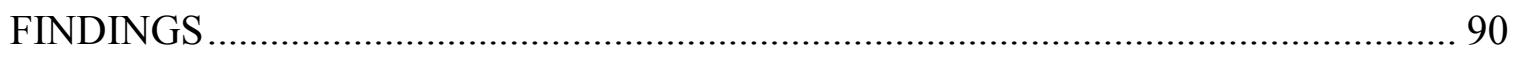

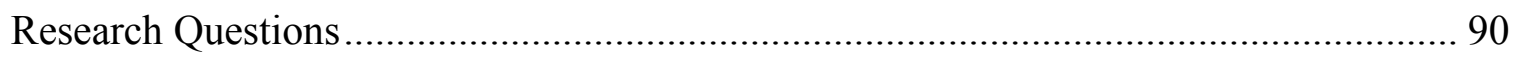

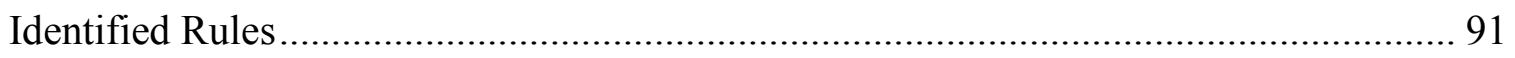

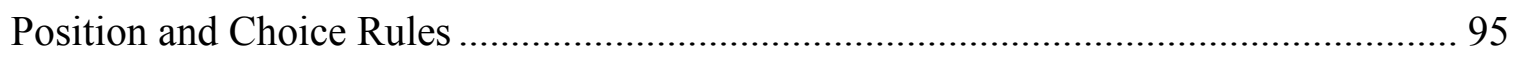

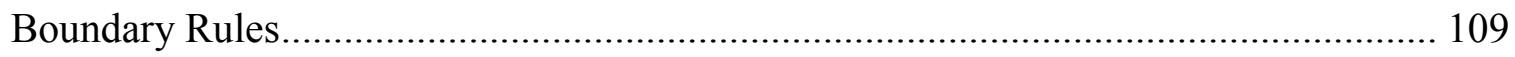

Aggregation and Information Rules .................................................................... 117

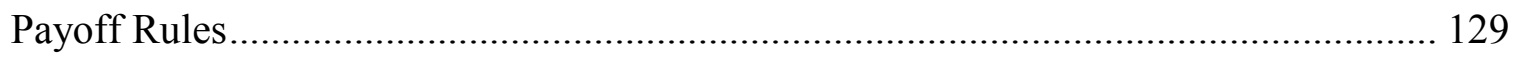

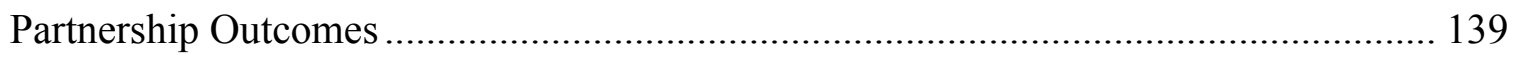

Updated and Added Curriculum \& Improved Website ………………......................... 140

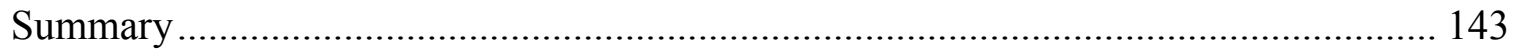

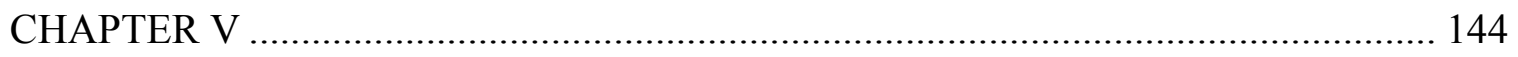

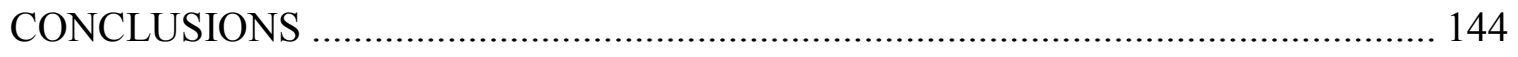

Revisiting the Purpose of the Study ......................................................................... 144

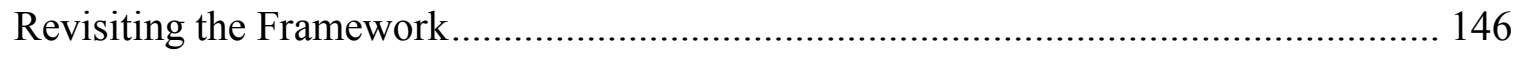

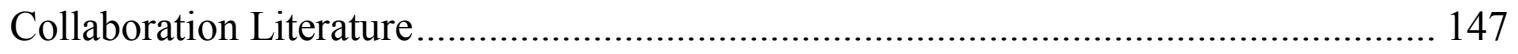

Applicability of the Rules .................................................................................... 148

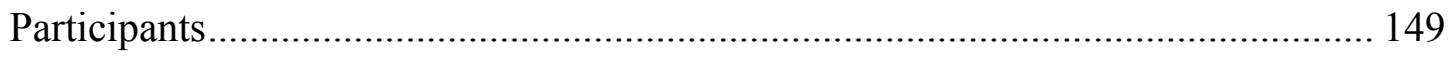

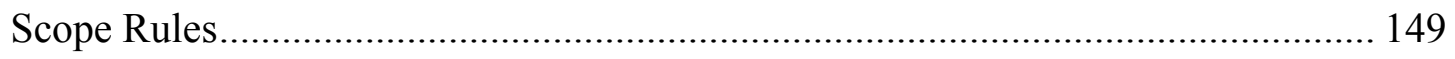

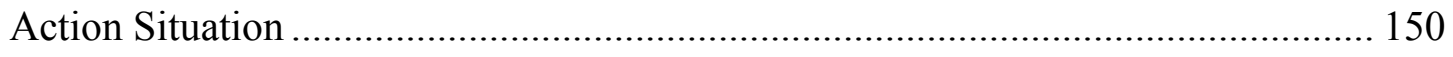

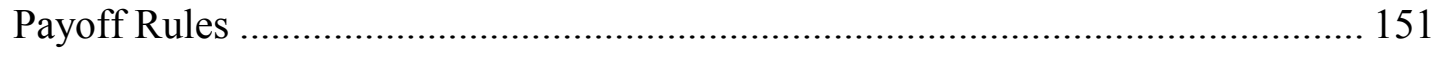

Assessing the Outcomes .................................................................................. 152

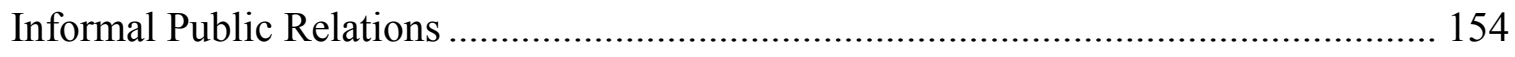


Implications for Future Research .................................................................. 155

Implications for Practice .................................................................................... 156

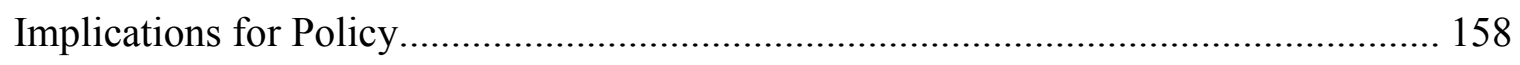

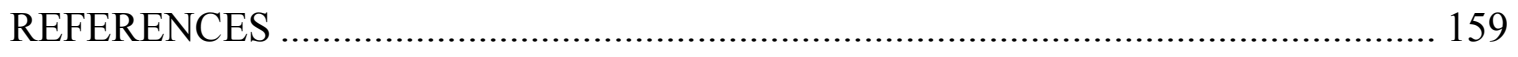

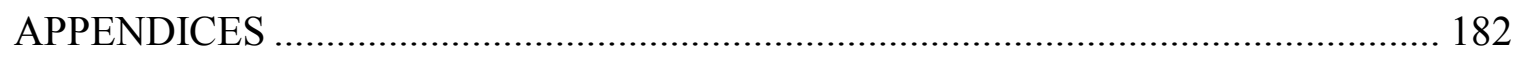

Appendix A. Observation Protocol ............................................................... 182

Appendix B. Unstructured Interview Guide ................................................ 183

Appendix C. Provisional List of Codes for Identified Rule Types ......................... 184

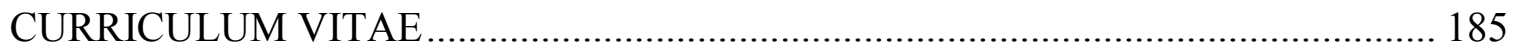




\section{CHAPTER I}

\section{INTRODUCTION}

The United States is concerned with its ability to be competitive as producers of goods and services in a global marketplace. The World Economic Forum (Schwab, SalaiMartin, \& Greenhill, 2011; Schwab, Sala-i-Martin, Eide, \& Blanke, 2014) defines the position of countries as global competitors based on the development of 12 pillars: institutions, infrastructure, macroeconomic stability, health and primary education, higher education and training, goods market efficiency, labor market efficiency, financial market sophistication, technological readiness, market size, business sophistication, and innovation. Within those pillars, education plays an important role in preparing citizens to be a part of the workforce and enhance the innovativeness of industry (Arbo \& Benneworth, 2007; Hayter, 1997; Porter, 2000; Schwab et al., 2011; Schwab et al., 2014). The United States has performed well in these areas, ranking seventh in the overall quality of our higher education and training programs and fifth in our ability to innovate (Schwab et al., 2014). These rankings have contributed to the United States being ranked as third in the world for our competitive advantage (Schwab et al., 2014).

As a key economic power, the United States has participated in many global conferences and assemblies to discuss its role and the development of the global economy. As part of the G20 Summits throughout 2010, all participating countries agreed about the importance of developing an "employee-oriented framework" that improved 
skill training and development in order to responsibly sustain economic growth (International Labour Office, 2011). The United States invested in this strategy through the American Recovery and Reinvestment Act of 2009. Almost four billion dollars was allocated to expand existing training programs and grants to develop programs in emerging industry sectors, such as green and renewable energies. This has helped to spur the growth of industry at local and regional levels in the country (Hamilton, 2012). This strategy improved the relationships between local and regional workforce organizations and private industry (Hamilton, 2012).

However, as we look more in depth at the rankings and definitions as described by the World Economic Forum, it is easy to determine that there is a great deal of room for improvement. The United States is ranked first for its quantity of higher education (percentage of students enrolled in higher education and the availability of research and training services), but $20^{\text {th }}$ for its quality, which was defined by business leaders with the purpose of developing a workforce that can perform and improve on complex tasks and processes (Schwab et al., 2014). In addition, it is ranked $12^{\text {th }}$ overall for on-the-job training, $8^{\text {th }}$ in terms of the local availability of specialized research and training services and $14^{\text {th }}$ for staff training within businesses (Schwab et al., 2014).

The United States is at a disadvantage in the vocational and technical training of the workforce and at continually upskilling workers to meet the progressing needs of industry (Schwab et al., 2014). The workforce development system in the United States has a long history of fragmentation into three distinct and unaligned streams: career and technical education in the school system, government and community sponsored adult training and education, and human resource development in private industry (Gray \& 
Herr, 1998; Kuchinke, 2002). The efforts taken by the United States to improve the quality of the preparation of its workforce has resulted in some progress. However, the long history of fragmented processes requires continued focus and effort in order to sustain this progress.

Support at the federal level for community college to aid in the improvement of specialized workforce demands and innovation has come in the form of vocal support and funding initiatives. In 2012, the U.S. Department of Education, Office of Vocational and Adult Education published a report, stating:

A troubling gap currently exists between the skills and knowledge of the country's current and projected workforce and the demands of jobs expected to grow most rapidly during the next decade. Community colleges are ideally positioned to help close that gap. (p. 1)

Since 1996, each U.S. President's State of the Union address has included a reference to the need to utilize community colleges to bolster the country (Katsinas, D'Amico, \& Friedel, 2012). Clinton (1998) and Obama (2009) have emphasized the importance for students to earn at least an associate's degree because of the impact it can have on the student's opportunities following graduation. This included Obama's 2009 State of the Union address, which outright acknowledged the importance of a technical or vocational education:

“...tonight I ask every American to commit to at least one year or more of higher education or career training. This can be community college, a four-year school, vocational training, or an apprenticeship. But whatever the training may be, every American will need to get more than a high school diploma." 
In the second year of Obama's presidency, 2010, the first Community College Summit was held at the White House to facilitate the discussion about the trends and effective practices that could improve the community college system. In 2012, The Office of The American Graduation Initiative offered $\$ 12$ billion to community colleges with the purpose of reaching five million new graduates by 2020 (Lederman, 2011; Shear \& de Vise, 2009). The stimulus package indirectly offered community colleges funding through the American Recovery and Reinvestment Act (Brumbach, Conner, \& Van Nostran, 2009). The Trade Adjustment Assistance Community College and Career Training grant program funded community college programs to work with industry in the development of curriculum and programming, which has been a part of the effort to improve postsecondary education's ability to respond to regional workforce needs (U.S. Department of Labor, 2011). In 2015, Obama announced his support to send responsible students to community college tuition free. The majority of the initiatives have been temporary resources to jump-start the development of community college partnerships and encourage citizens to commit to their education at these institutions. It is important to look at sustainable strategies for community colleges to maintain outside partnerships that can continuously improve their role as a leader in providing relevant workforce opportunities to students.

The direction the federal government will take in the upcoming years is unclear in the Trump administration. The current U.S. President ran on a platform that promised to bring back manufacturing jobs (White House, 2017). He has communicated his efforts to back this campaign promise by forming the White House's American Manufacturing Council with the purpose of opening communication with American businesses to 
increase employment (White House, 2017). At this meeting, employers emphasized that manufacturing jobs exist and are open in the U.S., but they are unable to find qualified applicants (Rugaber, 2017). The current administration's response was that they would consider the suggestions produced at the meeting and some solutions may end up in proposed legislation or executive orders (Rugaber, 2017). However, in August 2017, the Trump administration disbanded the council via a tweet (Pramuk, Domm, \& Breuninger, 2017)

Reports from non-governmental organizations have specified the need for community colleges to improve their relationships with industry because of a need to improve regional workforce development. Harvard's Pathways to Prosperity report (Symonds, Schwartz, \& Ferguson, 2011) detailed the importance of developing career pathways for all students across educational institutions, including community colleges: Community college programs also need to be more closely connected to regional labor market demands, as well as to state and local workforce development systems...We are calling for a much larger system-building effort, an effort in which the employer community needs to take a leadership role along with educators and governmental leaders. Much of this work needs to take place at the state and district level. (p. 28-31)

The Education Commission of the States and the KnowledgeWorks Foundation produced Revving the Education Engine (Vandal, 2009), dedicated to engaging state education, business and workforce development leaders in the creation of a framework for how states can more effectively align education, economic development, and workforce 
development policies. Vandal (2009) outlined steps educational institutions, all levels of government, and industry should take to work together to improve the education system.

\section{Background and Rationale}

Globalization has created forces that increase the difficulty for any region to establish a stable and secure economy (Friedman, 2005; Leigh \& Blakely, 2013). The "flattening" of the world as described by Friedman (2005) is due to the increased ability for organizations to benefit from the ease of shared knowledge, outsourcing, and improved technology and logistics, among other factors. However, solutions for responding to this concern cannot be universally applied. Businesses and their employees are developed on a regional scale (Arbo \& Benneworth, 2007; Hayter, 1997; Porter, 2000). Regional economies are primarily responsible for the execution and development of the pillars, such as infrastructure, health of residents, primary and higher education, and business sophistication and innovation, described by the World Economic Forum (2015), because they are a product of institutions and policies (Hayter, 1997; Porter, 2000). Regional development allows for specialization unique to the characteristics of the businesses and citizens (Porter, 2000). As a result, human resource development plays a crucial role in regional economic development with education at the heart of that development (Leigh \& Blakely, 2013). Human resource development for economic stability is a shared responsibility between public and private organizations in order to meet the needs of industry that are required to evolve with the environmental factors affecting globalization (Friedman, 2005; Leigh \& Blakely, 2013).

Community colleges are in a unique position to serve individuals' and their regions' economic needs (Mellow \& Heelan, 2015). This makes them a key resource in 
responding to our demand to increase global competitiveness. Among the roles community colleges play, an important one is to act as a bridge between regional businesses and the development of the workforce (Government Accountability Office, 2008; Leigh \& Blakely, 2013; Mellow \& Heelan, 2015; Skinner, Sanders, \& Beresford, 2004; Zinser \& Lawrenz, 2004). Community colleges are able to offer specialized training opportunities to both industries and their future employees (Leigh \& Blakely, 2013; Mellow \& Heelan, 2015), especially as it has been noted that current employers are offering far less resources and access to education and training for their employees (O’Toole \& Lawler, 2006).

Regional characteristics that have been identified as most helpful in the improvement of business productivity and efficiency is access to a qualified workforce and to a research or educational development center, such an institution of higher education or professional association (Arbo \& Benneworth, 2007; Hayter, 1997; Porter, 2000). Partnerships between educational institutions and industry have been repeatedly referred to as resources for improving the workforce development pipeline and enhancing the innovative nature of industry (ACT, 2011; Lamos, Simon, Waits, Fulton, \& Bird, 2010; Soares, 2010; Vandal, 2009). They can come in the form of industry advisory boards, targeted hiring agreements, various training programs, university and industry transfer agreements, or entrepreneurship programs, among others (Leigh \& Blakely, 2013).

Research has shown, however, that inter-organizational collaborations are difficult, with many of them failing because of the complex nature of the variables associated with the production and sustainment of a successful collaboration (Doz, 1996; 
Leigh \& Blakely, 2013). Community colleges and industry are not an exception to this finding. In order for community college and industry partnerships to be successful, they have to be dynamic and have the ability to change with the regional needs in order to stay current (Mellow \& Heelan, 2015). Factors such as a lack of resources and communication can stifle the growth of the relationships between industry and the community colleges (Mellow \& Heelan, 2015). Despite their shared goals to improve workforce development, each has a different set of stakeholders that influence their behaviors and incentive structures (Gray, 1997; Gray \& Herr, 1998; Kuchinke, 2002). As a result, these institutions have different strategies for making progress. Partnerships between the two may have more difficulties collaborating than two organizations that both primarily exist in the public sector or within the private sector. The two institutions have to develop long-term strategies that meet the needs of a broader set of stakeholders invested in the success of the partnership.

\section{Purpose}

In order to improve the development of community college and industry partnerships, it is imperative to understand the institutional structures that enhance and/or prevent positive collaborative principles. Research (e.g., Mattessich \& Monsey, 1992; Ostrom, 1990; Romzek, Leroux, \& Blackmar, 2012) has provided a great deal of information as to what makes collaboration work. Few studies have applied collaborative research to case studies looking at inter-institutional collaborations (e.g., Ostrom, 1990). Instead, most studies have observed successful cases of collaboration and attempted to understand best practices independent of collaboration research (U.S. Department of Education, 2012). In addition, these studies rarely look at how public and private 
organizations work together. Rather, the focus is on inter-organizational relationships between two public (e.g., a government entity working with a non-profit) or two private (two private companies; e.g., Mohr \& Spekman, 1994; Romzek, Leroux, \& Blackmar, 2012).

The purpose of this study is to observe the organizational structure of a community college and industry partnership through the lens of an existing collaborative framework, specifically, the institutional analysis and development framework, in order to understand how the institutional structure and policies support collaboration between multiple organizations. This framework is a commonly used tool for policy analysis (McGinnis, 2011; Polski \& Ostrom, 1999) and Elinor Ostrom won the 2009 Nobel Prize for Economic Sciences for its creation. The Ostrom Workshop Library contains almost 100,000 articles that relate to the use and application of the framework. By looking at the collaboration of a community college and industry partnership through this lens, a stronger understanding of how the institutional structures promoted positive collaborative principles will be gained, along with how collaborative mechanisms were sustained despite difficulties in partnership in the case of two organizations: a private sector company and the other, a regional community college.

\section{Research Methods}

A case study approach investigating the collaborative principles of a partnership between a community college and a private sector organization was identified as the best approach for this line of inquiry because of its ability to answer the "how" and "why" questions (Yin, 2014; Yin \& Davis, 2007). "How" and "why" are specific and verifiable questions that are important to a pragmatist's perspective. Pragmatism is focused on 
verifiable truth and knowledge and their direct impact on people (Pratt, 1909). This study is focused on understanding the functionality of how two different organizations and the people within them can work together effectively to produce positive outcomes for everyone involved.

The institutional analysis and development (IAD) framework (Ostrom, 1990) will be used as the lens to perform the case study. The framework's developer won the Nobel Prize in Economics because of the success of the framework and model's ability to improve and predict outcomes and functionality of the management of resources through the understanding of what affects people's behaviors. The framework and model that will be used in this study were created from an analysis of thousands of case studies across disciplines in a study funded by the U.S. National Science Foundation (Ostrom, 1986; 1990). It has been determined that researchers seeking to understand an institution's behavior should begin by understanding the "rules" that the individuals who participate follow both formally and informally. As a result, the following questions were identified and guided the development of this proposal.

- What are the rules (formal and informal) that govern the organizational structure of the partnership?

- How do the identified rules affect the outcomes of the partnership?

The case selected for this research study is a community college and industry partnership in the form of an industry advisory board. This particular community college has had a great deal of documented success utilizing industry advisory boards to adapt their programming to regional workforce employment needs, in areas such as semiconductor development and green energy. It was featured in TIME Magazine for its 
success in 2009 because of its capability to respond quickly to the regional industrial employment needs of the city within which it resides. Both the community college and various industries in the region have benefited from the restructuring of programs to improve the quality of the regional workforce. This case will look at the development of a new industry advisory board with the goal of restructuring the community college's information technology programming.

In order to answer the aforementioned research questions, data was collected from the active participants of the community college and industry advisory board members. These are the individuals who aid and develop the day-to-day operations and affect the decision-making patterns. The members consist of representatives from regional businesses who need qualified information technology (IT) employees, such as IT recruiters and leaders of IT teams at companies such as AT\&T and VISA as well as representatives from the community college, including the department chair and external affairs directors. Data was collected in the form of unstructured interviews with the individuals, documents and archival records (board meeting minutes, email communication), and observations of the meetings in which the individuals are able to discuss issues and make decisions.

Collected data was analyzed based on the research questions. The research questions are focused on the rules that guide the behavior of the individuals who participate in institutional decision-making. Formal rules were identified and coded through the analysis of formal documentation. Other forms of written communication (e.g., emails, meeting minutes) allowed access to understand any informal rules that have developed among the participants. The observation and field notes taken at in-person 
meetings allowed the researcher to triangulate the data, code for non-verbal communication, and identify other points that needed further clarification through interviews. Unstructured interviews allowed for the participants to explain what affects their decision-making patterns. The researcher was then able to code for understanding the rules that impact the participants' decision-making patterns. The rules affecting the participants were identified through the formal grammar of "rules" and further classified by category.

\section{Limitations and Delimitations}

This study has limitations and delimitations. Case studies have limited external validity (Lipset, Trow, \& Coleman, 1956; Poteete, Janssen, \& Ostrom, 2005; Yin, 2014). Findings cannot be generalized to other populations, but can be generalizable to theoretical propositions (Lipset, Trow, Coleman, \& 1956; Poteete, Janssen, \& Ostrom, 2005; Yin, 2014). However, results of case study findings can be consistent with more than one hypothesis (Poteete, Janssen, \& Ostrom, 2005). In this case, only one site had been selected to understand the collaborative dynamics that affect community college and industry partnerships in a successful situation. This was selected to understand one partnership's success and functionality in greater depth. Only a single researcher collected the data, therefore, the individual's bias had an impact on the interpretation of the data. Data triangulation was used to enhance the rigor of the study. Relevant data was more difficult to gain access to because information was sensitive or the individual had not fully processed the "why" for doing things (Ostrom, 2005).

\section{Definitions of Key Terms}

The following terms are used in the context of this study: 
Collaboration - organizations and/or individuals working closely together to achieve a specific goal. Collaboration includes the entities sharing a great deal of overlap in their resources.

Cooperation - a simple form of working together where individuals or organizations have little or no overlap of resources

Community College - a U.S. institution for higher education that serves the unique constituency of people and industries that reside in their region Industry Advisory Board - a group of individuals selected to advise a community college on its programming development, but does not have authority to vote on corporate matters

Institutional Analysis and Development (IAD) Framework - a political theory developed for analyzing policy and governance structures

Institutions - the structures individuals create to interact with one another in all types of situations, such as within their office, religious community, family, neighborhoods, and at all levels of government

Participants - the individuals actively participating in solving a problem or operating an institution

Partnerships - two or more organizations working together to achieve an agreed upon goal

Private Sector - institutions organized and led by individuals whose stakeholders primary objective is profit

Public Sector - institutions organized and led by individuals whose primary stakeholders are the public with the primary purpose of operating and creating public services 
Rules - the shared understandings among the participants about enforced, required, prohibited, or permitted behaviors within an institution (Crawford \& Ostrom, 1993;

Ostrom, 2005; Ostrom, Gardner, \& Walker, 1994)

Workforce Development System - career and technical education in the school system, government and community sponsored adult training and education, and human resource development in private industry organized to meet the demands of the U.S. workforce Organization of the Remaining Chapters

This paper includes five chapters to understand the depth of a community college and industry partnership. Chapter 2 reviews the literature on collaboration. It includes a comparison of the collaborative models, frameworks, and literature reviews on the topic and identifies the common themes. The chosen model that reflects the themes best, the institutional analysis and development framework, is then discussed in more depth. Community colleges and the role they play in regional development are discussed last. Chapter 3 is an explanation of the research methodology, data collection, and analysis. It also discusses the researcher's philosophical assumptions and positionality. Chapter 4 presents the findings to the research questions. Chapter 5 discusses these findings and provides suggestions for future research. 


\section{CHAPTER II}

\section{LITERATURE REVIEW}

Community college and industry partnerships are a critical resource for regional development (Symonds, Schwartz, \& Ferguson, 2011). However, creating and maintaining these partnerships is difficult (Doz, 1996). Research can provide us a great deal of information on what collaboration needs to work (e.g., Austin, 2000; Mattessich, Murray-Close, \& Monsey, 2001; Ostrom, 1990; Romzek, Leroux, \& Blackmar, 2012). It has not provided enough information about applying this knowledge to the unique nature of partnerships between community colleges and industry. The knowledge that does exist has been centered on the partnership of either two private (e.g., Mohr \& Spekman, 1994) or two public organizations (e.g., Romzek, Leroux \& Blackmar, 2012) and rarely about the development of a collaboration between public and private organizations (Austin, 2000).

This study first examined the literature as it related to institutional behavior, workforce development, and community colleges. It went further into depth about the literature focused on collaboration, including existing models, to understand the operation of how organizations collaborate. The themes identified in the collaboration literature were compared and contrasted with existing models and literature. The role of each of the themes in a collaborative environment is discussed in more depth. Through the research, 
one framework was selected as the lens for observing the collaboration between the organizations, the institutional analysis and development framework (Ostrom, 1990). A pilot study applying this lens to a community college and industry partnership confirmed that the framework could be applied in this context (DiMattina, Alagaraja, \& Stone, 2013).

The institutional analysis and development framework (Ostrom, 1990) is a policy theory that observes the governance structure of institutions. Rooted in game theory, the framework brings together theories about human behavior across disciplines in order to predict and evaluate the effectiveness of institutions (Ostrom, 1990; Polski \& Ostrom, 1999). A model of the framework brings together the inputs and variables that shape the outcomes of any decision-making process, including environmental factors and the participants who shape the institution and its decision-making patterns (Ostrom, 1990; Ostrom, Gardner \& Walker, 1994). Understanding the variables and dynamics that impact the relationship between the two organizations can help to facilitate future relationships.

\section{Community College and Industry Collaboration}

Collaboration between industry and community colleges has increased over the past decade. In 1990, less than half of community colleges had working relationships with industry (Stamps, 1995). By the mid-90's about 90\% of community colleges were utilizing relationships with local industry to offer specialized training (Stamps, 1995). However, the data is limited regarding the governance systems and the variables that have made some of these relationships effective, while others have failed (Amey, Eddy, \& Ozaki, 2007; U.S. Department of Education, 2012). Preliminary findings suggest that 
the private sector has positive influences on the enrollment, retention, and graduation rates of students in higher education (Richardson \& Martinez, 2009). It is in the public's interest for us to have a greater understanding of the formation, sustainability, and impact of these partnerships in order to maintain them as an economically efficient and beneficial public resource (U.S. Department of Education, 2012).

The rise in community college and industry partnerships has been a result of many factors, including the evolving needs of industry that have increased demand for specialized technical training and more well-rounded employees who possess academic and soft skills, (Bresnahan, Brynjolfsson, \& Hitt, 2002; Carnevale, Smith \& Strohl, 2010; Information Technology Association of America, 2002; NAM, 2005; Partnership for $21^{\text {st }}$ Century Skills, 2008) as well as, budget cuts that have impacted programming and services at public higher education institutions (Hebel, Schmidt, \& Selingo, 2002; Jackson \& Glass, 2000; Moltz, 2011). Alignment of community college programming with industry needs allows for improved curriculum and instruction, career guidance, and professional development (Agrawal et. al, 2007).

Globalization, technology, and a new economy have influenced the way that organizations do business and, therefore, the skills workers require (Bresnahan, Brynjolfsson, \& Hitt, 2002; Jacob \& Hawley, 2009). Globalization has increased competition and the flow of information (Bresnahan, Brynjolfsson, \& Hitt, 2002; Jacob \& Hawley, 2009). Open markets have allowed for a broader exchange of resources and have created a global marketplace (Jacob \& Hawley, 2009). Technology and the new economy have altered the landscape of the job market. Job requirements have shifted and employment opportunities increasingly require either highly technical skills or are low- 
wage service industry positions (Bresnahan, Brynjolfsson, \& Hitt, 2002; Carnevale, Smith, \& Strohl, 2010; Jacob \& Hawley, 2009). This is in part a result of technological advances in the workplace that have reduced the need for humans doing limited routine tasks and complementing workers by aiding them in complex and problem-solving tasks (Autor, Levy, \& Murname, 2003). Job growth has been concentrated in positions that require complex problem-solving, high interactions with other people, experience, and judgment (Manyika, Lund, Auguste, \& Ramaswamy, 2012). Although, these jobs are at increasing risk of disappearing in future years as technology becomes more adept at storing and processing massive amounts of data that allow it to perform complex tasks and communication (Brynjolfsson \& McAfee, 2011).

Issues in the United States have also influenced the collaboration of industry and community colleges. Almost all community colleges have faced reduced budgets in recent years from reduced state support (Hebel, Schmidt, \& Selingo, 2002; Moltz, 2011). The cuts experienced have varied by state due to a complex set of variables, including the increased pressure that community colleges have experienced to fill the workforce and skills gap, the perceived effectiveness they have in accomplishing the task in the past, and budget constraints. Pennsylvania's community college budget was reduced by one percent. A nominal amount considering the budget for four-year institutions was reduced by almost half. In contrast, Arizona reduced their state's community college budget by about half and their four-year institutions by about 20 percent (Moltz, 2011).

These shifts in resource distribution have impacted the value that industry and community colleges can reap from collaboration. Both profit from the shared resources and strategic planning that can facilitate a better experience for the students and a higher 
quality graduating class (Agrawal et. al., 2007; Jackson \& Glass, 2000). Community

colleges have found some of their lost funding from industry (Jackson \& Glass, 2000). In addition, the community colleges are better able to meet community educational needs, consistent with their mission and role (Jackson \& Glass, 2000). Industry benefits from the tailored programming that produces a higher quality employee (Jackson \& Glass, 2000).

\section{Supply and Demand Problems in Workforce Development}

The demands from industry have evolved at a greater rate than the U.S. public education system has for preparing the workforce (Capelli, 2012; Gray \& Herr, 1998). This has created a problem in supply for industry. Supply problems concern the optimal size in production of a service or resource that requires the examination of supply and demand (Ostrom, Gardner, \& Walker, 1994). The practical application of supply and demand in the U.S. workforce appears as either a shortage or oversupply of qualified workers, generally in conjunction with static wages (Capelli, 2012; Gray \& Herr, 1998). In addition to a problem with educating individuals for positions, low wages do not incentivize individuals to pursue the education, which creates a shortage of workers (Capelli, 2012; Gray \& Herr, 1998). An oversupply of qualified workers has been linked to highly paid positions that incentivize individuals to prepare themselves with the education (Gray \& Herr, 1998). However, the oversupply leads to high unemployment, because the number of open positions in the job market does not reflect the number of individuals prepared to enter the market (Gray \& Herr, 1998).

The U.S. workforce and education system have both supply and demand side problems. Supply-side problems are a product of another's ability to free ride on the current system of production (Ostrom, Gardner, \& Walker, 1994). In the case of the U.S. 
workforce, industry is able to free-ride on the U.S. education system for its worker production. Industry relies on the U.S. education system to produce their qualified workforce with limited investment or participation until people are hired as employees (Gray \& Herr, 1998; Kuchinke, 2002). Demand-side problems stem from the lack of production of a needed resource (Ostrom, Gardner, \& Walker, 1994). In this case, the U.S. education system has produced a shortage of qualified workers. Supply and demand problems in the U.S. workforce require collaboration between the education system and industry.

\section{The Skills Shortage}

Employers have been increasingly demanding more skills and abilities of their employees. A large number of employers have stated that they are unable to find qualified workers for their job openings (ACT, 2011; ManpowerGroup, 2011; 2012; National Association of Manufacturers, 2005; U.S. Bureau of Labor Statistics, 2012). To reach this quality of employability, all fields have increased demand for workers who have completed some form of postsecondary education (Carnevale, Smith \& Strohl, 2010; 2013; Carnevale, et. al., 2011). Carnevale, Smith, and Strohl (2010) predicted that at the current rate of education projections and the needs of the workforce, the United States workforce will need 3 million more workers with at least associate's degrees in 2018, than it will produce. Since the recovery of the workforce after the most recent recession, jobs have been returning (Carnevale, Smith, \& Strohl, 2013) and the general demand and turnaround of jobs that characterize these industries have remained static (U.S. Bureau of Labor Statistics, 2016). However, the Federal Reserve System Chair has cautioned that some of the statistics informing these numbers may be misleading, as the 
unemployment number includes only people who are seeking positions and many individuals have reported that they are no longer actively seeking work and the rate of those currently in part-time positions who would prefer full-time have remained unchanged (Yellen, 2016). People who were the most likely to have lost their jobs during the recession were less likely to have obtained higher education credentials and today's hires for those same positions, are more likely to have obtained a higher educational credential (Carnevale, Smith, \& Strohl, 2013; Carnevale, Jayasundera, \& Gulish, 2016). Jobs that have returned to the economy are primarily managerial and professional for individuals with a college degree or higher (Carnevale, Jayasundera, \& Gulish, 2016). People without training or abilities in utilizing new technologies will find limited opportunities (Carnevale, Smith \& Strohl, 2010), as well as those without higher education credentials (Carnevale, Smith \& Strohl, 2013; Carnevale, Jayasundera, \& Gulish, 2016).

Workforce projections suggest that in approximately a decade the United States will have the largest occupational demand in professional and business services, blue collar industries (i.e. construction, manufacturing and production), food and personal services, and healthcare (Carnevale, Smith \& Strohl, 2010; ManpowerGroup, 2016; US Bureau of Labor Statistics, 2012; 2016). These numbers seem contrary to the data offered by Acemoglu and Autor (2010), who published findings that operator, labor and production jobs have decreased most in the United States, from 1999 to 2009. However, after 2009, a positive growth rate is projected through 2018 at a rate of almost $7 \%$ annually (Carnevale, Smith \& Strohl, 2010). Immediately following the recent recession, manufacturing has seen some of the largest increased growth across the United States 
(Carnevale, Smith \& Strohl, 2013). In 2012, the Bureau of Labor Statistics reported that there will be approximately $8,951,200$ jobs in production occupations in 2020 , an increase of $4.2 \%$. However, manufacturing growth is not expected to continue consistently at this rate (ManpowerGroup, 2016; U.S. Bureau of Labor Statistics, 2016). It is expected to continually grow at a slower rate along with other industries, such as finance and education, that ensure a steady workforce with potential for growth (ManpowerGroup, 2016; U.S. Bureau of Labor Statistics, 2016).

The projections depict the increased need that will be experienced in the future, but the United States has been slow in preparing this workforce for our current needs. In October of 2009, the nation reached a peak of $10 \%$ unemployment. The rate has dropped over time, however, there are growing reports that in spite of the high unemployment rates, many employers are unable to find qualified applicants for positions (U.S. Bureau of Labor Statistics, 2012). Highly technical, "middle-skill" occupations tend to be the most difficult positions to fill (Holzer, 2010; ManpowerGroup, 2012; 2015; National Governors' Association Center for Best Practices, 2010). The presidential election in 2016 included increasing manufacturing positions as one of its prominent themes and promises (White House, 2017). CEOs from companies with large manufacturing components met with President Trump to communicate that jobs in manufacturing existed, but skills among potential hires did not (Rugaber, 2017). In 2015, 33\% of employers reported that they were not receiving any qualified applicants for their open positions with the greatest persistent problem areas to be in the skilled trades, drivers, engineers, and sales representatives (ManpowerGroup, 2015). The reliability of this survey is difficult to determine, however, other organizations have had similar findings, 
so the results of the survey cannot be completely discounted. The National Association of Manufacturers (NAM, 2005) performed their own survey of employers, unique to their industry. They found that $80 \%$ of employers reported a gap between the skills they needed and the skills their employees possessed (NAM, 2005). Another study done by ACT (2011) found that a large portion of employees in positions where a high or middle level of education is needed in manufacturing, healthcare, construction or energy-related fields, are not meeting math skill benchmarks required for their field. These same people performed significantly better in their reading and locating information benchmarks as required by their field (ACT, 2011). The Program for the International Assessment of Adult Competencies, which compares the abilities of U.S. citizens with those of other technology-rich countries in literacy, numeracy, and problem-solving skills, determined the U.S. to be at or below average across all competencies (Goodman, Finnegan, Mohaadjer, Krenzke, \& Hogan, 2013).

There is one dissenting opinion from the sources cited above. Peter Cappelli (2012) wrote Why Good People Can't Get Jobs: The Skills Gap and What Companies Can Do About It. The book focuses on the role companies play in the job market. While companies conform to the traditional supply and demand market in regards to the products and service they produce, they are avoiding these tenets when it comes to the supply and demand of labor. Companies place high and unobtainable demands on job candidates, despite the availability or lack thereof. Cappelli (2012) relies a great deal on anecdotal evidence to support his argument and suggests that the research mentioned above (i.e. ManpowerGroup, 2011; NAM, 2005) has been misinterpreted, while other relevant evidence has been avoided. Carnevale, Smith and Strohl (2013) add some weight 
to Cappelli's argument with their analysis of employee educational credentials versus the Bureau of Labor Statistic's defined entry-level need for the position. They find that there are a large portion of candidates who enter careers with higher educational credentials than what is required for entry-level (Carnevale, Smith \& Strohl, 2013). Those with a bachelor's degree or higher have fared better in the economic recovery (Carnevale, Smith, \& Strohl, 2013).

Further analysis of the ManpowerGroup's (2011) data shows that in the five hardest to fill jobs, only a few of them require technical education. Capelli (2012) argued that the technical ability to perform these jobs is primarily obtained from on-the-job training. Manpower's (2011) survey also determined that $11 \%$ of employers were not able to find qualified applicants at the wage they were willing to pay, suggesting that employers are not willing to pay the market wage for the employees they seek. This idea is still potentially supported by the low hire, high job opportunities consistently available in certain industries, such as finance and insurance and information (U.S. Bureau of Labor Statistics, 2016). In addition, Capelli (2012) argues the higher unemployment rate allows for companies to spend more time "shopping around" for their ideal candidates and hire the over-qualified candidates. To support this argument Vaisey (2006) is cited, a study that that found employees are three times more likely to have three more years of education than is required for their current position, than be underqualified by three years of education. A part of the argument is that the demand for employees with college degrees are inflated, because so many candidates have them and they act as a signal of a person's ability to persevere and complete tasks (Capelli, 2012). 
The key part of Capelli's (2012) argument, as it relates to the examination of community college and industry partnerships, is that companies prefer to hire candidates that are above an entry-level position. Employees are preferred to have on-the-job experience, which severely narrows the job pool. This argument is consistent with the current criticism of the United States' workforce development system. The system is fragmented, rather than streamlined (Gray \& Herr, 1998; Kuchinke, 2002). Employers cannot be sure that the knowledge and experience they need, can be provided or supplied by the degree holder (Capelli, 2012).

\section{Education as a "Public Good"}

The U.S. education system is generally accepted as a public good because of its role in the preparation of individuals who are competent democratic citizens and able to work and contribute to the economy (Labaree, 1997). There is some disagreement about this concept in practice when the topic is solely focused on higher educational institutions, because of the nature of individuals to use it for personal or private gain, such as financial security (Hebel, 2014; Labaree, 1997). As individuals benefit from the system, it appears as though education becomes increasingly a private good (Hebel, 2014; Labaree, 1997; Shaw, 2010). This topic was popular in the early 2000's and academics tended to agree that the benefits of the collective should make higher education a public good (Chambers \& GoPaul, 2008). However, these definitions for public and private goods look specifically at the U.S. education system in terms of its value as a public interest. In economics, public goods have a more specific classification based on exclusion and subtractability (Ostrom, Gardner, \& Walker, 1994; Ostrom \& Ostrom, 1977). Exclusion defines how easily or costly it is to limit or prohibit the use of a specific 
good. Subtractability defines how the use of a good may subtract from another person's ability to use it (Ostrom, Gardner, \& Walker, 1994; Ostrom \& Ostrom, 1977). Public goods are defined as goods that are difficult to exclude people from and have low subtractability (Ostrom, Gardner, \& Walker, 1994; Ostrom \& Ostrom, 1977). While the quality of the education through secondary school has been debated, there is no doubt that it is considered a public good because of each of the principles listed above (Shaw, 2010). However, the definition is more complicated for higher education. The purpose and value of higher education stand in terms of public interest and the institutions are generally subsidized with public funds to keep tuition costs low. These points do not change the fact that tuition makes higher education highly excludable. With that in mind, the higher education institution focus in this paper is the community college. This higher education sector is the closest to a public good available in the United States. The purpose of the community college is to serve the needs and people of its community and is highly affected by public opinion and policy (Cohen, Brawer, \& Kisker, 2014). Even recently, it was proposed by President Obama that community college tuition be made free to all in the U.S. in order to make it more easily accessible (Hudson, 2015).

\section{Bureaucratic Incentive Structure}

Community colleges operate in the public domain as a publically funded organizations meant to serve the people (Cohen, Brawer, \& Kisker, 2014; Gray \& Herr, 1998; Richardson, Blocker, \& Bender, 1972). More broadly, workforce education is often affected by a range of legislation and policy regulations, from federal laws such as OSHA and the Workforce Investment Act to welfare reform that includes training provisions (Gray \& Herr, 1998). 
Cohen, Brawer, and Kisker (2014) use the research of Richardson, Blocker, and Bender (1972) and Richardson (1975) in the $6^{\text {th }}$ edition of their book, American Community College, to describe community college governance. Richardson, Blocker, and Bender's (1972) research of community college governance structures is still the most comprehensive examination of them. They found the governance structure to be slow to adapt to changing environments and two separate decision-making structures (Richardson, Blocker, \& Bender, 1972). Administration acts as one decision-making structure responsible for long-range planning and resource allocation (Richardson, Blocker, \& Bender, 1972). Faculty is the second decision-making structure responsible for educational programming (Richardson, Blocker, \& Bender, 1972). However, the administration held and maintained greater power in the hierarchal structure and was more sensitive to national, state, and regional politics (Richardson, Blocker, \& Bender, 1972). The competing decision-making structures between administration and faculty caused students and faculty to demand a greater voice and power because of the community college's purpose to serve the community (Richardson, Blocker, \& Bender, 1972).

This early research in community college governance is consistent with Cohen, Brawer, and Kisker (2014). Despite the mission of the community college to serve the needs of the community and students, decision-making has focused on "protecting the staff's rights, satisfaction, and welfare" (Cohen, Brawer, \& Kisker, 2014, p. 111).

Governance has become a more of a joint effort between faculty and administration, with students having very little voice (Cohen, Brawer, \& Kisker, 2014). Richardson's (1975) bureaucratic model of governance remains applicable because of its top-down hierarchy 
with distinct responsibilities, competencies, and privileges with students at the bottom of the hierarchy (Cohen, Brawer, \& Kisker, 2014). Financing, staff morale, and conformity to state legislation has always remained a priority (Cohen, Brawer, \& Kisker, 2014).

This is consistent with bureaucratic organization literature. Early and foundational research in bureaucratic structures describes how individuals are incentivized to conform to rules and norms that are not necessarily beneficial to the aims of the organization (Merton, 1957). Instead, the individuals are incentivized to value and maximize the security of their position (Cahen-Salvador, 1926). The bureaucratic structure places the emphasis on the maintenance and devotion to rules and regulations, which become absolutes, rather than in support of an organizational purpose (Merton, 1957). The individuals are incentivized to maintain rules, norms, and behaviors that are inefficient (Merton, 1957). This is also supported by the individual's preference to avoid and not trust change (Gulick, 1937; Merton, 1957). As public funding dwindles for higher education (Hebel, Schmidt, \& Selingo, 2002; Moltz, 2011), the bureaucratic nature of the community college is shifting to reflect some market-based incentive structures (Cain, 1999).

\section{Market Incentive Structure}

It is widely accepted that industry is driven by the market system or capitalism (Mankiw, 2014). Early literature emphasizes the importance of efficiency in the development of organizations to raise profits and improve workplace and organizational performance (Fayol, 1916; Smith, 1776; Taylor, 1916). Today’s main economic textbooks support and describe these accepted concepts (e.g., Mankiw, 2014). Classics of Organization Theory (Shafritz, Ott, \& Jang, 2011) a common text used to 
teach the important theories and concepts that have developed our current understanding of organizations feature Fayol, Taylor, Selznick, Cyert, and March because of their contributions to the field. Fayol (1916) states, "the object of division of work is to produce more and better work with the same effort" (p. 52). Taylor (1916) produced scientific management to combat the development of soldiering in the workplace so that industry could produce at maximum efficiency. As organizations that have been traditionally treated as responsive to the economy, they seek to define their scarce resources and manipulate the relationships within the system to maximize the effective use and efficiency (Selznick, 1948). This concept led to a great deal of organizational neoclassical research to focus on the incentive structures of individuals, in order to encourage them to adapt to the hierarchal needs of the organization (Selznick, 1948). These theories, concepts, and ideas are the groundwork for our current understanding of a market driven system (see Mankiw, 2014). However, isomorphism as described by DiMaggio and Powell (1983) depict a pattern of market-driven institutions as taking on increasingly more bureaucratic tendencies, as they become more homogeneous.

Our foundational literature has described the many competing differences between bureaucratic and market organizational structures (Boyne, 2002; Rainey \& Bozeman, 2000). This tends to be expressed through literature with information on the development of governance that includes an increased reliance on traditional industry strategies to improve their efficiency and outcomes (e.g., Allison \& Kaye, 2005; Kearns, 2000) or literature describing the increased gray area of institutional governance that incorporates both private and public characteristics (e.g., Boyne, 2002; Frederickson, 1991; Treib, Bahr, \& Falkner, 2007). The opposing structures traditionally have 
incentivized two different strategies for those who operate within them. Individuals in the bureaucratic structure work to maintain a status quo (Merton, 1957), while the individuals in the market structure have been incentivized to adapt more quickly to changing conditions (Selznick, 1948). No organization operates completely in a public or private arena (Boyne, 2002; Frederickson, 1991; Treib, Bahr, \& Falkner, 2007). Rather, the general organizational structure tends to shape the goals and strategies of each institution, with researchers tending to agree that public institutions have vague and hard-to-measure goals (Rainey \& Bozeman, 2000). This indicates that incentives aid in the shaping the behavior of the individuals in the organization, but cannot give us the entirety of the picture of the difficulties affecting the collaboration of public and private institutions. However, the need for these two opposing structures to come together has been noted enough to increase the number of attempts between community colleges and private industry (Stamps, 1995), but also creates a difficult situation to overcome in order to achieve a collaboration that can effectively produce goods or services (Doz, 1996).

Workforce Development in the Public and Private Sectors

Workforce development has some additional complications that have affected its ability to progress. The concept of workforce development exists within both the public and private domains (Gray \& Herr, 1998; Kuchinke, 2002). Education policy affecting the development of the workforce occurs at federal and state levels and is affected by the enacted legislation and funding at these multiple levels (Gray \& Herr, 1998; Kuchinke, 2002). Industry has developed its own form of workforce development but has defined it as human resource development (Kuchinke, 2002). 
Human resource development occurs in response to specific organizational and market changes that increase the organization's productivity (Kuchinke, 2002). While the two lines of development share a mission (providing work related education for the improvement of individuals and organizations), ethical standards (promotion of learning and establishment of trust and safe conditions for participating individuals), and their base of knowledge (rooted in labor economics, sociology of work, curriculum instruction and delivery, and career related psychology research), their separate existence in public and private domains, strongly impacted by their autonomous funding streams, have impacted their growth and development as two distinct lines of research (Gray, 1997; Gray \& Herr, 1998; Kuchinke, 2002).

\section{Collaboration}

Collaboration between organizations as a strategy to improve products and services has increasingly become a norm over recent decades. Collaboration between institutions has appeared in many forms, including mergers and acquisitions, joint ventures, inter-organizational collaboration, and strategic partnerships. It has been deemed an important trend to improving organizations' strategic ability to compete in the $21^{\text {st }}$ century (Kanter, 1993; Logan \& Stokes, 2004). For example, partnering with organizations that are more familiar with certain aspects of an industry or that have already invested significant capital in an endeavor can reduce costs and maximize productivity, in contrast to attempting to recreate the service or product with less experience and investment and then competing in an open market (Alter \& Hage, 1993; Drucker, 1993; Trist, 1983). The purpose of this study is to examine the unique 
relationship between community colleges and industry in order to add to our knowledge of improving the effectiveness of outcomes.

The U.S. education system has been affected by these shifts in organizational strategies. The Education Commission of the States suggested policies at all levels of education, workforce development, and economic development need to be aligned in order to achieve economic success (Vandal, 2009). This will require collaboration among leaders from industry, education, and government (Vandal, 2009). Other organizations (e.g., ACT, 2011; Lamos et al., 2010; Soares, 2010) have expressed the need for increased education and industry alignment as well. Industry leaders are important to workforce development, because of their vested interest in the production of a skilled workforce and their ability to define the skill level requirements for occupations (ACT, 2011; Lamos et al., 2010). To meet this need, organizations have increasingly begun to suggest policy initiatives that could influence changes in education that work to integrate industry needs into academic curricula. Examples include the Common Career Technical Core (National Governors Association Center for Best Practices \& Council of Chief State School Officers, 2010), the Partnership for $21^{\text {st }}$ Century Skills (2008), and increased funding initiatives to support the inclusion of private industry into secondary and postsecondary institutions, such as the Trade Adjustment Assistance Community College and Career Training Grants Program (U.S. Department of Labor, 2009). However, research has shown that collaborations are difficult, with many of them failing because of the complex nature of the variables associated with producing a successful collaboration (Doz, 1996; Ostrom, 1990). 
Collaboration models, theories, literature reviews, and frameworks have been produced to examine the processes that have allowed for those involved in an interorganizational partnership to create productive results, such as between community colleges, multiple private organizations, multiple public organizations, and a combination of public and private organizations (Amey, Eddy \& Campbell, 2010; Austin, 2000; Copa \& Ammentorp, 1998; Hord, 1986; Kezar, 2005; Mattessich, Murray-Close, \& Monsey, 2001; Mohr \& Spekman, 1994; Ostrom, 1990; Romzek, Leroux, \& Blackmar, 2012). To first understand the commonalities of what is important for all collaborative efforts, nine examples of research in collaboration were selected, compared, and analyzed.

- Amey, Eddy, and Campbell's (2010) model was developed for community colleges following consulting experiences with a community college advisory panel and a review of research and literature of community college partnerships.

- Austin (2000) was the only model found that examined relationships between private and public sector organizations. It focused on the relationship between businesses and non-profits.

- Copa and Ammentorp (1998) published a book on redesigning the community college with a chapter dedicated to outside partnerships.

- Hord's (1986) article identified and defined the components of collaboration and cooperation.

- Kezar (2005) focused on internal collaboration within higher education. 
- Mattessich and Monsey (1992) synthesized findings regarding collaborative relationships between organizations that are characterized as non-profits, government, or in human services.

- Mohr and Spekman (1994) examined business-to-business partnerships.

- Ostrom (1990) established the institutional analysis and development framework. It won the Nobel Prize in Economics in 2009 for its usefulness in understanding successful governance structures for managing public resources.

- Romzek, Leroux, and Blackmar (2012) created the preliminary model of informal accountability among network organizational actors. It discussed networks of public or non-profit entities that work together in achieving shared goals.

Each model, theory, and framework provides some insight into the collaboration process for community college and industry. Most of the models, however, have been subjected to limited testing, so their ability to explain diverse situations is unclear. Literature reviews can only provide general "best practices" or strong concepts that have been found to be important to the process of collaboration, but how to implement the concept is more difficult to interpret. Within this body of research, however, are identifiable themes that are highly intertwined with one another: environmental factors, membership characteristics, structure, leadership, communication, purpose, resources, rewards, incremental time, and conflict resolution. Table 1 is a chart adapted from Culver-Dockins (2012) that compares and contrasts the components of collaboration among the nine selected models. The next subsections of the chapter discuss each of these themes. 
Table 1.

Comparing Components in Models, Theories, and Frameworks of Collaboration (Adapted from Culver-

Dockins, 2012)

\begin{tabular}{|c|c|c|c|c|c|c|c|c|c|c|c|}
\hline Articles & 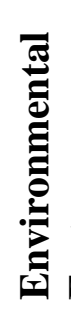 & 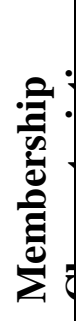 & 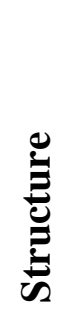 & نี & है & 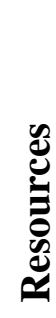 & 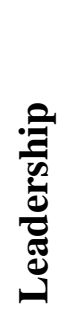 & 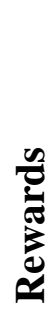 & $\stackrel{\mathscr{E}}{\mathrm{E}}$ & ن & 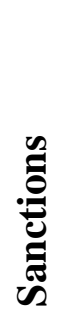 \\
\hline Amey, Eddy \& Campbell, 2010 & & $\mathrm{X}$ & $\mathrm{X}$ & & $\mathrm{X}$ & $\mathrm{X}$ & & & & & \\
\hline Austin, 2000 & & & $X$ & $\mathrm{X}$ & $X$ & $\mathrm{X}$ & $\mathrm{X}$ & $X$ & $\mathrm{X}$ & & \\
\hline Copa \& Ammentorp, 1998 & $\mathrm{X}$ & $\mathrm{X}$ & $X$ & $X$ & $X$ & $\mathrm{X}$ & $X$ & $X$ & & & \\
\hline Hord, 1986 & & $\mathrm{X}$ & $\mathrm{X}$ & $\mathrm{X}$ & & $\mathrm{X}$ & $\mathrm{X}$ & $\mathrm{X}$ & & & \\
\hline Kezar, 2005 & $\mathrm{X}$ & & $X$ & $\mathrm{X}$ & $\mathrm{X}$ & & $X$ & $\mathrm{X}$ & $\mathrm{X}$ & & \\
\hline Mattessich \& Monsey, 1992 & $\mathrm{X}$ & $\mathrm{X}$ & $\mathrm{X}$ & $\mathrm{X}$ & $\mathrm{X}$ & $X$ & & & & & \\
\hline Mohr \& Spekman, 1994 & & $\mathrm{X}$ & & $\mathrm{X}$ & & & & & & $\mathrm{X}$ & \\
\hline Ostrom, 1990 & $X$ & & $X$ & $\mathrm{X}$ & & $\mathrm{X}$ & $X$ & $\mathrm{X}$ & $\mathrm{X}$ & $X$ & $\mathrm{X}$ \\
\hline Romzek, Leroux, \& Blackmar, 2012 & & $\mathrm{X}$ & & $\mathrm{X}$ & & & & $X$ & $X$ & & $X$ \\
\hline
\end{tabular}




\section{Environmental Factors}

The environment or context that the collaboration is operating within influences the ability, reasons, and potential success of the collaborative partnership. There are a great number of themes within the context of environmental factors that can be covered, including the economy (e.g., Acemoglu, 2009; Mankiw, Romer, \& Weil, 1992) and its impact on access to different forms of financing (Guscina, 2008), the physical or geographical environment (Ostrom, 1990), the accessibility of education and its impact on productivity (Hall \& Jones, 1999), political stability (Roe \& Siegel, 2011), the role of external stakeholders (Mintzberg, 1983), among many others. External factors are highly intertwined as they impact one another and vary in how they impact organizations (Pfeffer \& Salancik, 2003). Entire books have been written about the complexities of context and its impact on institutions (e.g., Pfeffer \& Salancik, 2003). This review will discuss some of the more popular versions of the definition and articles, as it relates to collaboration of regional development and collaboration, especially between community colleges and industry.

The internal workings of the participants or individual organizations have been an aspect of environment discussed in the literature. This concept is characterized by the rules, requirements, norms, and policies that govern the operations, decision-making, preferences, and strategies of the organization (Meyer \& Rowan, 1977). The internal structure of the organization can affect the organization's relation to external pressures, such as competition and interactions with other related industrial actors as well as its need to adapt or take on the structure of other similar organizations to gain legitimacy in their larger environment (Fombrun, 1986; Singh, Tucker, \& House, 1986). Romzek, Leroux, 
and Blackmar (2012) discussed the negative impacts that environment can have on collaboration, stating that turf battles, high-turnover rates, and financial concerns will have a negative impact on an organization's ability to collaborate. These are all indicators of a dysfunctional work environment (Rose, Schuck, Twyford, \& Bergman, 2015).

Environmental factors relate strongly to research in isomorphism. DiMaggio and Powell (1983) discussed the concept in relation to the effects of political and social climate in more depth, with the description of three processes that influence the development of institutions, normative (educational and professional norms and standards), coercive (political and social pressures), and mimetic (the imitation of other successful institutional structures), all of which influence institutions to shape themselves based on their environment. The isomorphic process does not only occur in defined geographical regions, however, the focus of this paper is on regional economic development, which is influenced strongly by these concepts. Isomorphism creates an ideal context for the growth of collaboration. Industrial centers bring together the required actors (i.e., suppliers, consumers, resources, regulatory agencies, professional associations) in an environment that is both economically competitive while also attempting to meet institutional benchmarks, practices, or regulations stipulated by professional organizations or government (DiMaggio \& Powell, 1983).

Gary (1989) identified contextual factors in the United States that have contributed to the creation of an environment where collaboration is key to the development of industry competition, including rapid economic and technological change; declining productivity and increased competition; global interdependence; the increasingly blurred boundaries among private, public, government, and labor 
organizations; decreasing federal money; and frustration with the judicial process' ability for problem solving.

Ostrom's (1990) institutional analysis and development framework was designed for the purpose of managing common-pool resources in the natural environment. The definition of environment in this case relates strongly to the common biophysical and physical definitions we would normatively place on this word (Ostrom, Gardner \& Walker, 1994). The concern for depleting and losing the resource is a part of the incentive of individuals to participate in a cooperative endeavor (Ostrom, 1990).

A synthesis of literature on collaboration performed by Mattessich, Murray-Close, and Monsey (2001) focused on non-profits, human service organizations, and other public entities identified the following components of environmental context: the historical practice of collaboration, perception of leadership among the collaborators, and political and social climates surrounding the partnership. Amey, Eddy, and Campbell (2010) defined context similarly by focusing on the social, organizational, and political capital that is used to facilitate the partnership. They describe this capital among other factors that have been identified in this paper, such as purpose and goal setting, the buildup of intangibles (i.e., trust), and the contribution of resources.

A case study of collaboration between industry and academic institutions support this concept of environmental factors' influence on collaboration. Sharfman, Gray, and Yan (1991) identify several employers in the garment sewing industry that utilize a private industry council (PIC) to discuss a regional concern with creating a qualified workforce to meet labor demand. The PIC initially informed the garment industry employers that they could not help due to the public's negative perception of working in 
that area (Sharfman, Gray, \& Yan, 1991). Leadership within the regional garment industry and technical schools reconvened with the purpose of revamping their image and improving the quality of their workforce (Sharfman, Gray, \& Yan, 1991). Regional industry leaders had a common purpose to correct a public deficiency that decreased each of the entities' ability to compete in a global market. A more recent case study of a community college and industry partnership found the same results (Caton \& Mistriner, 2016). A city's residents, government officials, community employers and college administrators came together over a shared goal of revitalizing the city's employment opportunities in the tourism industry with the community college as a resource for improving the outcomes (Caton \& Mistriner, 2016).

\section{Membership Characteristics}

Membership characteristics describe the organizations involved in the partnership and include intangible factors, such as respect, trust, commitment, and understanding. Mattessich, Murray-Close, and Monsey (2001) list trust, understanding, and ability to compromise, along with an incentive structure that benefits the organization to participate and appropriate representative partners as defining membership characteristics. These characteristics are generally fostered through relationships and communication.

Literature in collaboration across all types of organizations support these characteristics as important. Mohr and Spekman's (1994) collaboration model for private business focused on the development of commitment, coordination, and trust between the organizations. Copa and Ammentorp's (1998) research addressing the future of community college development included understanding and trust as important underpinnings for success as community discussions and involvement evolves and 
addressed appropriate representation due to the nature of community colleges as a resource for community development (Copa \& Ammentorp, 1998). Kezar (2005) researched the development of collaboration within a broader higher education context and found that building commitment through mutual goals was key for successful collaboration. Ansell and Gash (2007) depicted a pattern showing that completing small goals and tasks cyclically increases trust and commitment as central of their model of collaborative governance (Figure 1).

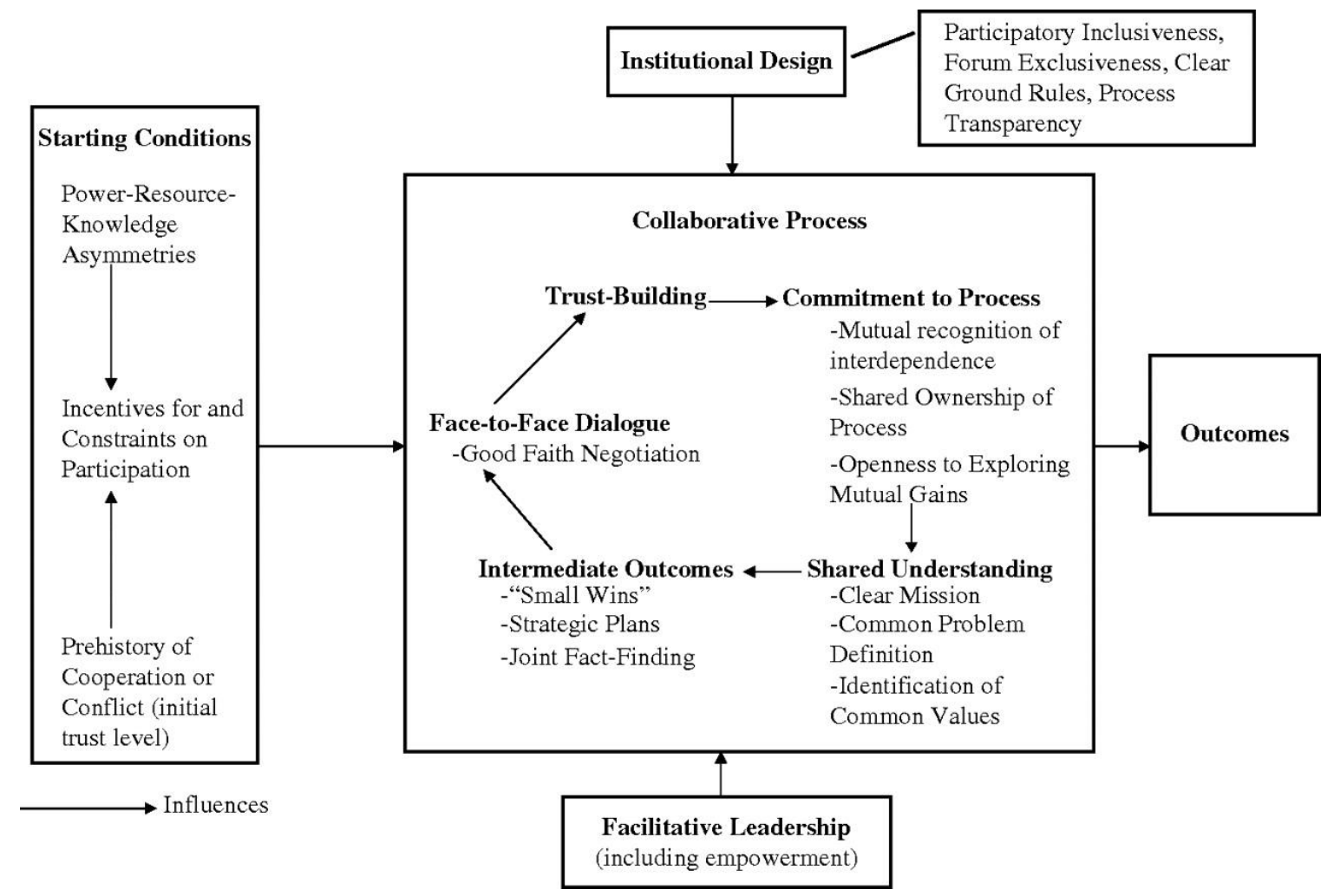

Figure 1. Ansell \& Gash's (2007) model of collaborative governance

Hord (1986) and Austin (2000) describe these characteristics on a spectrum of cooperative to highly collaborative partnerships. Hord (1986) identifies that cooperative relationships require less trust and understanding and collaborative relationships share 
commitment, risk, and have the ability to compromise. Austin's (2000) research has built on this concept and focuses on relationships between people and commitment as drivers that allow organizations to develop from a cooperative initiative to one that has increasingly complex goals and processes to meet the needs of a highly collaborative initiative.

\section{Structure}

The structural component is defined as specific processes, roles, policies, and decision-making structures that guide the governance of the collaboration. Mattessich, Murray-Close, and Monsey (2001) listed several important components: all members participating in the collaboration should have the ability to influence the process and outcomes; decision-making occurs on multiple levels; adaptable and flexible organizational structure to accomplish goals and work within changing conditions; and roles, responsibilities, and policies are clearly identified.

Kisker and Carducci (2003) and Copa and Ammentorp (1998) discuss these themes within a collaborative partnership and more specifically towards higher education. Copa and Ammentorp (1998) go into more depth on the topic. One of their first points was that those affected by the partnership should contribute to discussions and influence decision-making. They identify several potential groups that should participate in the development of the collaboration, depending upon its purpose, including community members, public and private organizations, government, and youth services (Copa \& Ammentorp, 1998). Infrastructure and available staff were another important concept discussed as a means to accomplish goals and tasks, as well as increased organizational flexibility and adaptability so as to respond to the needs of the community 
more efficiently (Copa \& Ammentorp, 1998). Copa and Ammentorp (1998) suggest that because the needs of the community are inherently multidisciplinary, community colleges should be able to respond by creating programming that better reflects this. This means creating policies that increase the community college's ability to adapt. Building on Mattessich, Murray-Close, and Monsey’s (2001) requirement for policies, roles, and responsibilities to be clear, Copa and Ammentorp (1998) add that policies and agreements can be formal and informal in nature to reflect the organization and its purpose. Kisker and Carduci (2003) add that the structure should facilitate accountability among the participants in the collaboration.

These concepts are consistent with Ostrom's (1990; Ostrom, Gardner \& Walker, 1994) institutional analysis and development framework that participants should have influence on the policies and outcomes as it relates to them. Their inputs or contributions towards this will shape the development of policies, roles, and responsibilities as it relates to the purpose of the collaboration (Ostrom, 1990; Ostrom, Gardner \& Walker, 1994). This type of organizational structure is decentralized in nature (Ostrom, 1990) as responsibilities and decision-making are delegated and addressed at multiple-levels (Hord, 1986; Ostrom, 1990).

Austin's (2000) collaboration research depicts that managerial complexity of a collaboration increases as it becomes more integrated. Kezar's (2005) research supports this, having found that successful higher education partnership structures become increasingly integrated and formalized over time. Amey, Eddy, and Campbell (2010) stated that formalized processes were needed less over time to sustain the collaboration. This may be attributed to the informal pattern of norms, accepted unwritten policies, and 
expectations that are established over time and add to the governance structure (Polski \& Ostrom, 1999; Romzek, LeRoux, \& Blackmar, 2012).

\section{Leadership}

In this context, leadership refers to the discussion of management and hierarchy within the structure of the organization. This component of collaboration is closely connected to structure. Leadership is a less discussed component within the literature on collaboration, because of the nature of the collaborative structure is to be decentralized. This is consistent with the literature relating to structure that all members affected by the collaboration should have a stake in influencing the outcomes. Leadership within the collaborating organization should be dispersed among participants and control shared between each of the participating organizations (Hord, 1986; Ostrom, 1990). As Hord (1986) differentiates between cooperative and collaborative leadership; leadership of a cooperative initiative has a higher centralized chain of command from autonomous agencies.

While leadership and responsibility is dispersed in a collaborative agency, the leadership of each of the collaborating organizations has influence on the development of the collaboration. Their support can facilitate collaboration (Copa \& Ammentorp, 1998; Kezar, 2005) by increasing the legitimacy of the collaboration's efforts (DiMattina, Alagaraja, \& Stone, 2012; Kisker \& Carducci, 2003; Ostrom, 1990; Singh, Tucker, \& House, 1986) not only by providing access to resources, such as time, staff, equipment, or money, but also by increasing the commitment of others to successfully meet a goal (Kezar, 2005; U.S. Department of Labor, 2009). In practice, grants offering resources to facilitate collaboration have required formal commitment letters from leadership, 
including the Governor and other related organizations in the region (U.S. Department of Labor, 2009). The case study of the community college and industry partnership in Niagara County moved forward because of the legitimacy and support it received from private businesses who would benefit from the employment and local government (Caton $\&$ Mistriner, 2016). This outward support is interpreted as increased legitimacy and investment into the collaboration's success (Vajjhala, 2013). Mattessich, Murray-Close, and Monsey (2001) shared this concept but considered a skilled leader to be a resource that could add fairness and legitimacy to the collaborative effort.

\section{Communication}

Communication aids individuals in processing information, which resolves ambiguity and reduces uncertainty among participants (Daft \& Lengel, 1984; Fulk \& Boyd, 1991). It is foundational towards success in any exchange of information and services (Reinsch, 2001). Kanter (1994) describes collaborative successes and failures between organizations as being highly related to the relationships among the individuals within the organizations, making the human element of collaboration increasingly important. Madhok and Tallman (1998) identify relationships among actors as a valueadded investment for the success of collaborations. Daft and Lengel (1984) define four criteria that assist in exchanging information in their media richness model: speed of feedback, diverse communication channels, the nature of the relationship of the source, and the use of explanatory language. By their definition, face-to-face communication facilitates the greatest exchange of information and the task or type of information that needs to be exchanged should define the communication channel (Daft \& Lengel, 1984). Daft and Lengel (1984), essentially, created a continuum regarding the most effective 
channels for communication, with face-to-face being the greatest and written communication being the least, and the actual activity or information shared should define the level of communication warranted. However, the media richness model was developed prior to the prominent use of technology as a mode of communication.

Within theoretical models of collaboration, communication most often has been described by the frequency and intensity of interactions and the informal and formal structures that enable the exchange of information. The levels and development of communication aid in beginning to define the partnership as cooperative because they are highly controlled at specific intervals or collaborative due to the multiple layers of communication patterns (Hord, 1986). To understand collaboration, network patterns become the focus of the research, especially through relational or structural analysis (Fulk \& Boyd, 1991). The most frequently studied features of network communication are properties of the links between entities, the roles of the individuals, their positions within the network, the type of information exchanged, and the properties of the network as a whole (Fulk \& Boyd, 1991).

Mattessich, Murray-Close, and Monsey (2001) listed two components as related to communication in collaborative partnerships: (1) group members share information openly and (2) formal communication channels and personal connections among group members occur to create regular flows of information. Austin's (2000) collaboration continuum depicts that a more integrated collaboration has a higher frequency of interactions among collaborators. A notion supported by an earlier theory is that connectedness is the "exchange in one relation is contingent upon exchange (or nonexchange) in the other relation" (Cook \& Emerson, 1978, p. 725). Highly integrated 
interaction or exchange has a greater likelihood of reinforcing collaborative behaviors while non-exchange will reduce the connectedness of the organizations.

Kezar (2005) found that a communication network was essential throughout the collaboration process but especially so in the initial stages of developing a partnership. In the initial stages of building a partnership, one leader's message of values and goals were not enough to build trust among all the participants. However, these values and goals were reaffirmed as valid by others communicating, interacting, and developing relationships, aiding in the creation and sustainment of commitment to the partnership (Kezar, 2005). This kind of network was created by holding open meetings and having informal sessions, such as lunches, to bring participants together (Kezar, 2005). Copa and Ammentorp (1998) support this same concept for community college partnerships, stating that a communication infrastructure is in order to support development. Communication helps set clear expectations and increased understanding among the participants (Copa \& Ammentorp, 1998). Mohr and Spekman (1994) approached this from the angle of business-to-business partnerships and found that frequent, truthful information and the willingness to share contributed to trust building and other intangible characteristics that aid collaboration. Romzek, LeRoux, and Blackmar (2012) found this to be true for partnerships between non-profits as well, claiming frequency of communication, information sharing, and following through on commitments aided in building trust and facilitating relationships.

In Ostrom's framework, communication occurs in the action arena and discussed as rules relating to information sharing (see Figures $3 \& 4$ ). Communication is a product of exogenous variables, such as the actors, environment, community interests and 
preferences, and existing policies, rules, and norms (Ostrom, Gardner \& Walker, 1994).

The factors combined contribute to the quality and type of communication and interactions that take place, which influences the outcomes (Ostrom, Gardner, \& Walker, 1994).

Purpose

Purpose defines the incentives, motivations, and goals for participating in the collaboration. The collaboration and exchange or cost of shared resources move towards meeting a purpose that is in each party's self-interest (Anderson, Hakansson, \& Johanson, 1994) and in some form increases their value and competitive advantage in accomplishing the mission of their individual organization (Dyer \& Singh, 1998; Madhok \& Tallman, 1998). Mattessich, Murray-Close, and Monsey (2001) list several factors describing purpose including concrete obtainable goals and objectives, shared vision, and a unique purpose

Having a specific set of obtainable goals is an important feature of collaboration literature. In creating a specific and clear mission or purpose, a common guide, thought process, or language can be adapted by each of the participants (Kezar, 2005). Goals should be understood by the participants, not just shared (Amey, Eddy, \& Campbell, 2010). This aids each of the participants in committing to decision-making and behaviors that facilitate reaching the objective (Kezar, 2005). The objectives should be restated on an ongoing basis to the participants, along with clear signs of support from leadership (Kezar, 2005). This drives further commitment from each of the participants and communicates that successful collaboration is a key priority (Kezar, 2005). 
In higher education, missions and goals can be particularly important considering the number of potential stakeholders that may be affected by the educational institution's collaboration. Literature that has discussed community college and industry partnerships has defined purpose as the recognition of a community or regional need that would benefit from the involvement of both institutions (Kisker \& Carducci, 2003). The institutions should then establish mutual goals to achieve the defined purpose (Kisker \& Carducci, 2003).

\section{Resources}

Resources are the amount and type of investments made by the organizations into the success of the collaboration. In past research, the concept of resources in collaboration has shifted, although it has consistently remained an important component. Hord (1986) defined resources by associating it with ownership. Cooperative arrangements meant that ownership remained separate, there was an exchange of services or some form of payment was arranged (Hord, 1986). A collaborative effort shared resources and some mutual form of funding (Hord, 1986). Mattessich, Murray-Close, and Monsey's (2001) review of research in collaboration defined resources as sufficient funds and a skilled convener who adds legitimacy and fairness to the collaborative effort. Austin's (2000) research depicts the magnitude of resources invested as the key area as to how resources contribute to our understanding of cooperation versus collaboration. However, the continuum is based on the concept that increased resources would likely also increase as the mission or goals became more complex (Austin, 2000). As the potential value of the collaboration increases, so would the amount of resources invested (Austin, 2000). This concept of resources has shifted towards a contribution of 
complimentary resources to achieve a goal that neither of the parties could do as well alone. In Copa and Ammentorp's (1998) discussion of resources relating to education and industry, resources are discussed as "academic" and "business" perspectives to provide students with a more well-rounded experience, while serving community needs. The case study of the Niagara County community college and industry partnership identified the community college as the resource itself (Caton \& Mistriner, 2016). Amey, Eddy, and Campbell (2010) took a more balanced approach. They determined that the exchange of resources occurred in the development of the partnership to reach the goal and once the partnership was established, resources would be communal (Amey, Eddy, \& Campbell, 2010).

\section{Rewards}

The contribution of resources is closely tied to the concept of rewards. Expectations of benefits or rewards increases with the amount of resources an entity places into a collaborative agency. Rewards can consist of monetary gain, increased positive public relations, or any other benefit or value that the organizations receive for their participation (Austin, 2000; Copa \& Ammentorp, 1998; Mohr \& Spekman, 1994; Romzek, Leroux, \& Blackmar, 2012). As the perceived or actual value of the collaboration increases organizations will continue to support the development of the collaboration (Austin, 2000; Mohr \& Spekman, 1994). Kisker \& Carducci (2003) state that in order to achieve collaborative success among community college and industry partnerships, all stakeholders involved in the partnership should gain value. They also specify that students should be included among the stakeholders (Kisker \& Carducci, 2003). 
The purpose of collaboration is to improve the possibility of achieving a goal that done alone would not be as successful. Therefore that incentive structure causing each of the entities to participate is an important aspect. Ostrom's (1990) institutional analysis and development framework uses neoclassical economic and game theories as a foundation for its research in collaboration. This literature is heavily based on the development of incentive structures that facilitate collaboration (Axelrod, 1984; Skyrms, 2003).

\section{Incremental Time}

Incremental time describes the slow development or evolution of the collaboration. This is expressed in the literature most often through cyclical or evaluative models. Austin (2000) may express this the most overtly, by displaying the collaboration on a continuum that moves from cooperative to a highly integrated partnership. The evaluation component of this model, expresses that the involved organizational entities assess the value received along with its cost to determine if the collaboration should progress further to become more integrated or if the entities should begin to separate (Austin, 2000). The action arena in Ostrom's research (2005; Ostrom, Gardener, \& Walker, 1994) depicts the cyclical nature: people follow through on decided actions, evaluate the outcomes, and then determine how or if they want to continue. Ostrom (1990) also discusses this concept in more depth as the opportunity for collaborators to adapt to a changing environment and resources. Romzek, Leroux, and Blackmar's (2012) preliminary model of informal accountability among network organizational actors also depicts the cyclical nature of collaborative relationships (Figure 2). The growth in shared norms and the frequency of facilitative behaviors, as well as the outcomes, positive or negative, of the collaborative efforts affects the way the 
collaboration moves forward (Romzek, Leroux, \& Blackmar, 2012). Kezar's (2005) research in collaboration of higher education institutions is in agreement with this. The author focuses on collaboration as an evolution of shared norms and resources that increase commitment over time. Copa and Ammentorp's (1998) discussion of the community college's role as a learning partner in the community includes a process component. In the process component, it is stated that each of the entities should participate in a needs assessment, have conversations about goals and expectations, and follow through with an implementation method (Copa \& Ammentorp, 1998). This fits into the other literature by producing a forum where the rules, norms, and shared expectations can be developed to increase commitment among the participants.

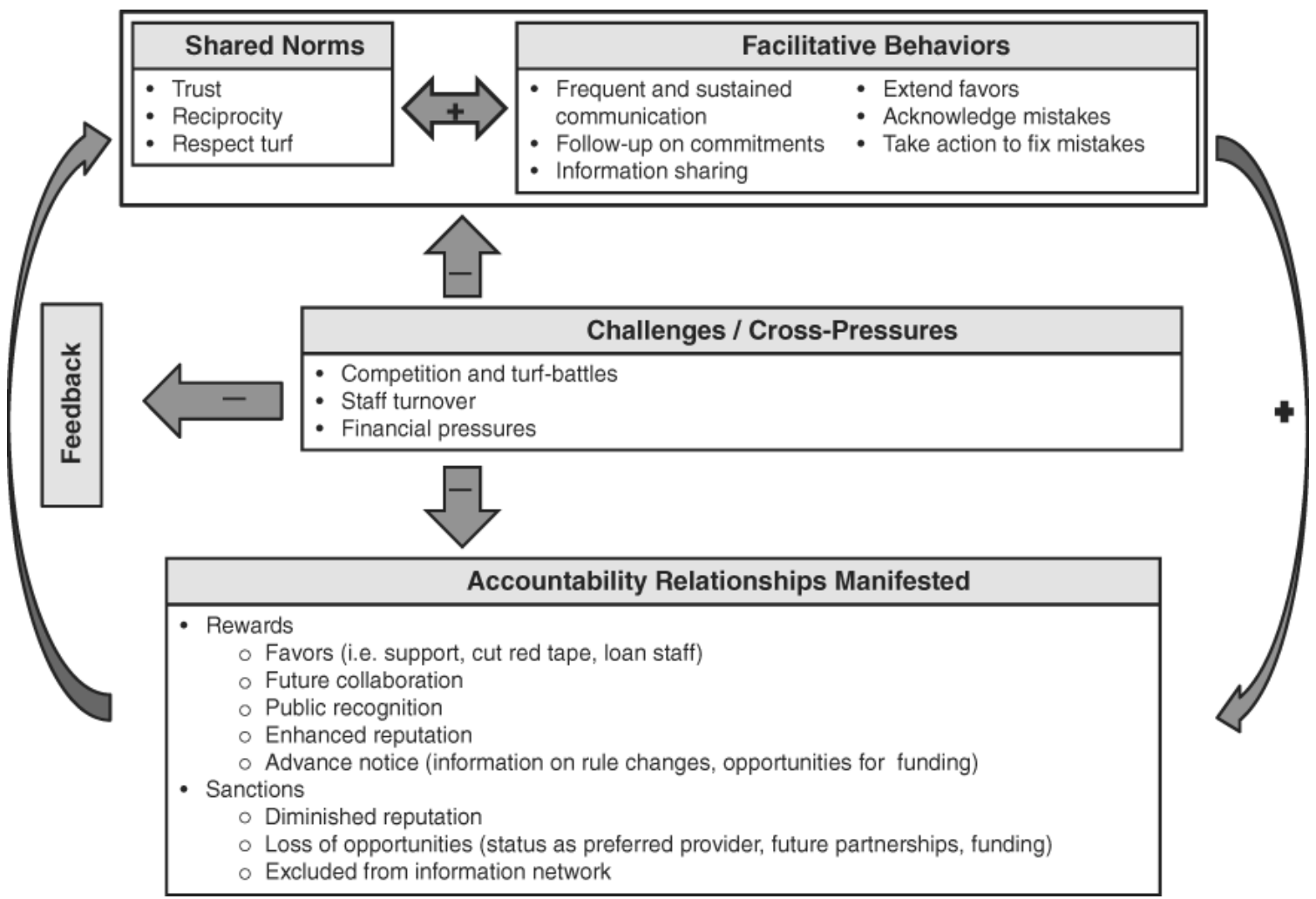

Figure 2. Romzek, Leroux, \& Blackmar's (2012) preliminary model of informal accountability among network organizational actors 


\section{Conflict Resolution}

Conflict resolution component refers to any process or discussion that focuses on overcoming barriers. In this case, it also includes sanctions. Conflict resolution techniques should be easily accessible and cost-effective (Ostrom, 1990). Conflict needs to be quick and relatively easy to solve so as not to increase barriers to positive outcomes.

Sanctions are a form of punishment to an organization if they fail to participate in the collaboration or make decisions that might harm the partnership. This is a less discussed area in the literature regarding collaboration. Romzek, LeRoux, and Blackmar (2012) and Ostrom (1990) touch on this concept as a way to understand accountability among collaborators. In practice, negative behaviors that harm the partnership prevent other individuals or organizations from taking the risk to invest in the collaboration, undermining long-term success (Romzek, LeRoux, \& Blackmar, 2012). Those who begin to create distrust, break policy, or harm the partnership should receive a fair punishment, consistent with the type of infraction (Ostrom, 1990). However, the organization or individual acknowledging their role in the error aids in reducing the amount of intangible values lost, such as trust (Romzek, LeRoux, \& Blackmar, 2012). This is consistent with traditional literature in collaboration and game theories that support the effectiveness of the tit-for-tat strategy (Axelrod, 1984). The tit-for-tat strategy was originally developed and tested through a computer game. It was most successful at achieving a high score, in comparison to 63 other models. The game begins by the computer's strategy to cooperate with the other player. If the other player defects, the computer responds in the following round by punishing or defecting once (defecting twice is considered an unjust or unbalanced punishment as compared to the original infraction). It then proceeds to 
cooperate (Axelrod, 1984). Essentially, it teaches the other player that it is most beneficial to consistently work together. Other forms of the game, such as tit-for-2-tats, that served defecting partners unbalanced punishments were not as effective at cooperation (Axelrod, 1984).

\section{Comprehensive Models of Collaboration}

Two complimentary models of collaboration were selected and examined to determine if they could provide insight into the relationship dynamics that could improve community college and industry partnerships, Austin's (2000) collaboration continuum and Ostrom's (1990) institutional analysis and development (IAD) framework. Each collaboration model was developed by analyzing a large number of case studies. The collaboration continuum was based on an analysis of 15 partnerships specific to the unique dynamic of collaboration between non-profit and for-profit organizations (Austin, 2000). The IAD framework is based on the synthesis of 5,000 case studies across disciplines (Martin, 1989). In addition, of all the collaboration research analyzed in Table 1, it had the greatest amount of supporting research. Both offer insight into the development and growth of the community college and industry partnership, but do so from different angles. Austin's (2000) collaboration continuum focuses on the strategic value and practical strategies for increasing and decreasing the relationships between public and private entities. Ostrom's (1990) IAD framework looks at the day-to-day operations and governance structure that drive human behavior. While primarily used for understanding the governance structures of common pool resources, the framework is intentionally written to encompass a wide number of variables. It does not specify or assume that any existing governance structure, such as hierarchy or decentralized 
organizations, are better than another (Imperial, 1999). This makes the framework applicable for analyzing any institution.

In addition, the IAD framework has been used to examine policies in higher education in the past. A recent book examined the higher education system at the state level through the institutional analysis and development framework, focusing on the rules guiding policy, in several states (Richardson \& Martinez, 2009). In addition, a pilot study examining the relationship between a community college and industry partnership through the lens of the institutional analysis and development framework was performed and confirmed the appropriateness of the framework for more in depth study and the institutional level (DiMattina, Alagaraja, \& Stone, 2012). The focus of the IAD framework as a tool to look at the operational structures of institutions and its ability to be applied to higher education institutions made it the selected instrument for this study.

Institutional Analysis and Development Framework

The institutional analysis and development (IAD) framework is a political theory that has been developed for analyzing policy and governance structures that impacts institutions abilities to meet its intended goals. Institutions are defined as the structures individuals create to interact with one another in all types of situations, such as within their office, religious community, families, neighborhoods, and all levels of government (Ostrom, 2005). Rooted in game theory, the framework has brought together multiple theories about human behavior across disciplines, including economic theory, transaction cost theory, social choice theory, and theories related to common-pool resources and public goods, to understand and predict the outcomes of situations when multiple people are involved (Ostrom, 2010). The core understanding is that organizations are products of 
a mix of variables that make up the rules, norms, shared and individual strategies of the people involved, and the physical world it takes place within (Crawford \& Ostrom, 1995). Through the identification, categorization, and organization of the variables within an institution's structure, an analysis can determine how each of them impacts one another and produces outcomes (McGinnis, 2011). This can identify the strengths of the institution or diagnosis its weaknesses (McGinnis, 2011).

Game theory utilizes literature and theory in philosophy and logic, economics, and the social sciences to understand people's behaviors and choices by understanding the payoff structure or benefits an individual receives in any given situation (Axelrod, 1984; Ostrom, 1990; Skyrms, 2004). Traditional game theory research has often required a strict set of rules limiting the effects of context on a person's behavior, such as limiting the number of interactions people have with one another (Axelrod, 1984; Ostrom, Gardner, \& Walker, 1994). The most popular example of game theory, the prisoner's dilemma, includes the assumption the interaction will occur only once (Ostrom, Gardner, \& Walker, 1994). Because the prisoners will never interact again, it is in their best interest for them to defect and tell on the other first (Rapoport \& Chammah, 1965). However, this kind of highly constructed game does not often occur in real life, so the prisoner's dilemma can only give us a limited amount of information into the behavior of people. The IAD framework adds complexity to game theory by depicting how outcomes are affected with a cyclical model that incorporates a multitude of variables, including context, rules, and participants, among others (Figure 3). These each occur around an action arena, which is the primary place where people interact, such as to exchange services, solve problems, fight, or collaborate (Poteete, Janssen, \& Ostrom, 2010). 
Within the institutions are mechanisms that organize repetitive situations that give people structure and rules for interacting (Ostrom, 2005). Based in neoclassical economic theory, the IAD framework includes the assumption that individuals will behave rationally within the structure and rules of the institution (Ostrom, Schroeder, \& Wynne, 1993; Williamson, 1973). Rational individuals make choices regarding best strategies and approaches that create outcomes with the highest amount of benefits to themselves (Becker, 1975; Friedman, 1953; Ostrom, 2005). There are many concepts that inform an individual's rational choice, some include incentives, bounded rationality, and adaptive learning (McGinnis, 2011). Incentives are the positive and negative outcomes that will impact an individual's behavior (Ostrom, 1992). They can come in all kinds of forms, including material, personal non-material opportunities, desirable physical conditions, and personal ideals (Barnard, 1938).

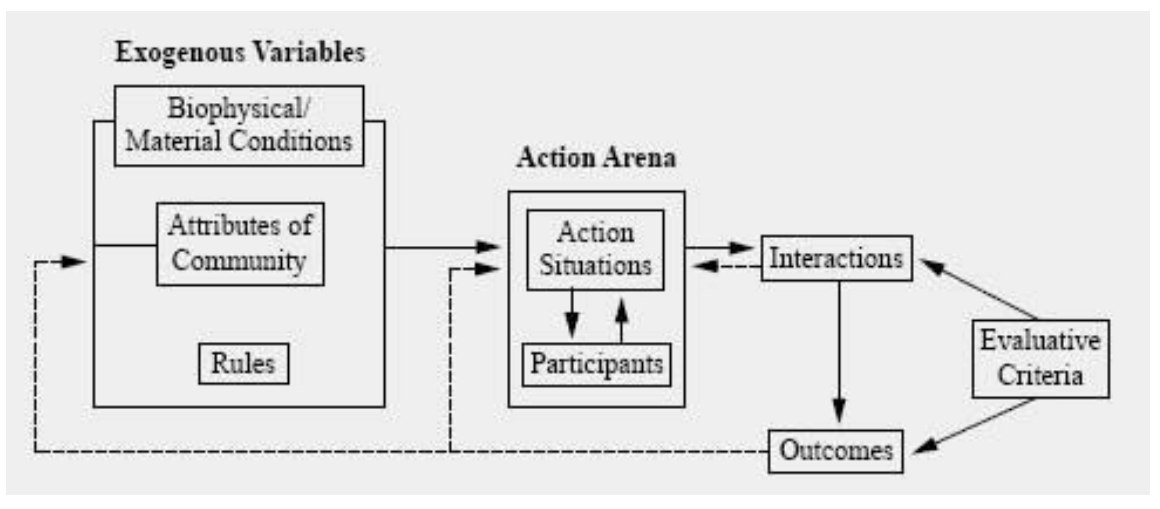

Figure 3. Ostrom's (2005) framework for institutional analysis

However, the IAD framework balances the neoclassical economic assumption with the assumption that information can be costly and individuals behave and make decisions with limited amounts of information or bounded rationality (Ostrom, Schroeder, \& Wynne, 1993; Williamson, 1973). Adaptive learning takes into account that individuals learn from their mistakes but at their own rate (McGinnis, 2011). 
This places the IAD framework in new institutional economics, which assumes that different problems require different arrangements (Coase, 1937; North, 1986, Williamson, 1973; 1985). Institutions are impacted by a range of opportunistic behavior and uncertainty from the individuals involved (Williamson, 1973; 1985). The IAD framework has built on this concept and established a set of universal components that make up all institutions. Through the identification and categorization of these diverse variables, the institution's governance system can be viewed as a unique contextual situation (Figure 4; Ostrom, 2005).

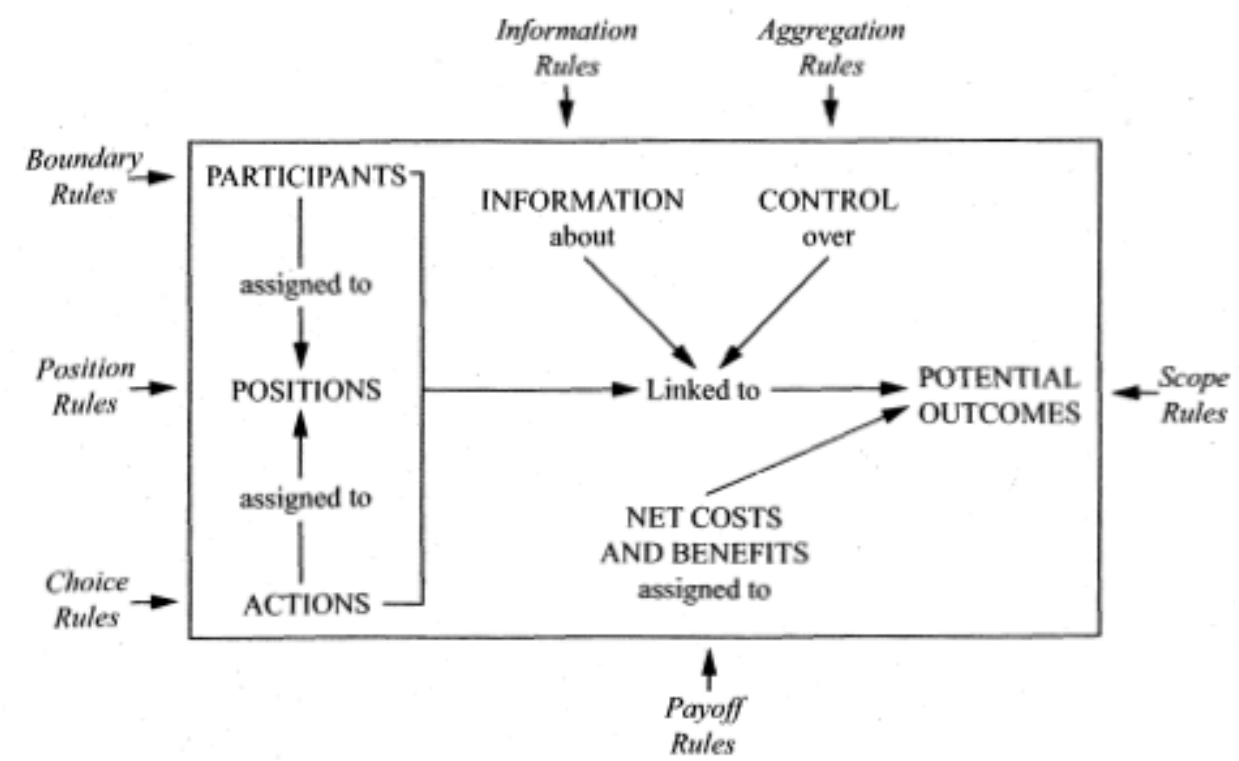

Figure 4. Ostrom's (2005) depiction of the interaction of factors that impact outcomes.

The universal components are comprised of seven elements that incorporate the complexity of various rules and components of the institution's governance system that converge to create an outcome (Ostrom, Gardner, \& Walker, 1994; Poteete, Janssen, \& Ostrom, 2010). 
1. Participants are the individuals working to solve the problem. In larger, more complex situations, participants can be groups, such as organizations or countries.

2. Positions are the role of the participants that helps to define their authority and course of action, i.e. boss, employee, voter, or citizen.

3. Actions are the available set of choices to a participant.

4. Potential outcomes are the outcomes that the participant has some degree of effect or control over and the degree of that control.

5. Transformation functions are the combination of choices and actions from the participants that result in an outcome.

6. Information is what the participant has to make their choices with. It is expected that participants will not have all the information they need to make a fully informed choice. This is called bounded rationality. Participants make decisions the best they can with the information they have.

7. Payoffs are the benefits and costs to the individuals or organizations based on actions and outcomes.

The reality is that governance systems never occur in a syphon. Rather, they are affected by overlapping governance systems (McGinnis, 2011). A polycentric system may be affected by a combination of governance systems, including multi-level governance, such as national and regional level centers of authority, multi-sectoral governance, such as public, private, or community-based centers of authority, or multifunctional governance systems that have been tasked with specific goals (i.e., creating a product, managing funds; McGinnis, 2011). Community college and industry 
partnerships lie within a unique polycentric system of governance. By using the IAD framework to examine the relationship and cooperative arrangement of a community college and industry partnership, a more comprehensive view can be obtained of the incentives and structures aiding the two organizations in working together.

\section{Key Components of the Action Situation}

The utility function of the IAD framework is to understand the inputs of any given decision-making process that creates an outcome. That outcome can then be evaluated along with any other effects it may have on the action situation (McGinnis, 2011). The action situation (Figure 3 ) is where a set of individuals bounded by inputs make a decision (McGinnis, 2011). The process for understanding the action arena is the core component of the IAD framework (McGinnis, 2011). It begins with the identification of the main exogenous variables or inputs that define and impact it (Poteete, Janssen, \& Ostrom, 2010). They describe the contextual backdrop for the action arena, which are the biophysical/material conditions, attributes of the community, and rules.

Biophysical/material conditions are the structure of the resource system. It refers to the physical and human resources related to the development and production of goods or services, such as capital, labor, finance, or storage. Attributes of the community describe the cultural structure the action arena exists within. It includes the themes listed that support collaboration, especially membership characteristics. Example variables include the demographics of the community and participants' values, beliefs, and preferences. Rules come in a wide array of forms and specify the values of the institution's governance system. 
This process shapes the outcomes, which are then evaluated by the individuals involved. A cyclical situation exists, where the individuals affected by the outcomes adapt and learn from the decision-making process. They develop expectations and learn more about how to maximize their utility within the rules. As a result, they further develop their strategies for producing their best outcome in a given situation (Ostrom, 2005). Because rules are the most difficult aspect of the diagram to identify and have a significant impact on the behavior of individuals, the process for understanding an institution's dynamics begins with the identification of the rules.

Rules. Rules have traditionally been understood as laws (Fiebleman, 1968). Law creates and maintains order among people (Edgerton, 1985). Without laws, there is disorder and great uncertainty among people (Fiebleman, 1968). People prefer to reduce their uncertainty (Becker, 1976). The order created by law is meant to restrict behavior to create predictable outcomes (Becker, 1976). As a result, people create rules and order in every institution in which they participate in order to prevent detrimental behaviors and outcomes while increasing the likelihood of positive outcomes (Ostrom, 2005).

A literature review of rules defines them as actions and behaviors that are contextual, prescriptive, and followable (Shimanoff, 1980). The contextual aspect of rules describes that rules apply in similar situations but need not be acted on in different situations (Shimanoff, 1980). Traffic laws are utilized while driving on the road and a generalized version of the laws may be used by pedestrians on sidewalks. However, if people are not in a high traffic area or standing still, there is no need for individuals to follow the rules. The prescriptive aspect of rules describes the creation of the rule itself (Shimanoff, 1980). Prescriptive rules have been created and imposed by the participants 
(Fiebleman, 1968). The opposite of this concept is descriptive rules, which people do not have control over. Scientific findings are descriptive, such as the laws of gravity or counting proportions (Fiebleman, 1968). People can discover and name them, but are unable to control the way they influence daily life. Gravity cannot be turned off to fly to work each day, but traffic laws can be followed. Associated with the prescriptive aspect is prescriptive force, which refers to the individual's drive to follow (or not follow) a rule (Shimanoff, 1980). Rules are followable, which means that they are specifically related to human actions and behavior (Shimanoff, 1980). The nature of rules being followable also means that individuals can opt out of following a rule and accept the negative implications of doing so.

Rules within the IAD framework are defined as the shared understandings among the participants about enforced, required, prohibited, or permitted behaviors that lead to decision-making and outcomes (Crawford \& Ostrom, 1993; Ostrom, 2005; Ostrom, Gardner, \& Walker, 1994). They have been established with the intent to create order and predictability in the institution among the participants (Ostrom, 2005; Ostrom, Gardner, \& Walker, 1994). The research building on and towards the IAD framework accepts Shimanoff's (1980) description of rules as contextual, followable, and prescriptive (Poteete, Janssen, \& Ostrom, 2010). Rules in the IAD framework evolve over time as they are continually affected by the other variables in the model and the decision-making process (Figures 3 \& 4; Ostrom, Gardner, \& Walker, 1994).

Explicit and implicit rules. Formal or explicit rules have traditionally been understood as laws (Fiebleman, 1968). Any rule that has been stated fits into this category, including laws, bylaws, policy, contracts, among others that create and maintain 
order among people (Shimanoff, 1980). Without these formal rules, there is disorder and great uncertainty among people (Fiebleman, 1968). People prefer to reduce their uncertainty to create predictable outcomes; as a result, we tend to create rules and order in each institution in which we participate (Becker, 1975; Fiebleman, 1968).

However, rules do not have to be formally written to be utilized (North, 1993; Ostrom, 2005; Selznick, 1948). Implicit rules are those inferred from behavioral patterns of other individuals (Berger \& Calabrese, 1975; Shimanoff, 1980). In other words, individuals decide intuitively what is appropriate by evaluating their behaviors and the responses they receive from others (Berger \& Calabrese, 1975; Shimanoff, 1980). They are identified as controllable, criticizable, and contextual (Shimanoff, 1980). The controllable aspect is explained as the ability to perform a behavior or action. If a person is able to deviate from a behavior, then the action or behavior is controllable. The criticizability aspect refers to the ability to be evaluated, either with positive or negative reinforcement. The contextual nature of an implicit rule is the same of that of a general rule. It applies to a general set of situations.

The social structure and interaction patterns of the participants impact the organization's ability to meet its purpose (North, 1993; Selznick, 1948). Informal rules can define how people perceive they are to interact with one another. Rules become habitual and difficult to define as a result (Shimanoff, 1980). The impact of the informal social structure stems from the participants' preference to avoid being set into roles and instead participate as their whole selves, which may include competing goals or challenging personality traits (Selznick, 1948). More often, these social structures have created unwritten rules through statements that describe opportunities and constraints to 
alter and control repetitive group interactions so that increasingly better outcomes are produced (Ostrom, 2005; Selznick, 1948). However, these outcomes tend to be based on the preferences of the participants involved in the interaction (Cyert \& March, 1959). This lends itself to the explanation of why organizations do not always seem to make rational choices. The individuals within the institutions make rational decisions in their personal best interest and not in the organization's (Cyert \& March, 1959; North, 1993).

Language and rules. The basic and general structure of a rule is based on "if, then" statements (Shimanoff, 1980). The "if, then" statements that form a rule generally describe a causal relationship. However, in the form of rules the "then" aspect of the rule is not obligated to occur. In scientific laws, the "if, then" statement describes a causal relationship between two variables that is obligated to occur. However, in the prescriptive version of rules, "if, then" statements describe what "ought" to occur (Shimanoff, 1980). The "if" should dictate the circumstance or context of when the rule should apply, followed by a prescriptive term (i.e., must, should, should not), and last the specified behavior or action (Shimanoff, 1980). An example is "when meeting someone new, one must smile and say hello."

The IAD framework has built on this basic structure. It determined that there are five key pieces to understanding the syntax of a rule: attributes, deontic, aim, conditions, and "or else" (Crawford \& Ostrom, 1995). Attributes express participant-level variables or subset of individuals to whom a rule applies, such as underage, female, level of experience, or a specified title. Deontic identifies an auxiliary verb that predicate an action, including "may (expressing permission), "must" or "should" (expressing obligation), and "must not" or "should not" (expressing forbiddance). Aim describes the 
action that the deontic refers to. Conditions describe when and/or where the rule applies. "Or else" describes the consequence for not following the rule. The rules aid all the participants in their development of expectations within an action situation (Ostrom, 2005). An example of this is "all drivers must obey safety laws when on the highway or they will receive a ticket." Drivers are the attribute, must is the deontic, obey safety laws is the aim, the highway is the condition, receiving a ticket is the "or else."

The IAD framework further delineates rules from shared strategies and norms (Crawford \& Ostrom, 1995; McGinnis, 2011). Shared strategies are made up of only attributes, aims, and conditions (Crawford \& Ostrom, 1995; McGinnis, 2011). Norms are defined by the aims, deontic, aim, and conditions. The consequences for not conforming to the norms are nonexistent, minimal, and/or informal (Crawford \& Ostrom, 1995). How each aspect of the rules, shared strategies, and norms impact an individual's choice at any given point will determine their behaviors and choices and further develop the configuration of the institution (Crawford \& Ostrom, 1995)

Scope of rules. Rules occur at nested levels within the institution: constitutional, collective choice, and operational. Constitutional level rules establish the power structure of the organization and inform the rules at the collective choice level (Ostrom, 2005). They determine who is eligible to participate in operating the rules at the collective choice level and who can make changes to the decision-making patterns at the level (Ostrom, 2005). Collective choice rules determine the institutional construction and policies as determined by the constitutional rules (McGinnis, 2011). Operational rules impact the day-to-day operations and decision-making patterns. They tend to be the practical decisions that are made by the individuals who have been given permission to 
do so according to the collective choice rules (McGinnis, 2011). The rules at this level are the foundation of the action situation (Figure 4; McGinnis, 2011). They exist within several categories: positions, boundaries, choice, aggregation, information, payoff, or scope (Ostrom, Gardner, \& Walker, 1994; Ostrom, 2005). Position rules define the job placement and authorized actions of the participants. Example positions are president, parent, or manager. Boundary rules define the rules for entering and exiting positions. More specifically, the rules define who has access to a position, the process for determining eligibility for entering or leaving a position, and how the individual may leave the position. It includes the attributes or qualifications an individual must have to obtain the position. Choice rules specify what a participant in a position has the choice of doing in a decision-making process based on the deontic component of the rules. Aggregation rules define whether a single participant can make a decision or if the decision has to be made by some variation of the collective. Information rules define the flow of information. They give authorization for the participants to share information about the structure and current events. It also describes the frequency and accuracy of the communication. Payoff rules define the rewards or sanctions that are the result of decisions. Scope rules encompass all other rules that cannot be defined in these other categories but have impact of the decisions and outcomes in the action arena. How individuals interpret and apply these rules in a given action situation will determine the outcomes and impact of any decision (Crawford \& Ostrom, 1995).

\section{Evaluating Outcomes}

Policy and economic outcomes are generally assessed from different standpoints. The most common data points used to assess outcomes are economic efficiency, fiscal 
equivalence, distributional equity, accountability, conformance to general morality, and adaptability (Polski \& Ostrom, 1999). Economic efficiency refers to the development of maximized benefits at a given cost (Polski \& Ostrom, 1999). An accepted standard that is not as strict for the measurement of economic efficiency refers to the cost efficiency of outcomes (Polski \& Ostrom, 1999). The principle of fiscal equivalence is that those who have received greater benefit pay more than those who receive fewer benefits (Polski \& Ostrom, 1999). Distributional equity is the principle that payment for a good or service is based on the ability to pay for it (Polski \& Ostrom, 1999). Accountability outcomes refer to the limiting of opportunistic behavior by individuals (Polski \& Ostrom, 1999). Context and the extent to which policy can facilitate information sharing and transparency, the ability of participants to evaluate others in the action arena, and the mechanisms that allow participants to monitor and produce sanctions affect the organization's accountability (Polski \& Ostrom, 1999). Conformity to general morality is difficult to measure, in part, because the specification of a general morality is a slippery slope (Polski \& Ostrom, 1999). However, the participants' abilities to benefit through causing harm or creating mistrust are considered among the outcomes (Polski \& Ostrom, 1999). Policy or structure that allows for adaptability and innovation in response to dynamic environments is another evaluated outcome (Polski \& Ostrom, 1999). Each contributes to how the structure benefits the organization's ability to function and produce quality goods and services within its given context.

\section{Understanding Rules First}

To best understand the rules that impact decision-making, Polski and Ostrom (1999), suggest a rigorous analysis of the decision-making capabilities of the actors. This 
includes their access to resources, such as capital, labor, technology, and time, the preferences of the participants or what they wish to achieve in the action arena, their access and ability to use information, and their perception of other participants and behaviors (Polski \& Ostrom, 1999). Socio-psychological factors such as personality, education levels, and peer pressure impact the participants' ability to process and use information as well as their perceptions of others in the action arena (Polski \& Ostrom, 1999).

As a result, some rules will be formally documented, while others have been created as people attempt to solve problems (Ostrom, 2005). To understand rules within this framework, the researcher first has to identify the rules that participants use in their decision-making (Ostrom, 2005). Identification of the rules individuals use can be determined in their justification and explanation of their choices and actions to others (Ostrom, 2005). The next step is to define how these rules originated (Ostrom, 2005). The weakness in the attempt to understand rules is that they are defined through language that can lack clarity or easily be redefined, reinterpreted, or misunderstood (Ostrom, 1980; Ostrom, 2005). Changed shared norms, strategies, and context, along with new applications of technology alter actions and decision-making (Ostrom, 1980; Ostrom, 2005). In addition, rules are applied and enforced by people; as such, the application and enforcement of them may be strong or weak depending on the people in the action arena (Ostrom, Gardner, \& Walker, 1994). Because rules can be incredibly complex to identify, document, and categorize, the framework specifies that rules should directly impact the action situation (Ostrom, 2005). 
Observing an institution through the lens of the IAD framework has weaknesses. The purpose of the framework is to identify causal mechanisms of the structure on behavior and choices (Poteete, Janssen, \& Ostrom, 2010). The process for data collection is intensive and requires the researcher to have a thorough knowledge of the environment that they are observing (Ostrom, 1990). Because rules have the ability to be informal and interpreted by participants, the researcher may not be able to identify some of the rules that have an impact on the institution's governance.

\section{Conclusions}

The community college is a regional resource that connects industry needs to the diverse populations. Scholars and prominent government officials have been increasingly pointing out the disconnect that exists between the U.S. workforce development system and the needs of industry in our economic environment (Clinton, 1998; Katsinas, D’Amico, \& Friedel, 2012; Obama, 2009; Symonds, Schwartz, \& Ferguson, 2011; U.S. Department of Education, 2012; Vandal, 2009). However collaboration often fails (Doz, 1996). In order to begin aligning the organizations that can fix these workforce development issues, the unique factors that have an impact on industry and community colleges need to be identified.

This literature review identified the many variables that go into effective collaboration, along with characteristics of public and private institutions that impact their organizational strategies and development, and variables that are unique to the community college and industry partnership. Various models of collaboration were identified and analyzed. This literature review described the selected the IAD framework to study the community college and industry partnership case, because it was most 
inclusive of the variables identified as being important to successful collaboration and was designed to be applied to any institution. The IAD framework was designed to understand the outcomes of institutions by identifying the variables that affect the decision-makers of the institution and their perceived range of choices.

Looking at the governance structure of community college and industry partnerships is an important aspect of improving the efficiency of the U.S. economy, aligning education and the needs of the workforce, and providing more direct lines of opportunity to all people. In our current state, we do not have enough data to understand the needs of such a partnership. Rather, we are only aware of the diversity of variables that may shape the institution and the many obstacles that will need to be overcome. 


\section{CHAPTER III}

\section{METHODS}

Chapter three lays out the methodology for this study. The research questions are stated and the method for answering them are described in depth, including previous research that helped to inform the approach. This chapter will further describe the philosophical assumptions, data collection methods, and analysis approach taken in this study. The researcher's philosophical assumptions as a pragmatist address the viewpoints and foundational concepts of how the research questions and approach to answer them were developed. Case study methodology is discussed, along with the specific methods used for data collection. Discussion of how the data will be analyzed is addressed. The limitations and delimitations of the study are also discussed.

This study seeks to use a qualitative case study design to identify and examine the rules as categorized in the IAD framework, which enables individuals from both organizations to work together to build a successful partnership. This line of inquiry was determined after thorough research in collaborative literature and a pilot study (DiMattina, Alagaraja, \& Stone, 2013) that determined the relevance of the IAD framework to the collaboration of community college and industry. This process led to the development of a line of inquiry related to the rules within the context of 
collaboration and the institution as interpreted by the participating individuals. This study has identified two research questions:

- What are the rules (formal and informal) that govern the organizational structure of the partnership?

- How do the identified rules affect the outcomes of the partnership?

A qualitative approach to this research design was selected because of the desire to capture and describe dynamic and complex phenomena within the context of the community college and industry partnership (Burke Johnson \& Onwuegbuzie, 2004). Qualitative methods and tools provide a rich description of how each of the study participants experience and interpret the rules in their collaborative environment (Burke Johnson \& Onwuegbuzie, 2004).

Other methods have been employed to expand on the understandings of institutions, such as experimental designs or meta-analyses that have created a synthesis of findings from a larger set of cases (Poteete, Janssen, \& Ostrom, 2005). Experimental design, however, is not an appropriate method in this study for two reasons: (1) we do not know enough about human behavior and decision-making strategies in the context of community college and industry partnerships and (2) we are not able to control the variables. A meta-analysis would require a great deal more information regarding community college and industry partnerships than is currently available in order for there to be a synthesis. Other forms of qualitative study, such as a narrative or phenomenological would produce a great deal of data, but not necessarily data that would be relevant to the research questions. Narrative research is focused on the identities and stories of individuals (Creswell, 2013). This line of inquiry would produce a great deal of 
extraneous data related to the personal identities of individuals that are not relevant to the research questions. The purpose of phenomenological research is to capture and reduce common lived experiences to understand a phenomenon's nature (Creswell, 2013). The data produced from this line of inquiry would provide a great deal of information about the meaning of collaboration; however, this study is focused on the functionality of collaboration. Given the pragmatic focus of this study, the real world context, the research questions, and the established use of case study with the theoretical framework, case study is an appropriate choice of methodology.

Philosophical Assumptions and the Qualitative Case Study

This study will be performed from a pragmatist's perspective. Pragmatism is not a unified theory (Talisse \& Aiken, 2011). It was established by Pierce in the late 1800's to remove the abstract from how questions were answered (Pratt, 1909). Instead, it focused on the verifiable truth of knowledge and its actual or direct impact on people (Pratt, 1909). James, another pragmatist, expanded on this philosophy through his concept of learning (Kolb, 1984; Pratt, 1909). James' philosophy on learning is rooted in the development of experiential learning and that knowledge is acquired by individuals building on the information they currently have with new experiences and lessons (Kolb, 1984). However, it was not until more recently with Rorty's revival of the philosophy that it has become used more frequently (Talisse \& Aiken, 2011). Rorty discussed the philosophy within the idea of understanding knowledge through the operational definitions utilized by people (Talisse \& Aiken, 2011). The philosophy focuses on the verifiable definitions and truth that people use that impacts their actions and decisions (Rescher, 1977). The traditional view of pragmatists is that truth is determined by 
practical consequences or how things are expressed per the beliefs of those being studied (Murphy, 1990). This inherently places the role of values and beliefs on the participants being studied, instead of the researcher (Creswell, 2013). This means that there can be multiple truths and potentially better explanations for how something "works," however, until it is found, this one "works" (Rescher, 1977).

As we are seeking to discover "what works" in the operation of the collaboration between a community college and industry partnership, this philosophy will aid in us in understanding the values and knowledge as operated by the study participants (Creswell, 2013). The research questions, for instance, are tailored towards a pragmatist's point of view as they focus on the incentive structure and behavior of the participants in the collaboration. Incentive structure and behaviors have been identified as part of economic and game theories to predict the decision-making patterns of individuals (Axelrod, 1984; Buchanan \& Tullock, 1962; Ostrom, 1998; Ostrom, Gardner, \& Walker, 2005). This suggests that research can identify patterns of logical behavior in the participants. The research and the questions are focused on the practical implications and answers to the research problems. The research questions, however, are focused on how the rules of the collaboration are interpreted by and work for the participants involved in the collaboration. Therefore, values and beliefs are not created by the researcher; instead, they are defined by the participants. This combination of context and values, from the perspective of "what works" for the participants, will provide the data to answer the research questions.

The high degree of focus on the concept of verifiable truth within this philosophy causes many researchers to prefer a mixed method approach in their study designs to 
balance the strengths and weaknesses of qualitative and quantitative research (Burke Johnson \& Onwuegbuzie, 2004; Morgan, 2007). Among other strengths, quantitative studies have structure, providing increased control of confounding variables that allow for a better determination of cause and effect relationships and results relatively independent of the researcher (Burke Johnson \& Onwuegbuzie, 2004). However, the problems of interpreting cause and effect are not necessarily an argument in qualitative versus quantitative methods (Brady, Collier, \& Seawright, 2004). Instead, researchers (Collier, Seawright, \& Munck, 2004) argue when the appropriate assumptions are utilized in qualitative methods (e.g., causal homogeneity, independence of observations, and conditional independence) quality causal inferences can be determined.

In the case of community college and industry partnerships, there have been limited studies identifying "what works." In addition, consistent variables across cases and their operationalization have not yet been identified. The current lack of quantitative data, therefore, requires a rigorous qualitative process for understanding causal inferences. A thorough understanding of the literature on collaboration and its context is required to meet the assumption of causal homogeneity in qualitative research seeking to understand causal inferences (Collier, Seawright, \& Munck, 2004). This is accomplished through the analysis of an appropriate case, the consideration of how cases and observations have influenced one another, and the selection of appropriate variables and the relationship models between them (Collier, Seawright, \& Munck, 2004). Munck (2004) explains a specific case should be identified, along with its scope and distinct indicators of success and progress in the community college and industry partnership. In addition, data should be in-depth and deterministic hypotheses scrutinized against 
probabilistic alternatives through the identification of analytically relevant components of the collaboration (Munck, 2004). Over time, these hypotheses can be retested and identified through the analysis of further case studies in the field (Munck, 2004).

This approach and perspective contribute well to the theory and methods that will be utilized in this research, a case study performed through the lens of the IAD framework (Ostrom, 1990). Case studies are known for their ability to answer "how" and "why" questions in a real-world setting involving the understanding of contextual variables and conditions that impact the data (Yin, 2014; Yin \& Davis, 2007). In addition, they are often selected because of their ability to examine contemporary events when the boundaries between the phenomenon and context are unclear in a bounded situation (Yin, 2014). In this case, the bounded situation is the collaboration between the community college and the industry. The individuals from each organization contribute to the collaboration and bring a range of contextual variables influencing the decision-making patterns and ability of the organizations to collaborate. In order to answer the research questions regarding the structure of the collaboration and how it affects the patterns of behavior of individuals, the contextual variables will play a significant role. A case study allows for the researcher to focus on creating a rich description of the application of rules into strategic decision-making and behavior of the individuals involved in the partnership (Burke Johnson \& Onwuegbuzie, 2004; Poteete, Janssen, \& Ostrom, 2005).

Yin (2014) would describe this as a descriptive case study rather than an exploratory or explanatory case study. As exploratory case study is performed to identify research questions or procedures to be used in future research (Yin, 2014). An explanatory case study analyzes a sequence of events to explain and describe how a 
condition came to be (Yin, 2014). Descriptive case studies, however, describe the phenomenon in its real world context. In addition, Stake (1994) would define it as an instrumental case study because of its purpose to gain insight into an issue or theory. This case study, therefore, is both descriptive and instrumental. While the focus is on the operations between the community college and business (the real world context), the purpose is to gain insight into the application of rules in collaboration between these two types of organizations more broadly (the theoretical issue at hand).

Furthermore, research using Ostrom's IAD framework has relied a great deal on case studies as a methodology for their approach in understanding policy and human behavior within institutions (Poteete, Janssen, \& Ostrom, 2005; Ostrom, 1990). The assumptions underlying the framework are (1) individual behaviors influence collective action outcomes, (2) individuals are bound by rationality as described in behavioral theory, and (3) context influences individual behavior (Poteete, Janssen, \& Ostrom, 2005). In addition, the assumption of causal homogeneity is expressed through the need for comparisons of cases, but "there is more than one route to the same outcome" (Poteete, Janssen, \& Ostrom, 2005, p. 22). Case study has allowed for researchers seeking to understand collaborative behavior "to develop concepts, and theory, identify the limits of general relationships and disprove deterministic hypotheses, control for confounding effects through within-case comparisons, and disentangle causal processes" (Poteete, Janssen, \& Ostrom, 2005, p. 33).

\section{Overview of the Context and Site}

The partnership analyzed in this study was chosen because the community college administration organizing and developing the partnership has emphasized the importance 
of having industry advisory councils over the past decade. Over the course of the current Dean's career, he supported, established, and developed several industry advisory boards that have received support from the institution's administration. The success has been featured in major media outlets in previous years, especially during times of economic troubles for the U.S (Fitzpatrick, 2009). In addition, they have attracted participation from the largest companies in the city that have in turn established programs to hire the graduates.

The city has had immense population growth, almost $40 \%$, since 2000 (U.S. Bureau of the Census, 2014). According to the city's website, the state has attracted an increased number of tech-related companies, including Samsung and Microsoft, which have increased the amount of jobs by 1.2 million since 2003 . The community college and industry collaborate through an industry advisory board. Both the community college and regional industry have benefited from the restructuring of programs to improve the quality of the regional workforce. This case looked at the development of a new industry advisory board with the goal of restructuring the community college's information technology programming.

\section{Methods for Data Collection}

A case study is a methodological strategy that requires the implementation of several different research methods to understand and triangulate the phenomenon studied (Yin, 2014). The actual research methods were selected and employed based on the phenomenon, available data, and the type of data that is required to answer the research questions. In this case study, the data was collected through documentation and archival records, unstructured interviews, and observations. Documentation and archival records 
were identified and analyzed first to determine any existing formal rules shaping the interaction of the participants. These documented rules can then be directly addressed in unstructured interviews to understand if they play a significant role in the participants' decision-making and behavior or if they have no bearing at all. Unstructured interviews purposely follow in order to understand the participants. Observations were used last as a form of triangulation and to determine if further interviews are necessary.

\section{Documentation and Archival Records}

Documentation and archival records can have a high value in case study research. They can corroborate and augment data collected from other sources (Yin, 2014). Documentation can include letters, emails, personal documents, agendas, meeting minutes, other written reports of events, administrative documents, formal studies, and evaluations, among many others (Yin, 2014). Archival records may include public government files, service records, organizational records, and survey data produced from other sources (Yin, 2014). These can communicate formal titles and spelling, corroborate or contradict information from other sources, and help develop inferences that can open up new lines of questioning (Yin, 2014). The relevance of archival data is based on the case study and its research questions (Yin, 2014). For this particular study, email communication, meeting minutes, formal organizational records from the community college, and other public sources, such as webpages and press coverage were the primary sources of archival data. These offered the most relevant data as it related to the organizational shape of the collaboration and the informal and formal rules. The original partnership had been established with the use of grant funding. The materials utilized to be awarded the grant, the formal contracts between the two organizations, and public 
records, such as press releases were collected as best as possible. These documents were used as historical records to better inform the makeup of the current organization. As a source, documentation can only support the researcher, because often it is written for a specific purpose or objective not relevant to the case study and will carry some degree of bias (Yin, 2014). As a result, identifying the actual objective of the documentation will increase the likelihood its interpretation will be correct and not misleading (Yin, 2014). A similar concern is raised with archival records; the accuracy of a record should be ascertained, especially if it is central to the case study (Yin, 2014).

Documentation providing examples of communication patterns related to the development of the collaboration were particularly helpful in answering this case study's research questions. Formal documentation that dictated the community college's policies on working with outside organizations were examined in order to understand the limits that the collaboration operates within. In this case, the only formal documentation of policies related to working with outside organizations was the grant provided by the state workforce board. The documentation had the potential to specify rules that dictate limits industry is able play within the institution. Email communication were a primary source of data to help identify communication patterns and rules among participants. Email communication between the community college and the industry advisory board members were analyzed to identify formal and informal rules and used to triangulate the data. Meeting minutes provided a history of the communication patterns, participation, and decisions among the group, along with specific titles that the actors hold. Information taken from the meeting minutes were triangulated through unstructured interviews. 


\section{Unstructured Interviews}

Unstructured interviews are central to case study research (Yin, 2014). These interviews appear as guided conversations, rather than a structured pattern of questions (Yin, 2014) with the purpose of gaining access to the participants' perspective (Patton, 1990). Interviews bring data to light not directly observable or obtainable through documentation, such as feelings or intentions (Patton, 1990). The underlying assumption is the information obtained through interview has meaning and can be made explicit (Patton, 1990). Case study questions focus on "how" and "why" research questions, but interviewees asked these questions directly may feel threatened and defensive by the phrasing (Becker, 1998). The unstructured interview allows for the operation of two levels of questions to occur: those specifically tailored to the interviewee and those related to the purpose of the case study (Yin, 2014). The unstructured interview offers the researcher an opportunity to adapt their questions in real time to meet the needs of the interviewee and the purpose of the study (Yin, 2014)

The unstructured interviews were organized to have a conversational tone about the flow of communication among the participants in the collaborative structure. This allows for the interviewees to open up about their experiences and how their day-to-day events occur in a non-threatening way. Rules and data can usually be identified when participants justify how they made their decisions, as if to their supervisor (Ostrom, 2005). However, questions formed that directly ask for justifications from participants may be responded to with defensive language (Becker, 1998). Interviews are central to 
this study because of their use in providing humanistic evidence, especially as it relates to the decision-making patterns of the participants (Yin, 2014).

Participants. The participants in this study were three members of the Continuing Education Department at the community college, including the Dean and Coordinator who handle the day-to-day operations of the collaboration. Sixteen industry advisory board members representing local businesses of various sizes and city government were interviewed. The interviews were done with instrumental participants, especially the dayto-day operators of the collaboration from the community college and the industry advisory board representatives who actively participate. Each of these interviewees were identified through documentation, such as meeting minutes, email exchanges, and other instrumental interviews. The interviews were digitally recorded for accuracy and transcribed verbatim for systematic analysis (Patton, 1990).

\section{Observations}

Observations allow for current social and environmental evidence to be collected (Yin, 2014). Further, they provide additional insight into a topic (Patton, 1990; Yin, 2014). Observations allow the researcher to describe the setting, activities, the people who participated, and the meanings the setting and activities have to the participants (Patton, 1990). This descriptive detail allows the researcher to identify what occurred and understand how it happened (Patton, 1990). Within this case study, context plays a strong role. As this study is focused on collaboration, the observations were focused on the participants interacting and working together. All of the participants participate in a quarterly meeting designed to allow them to communicate in person. Two of these meetings were observed. Attendance was noted, along with the titles of those in 
attendance, speakers, and the frequency of communication. To better understand the rules that impact decision-making patterns, notes about any agreed upon next steps, who suggested them, and who took charge of moving forward with them, were included for analysis. Observational data provides a more holistic and firsthand perspective in understanding how the participants operate (Patton, 1990). This allowed the researcher to go beyond the descriptions and insights of interview methods, experience in the real world how communication and behavior were practiced, and bring to light unsaid patterns of communication, including the informal rules shared among the participants.

\section{Data Analysis}

Once the data was collected, the focus was placed on the categorization of the content as is relevant to the research questions (Robson, 1993). This research has theorized that the IAD framework effectively describes the institutional organization of community college and industry partnerships. This assumption prioritized and organized already identified themes within the collected data (Yin, 2014). It has also provided a logic model that operationalizes a complex set of variables that can show cause and effect patterns (see Figure 3; Yin, 2014).

The main focus of this study is to understand the rules that are in place that guide the behaviors and incentive structures of the individuals involved in the partnership. Rules are identified through the methods discussed above and analyzed to determine their application in the current setting. They are then further considered to determine their impact on the performance of the collaboration.

In order to fully document and realize the rules and their impact, the methods of data collection occurred in cycles. Historical documentation was coded first, then 
unstructured interviews, and observations followed to better understand and triangulate the findings. As new rules and outcomes were identified, documentation, observations, and unstructured interviews would be performed to confirm the findings. All rules were identified and coded using the syntax below (Miles \& Huberman, 1984). In addition, any decisions or outcomes made were placed in their own category.

\section{Identification of Rules}

Syntax and grammar play an important role in understanding and identifying the rules, especially those that are not as easily articulated because they have become a tacit part of the institution (Ostrom, 2005). Below is a list of the components that aid in defining rules as they apply to the people and organization (Ostrom, 2005).

- Attributes express participant-level variables or subset of individuals to whom a rule applies, such as underage, female, level of experience, or a specified title.

- Deontic express one of three auxiliary verbs that predicate an action, "may (expressing permission), "must" or "should" (expressing obligation), and "must not" or "should not" (expressing forbiddance).

- Aim describes the action that the deontic refers to.

- Conditions describe when and/or where the rule applies.

- Or else describes the consequence for not following the rule.

Following the identification of the rules, they were classified among several categories, positions, boundaries, choice, aggregation, information, payoff, or scope (Ostrom, 2005). - Position rules define the job title and the authorized actions of the participants. Example positions are president, parent, and manager. 
- Boundary rules define the rules for entering and exiting positions. More specifically, the rules define who has access to a position, the process for determining eligibility for entering or leaving a position, and how the individual may leave the position. It includes the attributes or qualifications an individual must have to obtain the position.

- Choice rules specify what a participant in a position has the choice of doing in a decision-making process based on the deontic component of the rules.

- Aggregation rules define whether a single participant can make a decision or if the decision has to be made by some variation of the collective.

- Information rules define the flow of information. They give authorization for the participants to share information about the structure and current events. It also describes the frequency and accuracy of the communication.

o Payoff rules define the rewards or sanctions that are the result of decisions.

○ Scope rules encompass all other rules that cannot be defined in these other categories, but have impact of the decisions and outcomes in the action arena. The rules identified in the analysis were further categorized by their impact on the collaborators' ability to work together to create a high-quality program.

\section{Analysis of Documentation and Archival Records}

The documentation was first placed in chronological order to understand the development of the collaboration over time. The documentation was then analyzed for any identified rules based on the syntax above and decisions or outcomes (Miles \& Huberman, 1984). Rules were written onto index cards with notes as to where they were identified, the date associated with their creation, and their category (Miles \& Huberman, 
1984). Index cards were also made for each decision identified along with the date of their creation and where the decision was identified (Miles \& Huberman, 1984).

\section{Analysis of Unstructured Interviews}

Unstructured interviews were conducted and recorded with the participants. Participants included three members of the community college administration who were integral to developing the partnership and the industry representatives who participate. Interviews were transcribed for analysis and coded for the rules syntax as specified above and their category, along with any decisions or outcomes identified in the discussion (Miles \& Huberman, 1984). Identified rules were written onto index cards with notes as to who identified them, the date of the interview, and their category (Miles \& Huberman, 1984). Index cards were also made for each decision identified along with the date of their creation and where the decision was identified (Miles \& Huberman, 1984).

\section{Analysis of Observations}

Observations aided in triangulating the already identified rules and outcomes. Language used in the meetings was transcribed along with notes about decision-making and communication patterns. The notes and transcriptions were analyzed and coded for the rules syntax as specified above and their category, along with any decisions or outcomes identified in the discussion (Miles \& Huberman, 1984). Identified rules were written onto index cards with notes as to who identified them, the date of the meeting, and their category (Miles \& Huberman, 1984). Index cards were also made for each decision made in the meeting, along with the date of the meeting (Miles \& Huberman, 1984). The identified rules were compared with meeting minutes. Other rules that were 
not expressed in interviews and documentation were noted, along with outcomes for further clarification. The observations were primarily used to triangulate the identified rules and outcomes from previous stated methods.

Credibility

The purpose of case study is to understand the rich complexity that results from the interactions of many variables in a real-world context. It is this rich description garnered from a rigorous methodology that includes findings triangulated from multiple sources of data that gives the study's findings credibility or a true representation of the case that is being studied (Appleton, 1995; Cutcliffe \& McKenna, 1999). The findings produced by case study, as a result, have limited external validity and cannot be generalized or replicated to other situations without a rich description that allows the readers to determine if the findings are applicable to their own settings (Hays \& Singh, 2012; Stake, 1994). This contributes to the case study's transferability to other cases as readers apply their own unique knowledge, frameworks, and theory to the study (Hays \& Singh, 2012; Stake, 1994). However, findings can be generalized to theoretical propositions (Lipset, Trow, Coleman, \& 1956; Poteete, Janssen, \& Ostrom, 2005; Yin, 2014), which is the intended purpose of this study. Rather than focus on the immediate findings, the preference is to over time collect a rich descriptions of multiple case studies on community college and industry partnerships to develop and realize the components of collaboration that are specific and unique to these groups.

In order to do this effectively, trustworthiness and credibility are key. To ensure that these concepts were met, the study was designed with procedural rigor (Kline, 2008). The unit of analysis, research purpose, and information sought were established in 
alignment with a thoroughly tested and respected conceptual framework (Hays \& Singh, 2012; Kline, 2008). The framework utilized as a lens for analysis was selected because of its unit of analysis, as individuals, and how they operate or work together to achieve goals. Using this lens, the research questions and methodology were developed to understand the constructs associated with how the individuals in a community college and industry partnership work together to achieve goals. Multiple sources for analysis, including interviews with individuals in different positions, document analysis, and observations were garnered and analyzed with the knowledge that the findings should be supported from multiple sources. Triangulation is the main method utilized in the procedural analysis with the purpose of having convergent evidence to strengthen construct validity (Yin, 2014). The unit of analysis, research purpose, and information sought were established in alignment with a thoroughly tested and respected conceptual framework (Hays \& Singh, 2012; Kline, 2008). In addition, the philosophical assumptions of pragmatism are focused on understanding the participant's truths and avoiding interference from the researcher's perspective (Murphy, 1990; Rescher, 1977), adding to the study's confirmability (Hays \& Singh, 2012).

\section{Limitations and Delimitations}

Access to relevant data is a limitation of any qualitative study. In this case, the focus is on understanding the rules. To uncover these rules, participants have to be able to communicate incentives and justifications that may be natural to them, although they may not have outwardly processed them (Ostrom, 2005). Identification of rules can be difficult and discovered only after a significant amount of time has been spent observing the behaviors and patterns of the participants (Ostrom, 2005). This study includes data 
from interviews and observations that were then triangulated with the participants to validate the findings (Yin, 2014).

A delimitation of this case study is the limited number of sites selected. This particular case study was selected for its success. A successful partnership was chosen to understand the dynamics in collaboration that has reached mutually beneficial goals. As a result, it is unclear how collaborative dynamics discussed, especially in regard to rules, would appear in a collaboration that was unable to meet goals. In addition, the other factors identified in the logic model of the framework that affect collaboration have been limitedly observed. These factors include federal and state policies that impact funding and the shifts in financial benefits from collaboration based on profit models.

\section{Researcher's Positionality}

This study will be performed by a single researcher. The researcher has had experience working in both the private and public domains and, therefore, has had personal experience with the effects of bureaucracy and market-driven incentive structures that impact the behaviors of individuals. My work experience has included a communication role at an advocacy organization for education legislation to promote funding for career and technical education. To account for these personal perceptions, the focus will be on defining the components of the IAD framework through the pragmatist philosophy. The identification and focus on the data that is most relevant to the definitions of the components has lessened the impact of other data that is irrelevant to the case study (Yin, 2014). 


\section{Introduction to Chapter Four}

The next chapter will answer the two main research questions. The first research question relates most to the formal structure of the organization or collaborative partnership. The rules as they relate to the organizational structure will be laid out, along with their classification. The second research question will then be answered. It relates most to the behavioral choices of the participants in the organization. Each part of the question will be identified, along with the rule categories. These findings are further discussed in chapter 5. 


\section{CHAPTER IV}

\section{FINDINGS}

In this chapter, the research questions will be restated for the benefit of the reader. Findings from the study will be identified and explained. The research questions were determined based on the institutional analysis and development framework that identifies the rules as our base for understanding institutions. The review of literature regarding the development and implementation of the framework specifies that rules are grouped into seven categories: position, boundary, choice, aggregation, information, payoff, and scope. As such, the answers to the first research question will be discussed by framing the analysis using these categories. The second research question focused on the outcomes of the community college and industry partnership. These outcomes will be identified, with a discussion of how the IAD framework and categorization of rules are linked to college and industry partnership outcomes.

\section{Research Questions}

The questions identified in this study were based on a practical need for research to look in greater depth at community college and industry partnerships for better understanding of implementation that is specific to their collaborative dynamics. The institutional analysis and development framework helped to identify these specific questions by providing us a lens to begin analysis. The framework was designed with the purpose of better understanding the collaborative dynamic of organizations with its main unit of analysis being people. The developers of the framework identified the first step to 
understanding an organization as understanding the rules. The research questions identified at the start of this study were the following:

- What are the rules (formal and informal) that govern the organizational structure of the partnership?

- How do the identified rules affect the outcomes of the partnership?

\section{Identified Rules}

The first research question seeks to identify the rules that govern the organizational structure of the industry advisory board that allows for industry and the community college to work together. Below is the restated question.

- What are the rules (formal and informal) that govern the organizational structure of the partnership?

To answer this question, the study focused on interviews with the participants in the partnership. In-depth unstructured interviews about the experiences of those who participated and how they participated provided the greatest information to understanding the answer to the research question. The responses were then analyzed for grammar that would identify a rule as described in the Identification of Rules section in the literature review. Specifically, auxiliary verbs were searched for within the interviews, such as "must" and "should," to understand how people believed they should act or how results were created within the relationship between the community college and industry partners. In addition, these rules were observed in meetings to triangulate and better understand the governance structure that allowed for the industry representatives and community college administration to work together. Meetings would be described as the action situation in the literature and the setting where decisions are made that lead to 
outcomes. In this case study, the general meetings were in-person meetings held as needed, based on the concerns, needs, and goals of the community college. At the time of the study, they were held approximately quarterly. The duration of this study occurred from June to October of 2016. During that time three meetings were held. The first was an advisory board meeting open to all membership in June to show and receive feedback on a video that was created by the internship committee. A marketing committee meeting was held in July that was facilitated by the Chair of the marketing committee to present his findings to the college's Dean, Marketing Director, and other staff for how the college could move forward with their marketing strategies. Another advisory board meeting open to all membership was held in September to address questions and concerns about enrollment for courses suggested by the curriculum committee. After identifying these three meetings as the action situation, the focus shifted to identification of the rules that governed the behavior of the participants.

Figure 5 identifies the rules discovered in this study and models their application. Rules that describe participants are position, choice, and boundary rules. These describe the participants' titles, purpose, and qualifications. Information and aggregation rules take place in the action situation. They are identified in the bubbles labeled general meetings, committee meetings, and leadership meetings and describe how information is communicated and who has the authority to make decisions. Payoff rules describe the costs and benefits participants receive for their participation. Scope rules encompass all other rules that do not fit into the other categories. In this case study, the scope rules described the general setting created by the community college that the action situation 
takes place within. Each of the rules depicted in Figure 5 is described in greater depth in this chapter. 


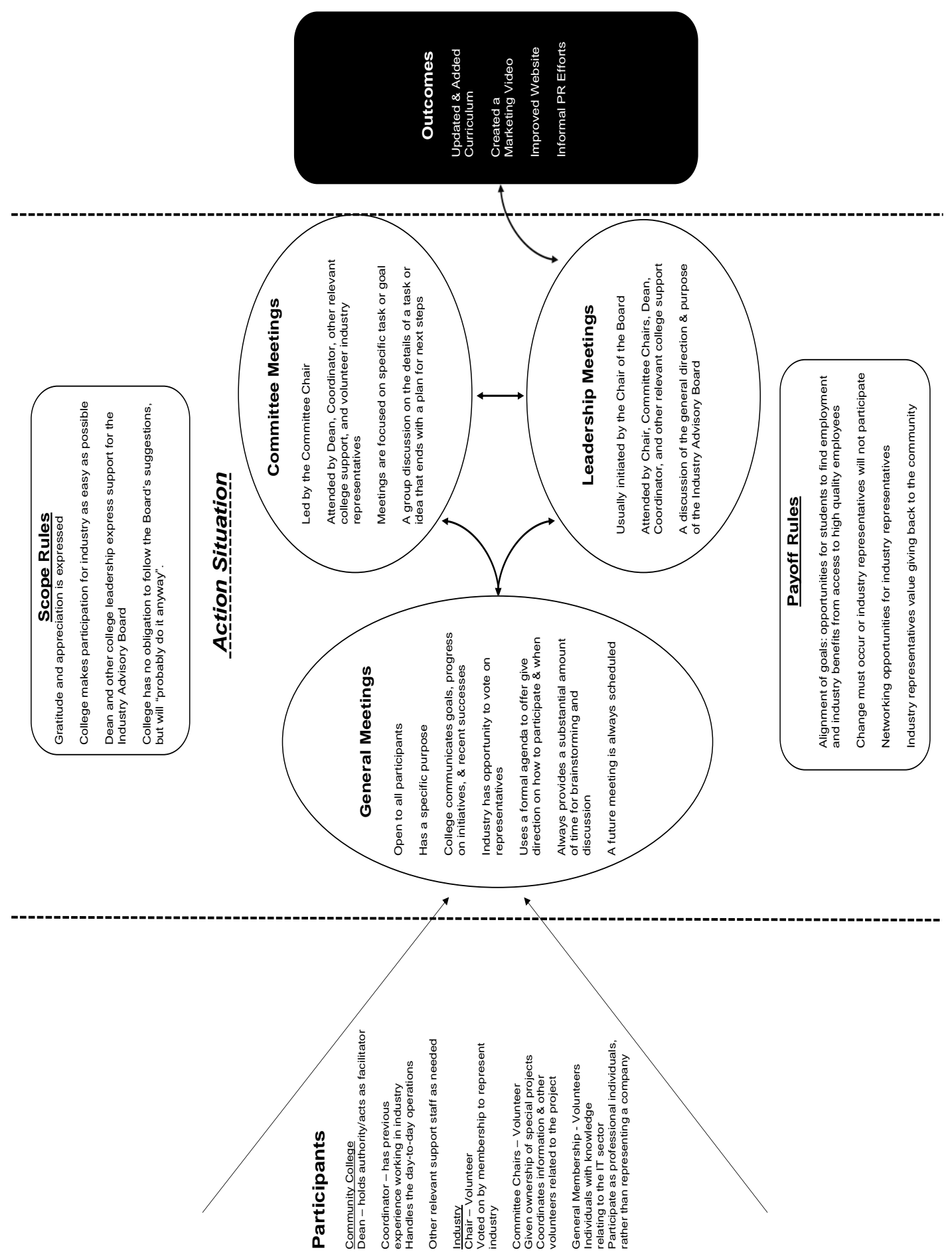

Figure 5. Depictions of the Rules Identified in the Community College Industry Partnership 
To stay aligned with the research, the identified rule and its description will be discussed by category. Rules relating to participants will be discussed first with the purpose of understanding the individuals that are a part of the industry advisory board. Scope rules will be discussed next to understand the setting the community college has created for the action situation. Aggregation and information rules will follow to describe in greater depth how the groups congregated and shared information within the meetings. More specifically, aggregation and information rules describe the type of information shared, the process used to communicate, and who has the authority to make decisions. Payoff rules will be discussed last. These rules described the cost and benefits to participants for their participation.

\section{Position and Choice Rules}

Position and choice rules are closely tied. They are used to describe the participants within an institution. The position rule defines the job title and closely related descriptive, such as the number of people who hold it. Choice rules describe the authority or set of actions that the individual in that position has the option to take. A leadership structure had been organized within the industry advisory board that gave the participants parameters for their potential to participate. There were five identified titles within the advisory board, Dean of the Continuing Education Department, Coordinator of IT Programs within the Continuing Education Department, Chair of the industry advisory board, committee chairs, and members of the industry advisory board.

The Dean of the Continuing Education Department. The Dean of the Continuing Education Department is at the top of the hierarchy of leadership of the 
industry advisory board. His position within the college gives him decision-making power and authority for hiring the Coordinators and approving the general direction that the programs in his care will take. The Chair of the industry advisory board stated, "Nothing happens without the Dean's approval." The Dean recognizes his authority because of the position he holds and the power he has to steer development, but prefers to utilize it more to facilitate.

I think initially when you start the board, you are the leader in the sense that you are advising people about why this is going to happen, what all of our roles are, and more or less direction of where we want to go and see if everyone is in agreement, but you are leading, because you are talking quite a bit, because it's initiating.

Instead, much of that power, along with the daily operations of the board, belong to the Coordinator, whose role will be discussed in more depth in the next section. The roles of the Dean and the Coordinator were emphasized in various interviews with industry representatives. One stated, "The Dean owns the overall program, but the Coordinator is the driver."

The Dean defined his own role and actions on the committee as being facilitative, as well. When asked about how the board operates, he discussed how he gives the power he holds to the industry representatives to direct its development:

As the leader, whoever is running that area on the college side, it is their job to first gather people to create the board. But then you have to let them, guide them into what the purpose of this board is. I tell them that they are going to drive. They are going to discuss, vote on a chair, and 
maybe even some support like officers, if that's what they want, because they are going to decide that. Then, they are going to discuss these issues, whichever way all of us find best. Meaning do we cover marketing for a few months? Or do we cover, curriculum, marketing and another area? However, we do it, is okay. What I want them to feel is that they are driving. It's their baby.

These descriptions were confirmed through observation of the meetings. The Dean attended all three meetings that were a part of this study. At the general meetings, he began with a ten minute conversation to communicate how the college was taking steps to make improvements based on the suggestions of the industry advisory board. Following this, he sat down and allowed for the rest of the meeting to be about the industry representatives sharing their ideas. This succession of events encouraged the industry representatives to share their thoughts and ideas. In the committee meeting, he asked and answered questions as needed to encourage and develop ideas that were executable for the community college and manageable for the industry representatives. This, again, allowed for the ideas and suggestions of the industry representatives to not only be shared, but be developed into fruition.

\section{Coordinator of IT Programs within the Continuing Education Department.}

As the "driver" of the committee, the coordinator is responsible for the day-to-day activities of the board, which includes being the main point of contact for members of the industry advisory board. The job description of the coordinator includes developing new programs, hiring people to develop courses, creating marketing plans and implementing them, along with managing the budget for achieving this. As such, the ideas and 
suggestions that often come out of the industry advisory board meetings are closely tied to her job at the college.

There was agreement among all the participants that the Coordinator was the leader or driver of the industry advisory board. She selected the primary goals for the group, directed the timeline for the general meetings, and was the primary point of contact for industry representatives. All information that was utilized to keep the industry advisory board progressing passed through her and actions taken by the board required her approval. As such, her description for how she chose her leadership strategies for managing the industry advisory board were based on the premise of keeping the industry board active and progressive. Some of the specific actions of she took that were visible during the observed meetings and communicated via interview during the study, included, communication with the members of the board via email to send reminders, meeting minutes, and schedule meetings, facilitation of the general meetings through a written agenda, starting and ending the meetings, and giving specific directions throughout them. In addition, she ordered and arranged for food to be at each of the meetings. She stated, "I must keep everything moving forward...I always monitor that the tasks directed by the board are moving forward by removing road blocks, putting people in contact with one another, whatever the needs are to get the task done." The Dean supported and relied on her to take on this role as primary decision-maker and leader of the industry advisory board. He described their relationship in managing the board as one where he relies on her to be the primary decision-maker:

The implementation of the details, should we do it this way or this way. My hope is the Coordinator comes in here and says we have two choices 
to make that objective happen. My question to the Coordinator is 'what do you think?' Because she has a business plan, it's her area, it's her business. Based on her math, she'll decide. My tendency is to agree.

The industry representatives described several instances that provided examples of their interactions with the Coordinator that supported the description of her role. One industry representative stated:

The Coordinator definitely drives the group. She's the one who organizes it, she's the one who structures it, and she's the one who communicates with the group about what's going on, what the topics are going to be, where we're going to be, etc...

Industry representatives, also, pointed to specific interactions with her that aided their participation or role on the board. One industry representative described a time when the Coordinator facilitated the goals of a committee by being a point of contact and removing a road block: "It wasn't going to be us. We're a bunch of IT people, right, we don't do that. That's when the Coordinator put us in touch with the college's internal video production." Another industry representative described how the Coordinator supported the Chair of the industry advisory board, "We had an advisory board meeting and the Chair was needing some help, so the Coordinator asked the board if there was anyone interested in being a cochair." The diverse interactions described by the industry representatives supported the role described by the Dean and the Coordinator. The Coordinator provided the primary goals for the industry advisory board and then facilitated the 
actions and ideas of the industry representatives in a multitude of ways, based on what was required.

Chair. The position of chair of the industry advisory board has been designed to represent the general membership and act as a leader that represents the industry in the partnership. It is an elected position by the industry representatives of the industry advisory board. The chair volunteers to be considered for the role and then the rest of the industry representatives vote to approve or disapprove of the volunteer. However, the role as viewed by the chair is more ambiguous, because guidelines or directions do not exist to give specific direction. At this point in the industry advisory board, there were three co-chairs who viewed their roles as voluntary. One co-chair stated, "Nobody else volunteered and the opportunity just presented itself and I thought why not? And I had never done anything like this before. It was just my opportunity." Another co-chair stated, "It is just a title. But at the end of the day, intrinsically, I feel that being a co-chair to this advisory board means that I'm giving back as much as humanly possible to the organization." The third co-chair stated, "They needed a volunteer and I raised my hand." Due to the flexibility of this role, the only rule was that the chair should be a representative from industry. The three Chairs were present at the three meetings observed during the study. They did not offer any extra input or add specific leadership function during the meetings.

Committee Chairs. Committees are designed to tackle a specific problem that the IT program is facing. In this case, three committees were created, curriculum (to address updating curriculum to meet the needs of industry), marketing (to increase awareness among potential new students), and internships (to increase awareness and create 
opportunities among regional businesses for graduating students). Committees were made up of volunteer board members with one individual opting to volunteer to lead the committee or become the Committee Chair. The Dean of the community college gave the committees the greatest amount of power. Throughout our interview, the Dean often referred to the power he gave to the committees and their impact on shaping the outcomes of the industry advisory board, including "Committees should drive the meeting" and "Everything that is done by the board is spearheaded by the committees. If it does not come from a committee, it does not get worked on." The ideas that are produced by the committees are collected by the Coordinator. Then the college determines if the suggestions can be spearheaded by the industry representatives or if the actions need to be taken within the college. If the industry representatives are tasked with spearheading the project, then follow-up meetings and communications are planned by the Committee Chair.

The only rule associated with the role of the Committee Chair is the Chair must own the outcomes of the committee. Once the committee is given approval to meet a specific goal or task, the ownership of the outcome belongs to the industry representative that volunteered to be the committee chair. It is the Committee Chair's responsibility to run the committee and become point of contact for the rest of the volunteers. The Coordinator's role is to facilitate their momentum by answering questions and aiding the Committee Chair with specific requests. Each of the Committee Chairs expressed apprehension with how this aspect of the industry advisory board was governed, but accomplished the task they had set out to achieve. The Curriculum Committee Chair asked for advice about how they should move forward and was given a previous record 
of how another committee had decided to move forward with their project by the Coordinator.

The way it worked for the Marketing Committee is that the Marketing Committee Chair called a meeting at her location and did not include the community college folks in order to keep the recommendations unbiased. Going back to our minutes from the September 5, 2014 meeting, here is what happened and who volunteered to be on the committee:

Then the Chair of the IT Industry Advisory Committee took over. He reiterated the purpose of the council and the goals for the day's meeting was to discuss 'our needs' at our respective organizations. He divided the council into two groups and asked each group to list the IT topics of need in their organization or industry and then to rank the top 3 or more topics.

The Coordinator did not express any concerns or rules when answering the question, but conveyed the message that the ultimate decision in how the Curriculum Committee was organized should be determined by the Chair. Based on this feedback, the Curriculum Committee Chair opted to host the curriculum committee at his office without representatives from the college or the Chair. Later, he determined that representatives from the college were necessary for the committee to move forward and insisted that they participate. As such, a representative from the college attended the next curriculum committee meeting.

At the first one there were only four of us. It wasn't real productive and we weren't real clear about our role and about what already existed at the college. We went online and we were looking at the online catalog and we 
found that to be pretty confusing. At the second meeting, we actually had a representative from the college there. We were told at the first one that they didn't want to send anybody over there as it might prejudice our deliberations. We were just the opposite. We said, 'look, we need some guidance here, you know. We need someone to represent the college.' We had someone at the next meeting and that was much more productive. This sense of ownership given to committee chairs was continued when the next committee was created for internships. The Internship Committee Chair described his role:

If I raise my hand and say I'm going to do it, I'll make sure it gets done. I say that. I want everyone's input, but if I'm not getting input, I'm going to press forward and make sure it gets done. That's the commitment that we as a group made and I made as the leader of it.

He then described his experience when he became stuck and utilized the Coordinator to help him move forward with the awareness that he owned the outcome of the final project:

If I'm stuck on something, like I had no idea who the contacts were to make a video to promote the college's IT program. Once the internship committee had the script, I went to the Coordinator and said, 'Well we have a couple of options, but we think the college should be the first place to produce it. Can you put me in touch with those people?' The Coordinator facilitated that, but once she facilitated, she stepped back out of the way. 
Other evidence that the committee chairs were the drivers of their respective committee came from attending marketing committee meeting, analyzing emails, and comments from other board members who had volunteered to participate on specific committees. At the marketing committee meeting, the lead facilitator was the Marketing Committee Chair, who had written the agenda, gave a presentation, and then took questions and comments. The Curriculum Committee Chair sent emails to his committee members to schedule meeting times and dates to discuss their issue in greater depth. Afterwards, he gathered the information and presented it to the Dean, Coordinator, and Co-Chairs of the industry advisory board. When asked during interviews about participation on committees, the members of the board supported the concept that the Committee Chair was given control to run the committee. One industry representative who participated on the Internship Committee stated, "The committee activity was really directed by the [Internship] Committee Chair. He was the center point for communication." Another industry representative who participated on the Curriculum Committee described her interaction with the Committee chair:

I spent the bulk of the time communicating with the Curriculum Committee Chair... I received the notes from that and responded back to those notes over a group email. We exchanged, refined, and honed and addressed and then a presentation was done after we had gone through all of that process. Then a more formal meeting or prepared presentation was given to the board overall.

Like the chairs of the industry advisory board, the chairs of the committees were not given any specific direction in how to behave in their role. They had the option to shape 
the role as it fit them. However, the committee chairs are given their role based on a task or goal, which makes them more active in determining how to shape it for themselves. The Coordinator did provide information based on the previous experience of other committee chairs. However, it was intended as guidance, not as specific rules that had to followed. The committee chairs and volunteers had the option of committing to and shaping the role as they saw fit to accomplish the goal of the committee.

Members of the industry advisory board. Other members of the industry advisory board came from a range of positions within the IT sector or represented the community college in some capacity. Many of the industry representatives either held leadership positions with IT companies and/or were recruiters for IT careers. Job titles included, owner, president, vice-president, chief technology officer, and technical recruiter. Representatives from the college that did not have functions related to running the board, included the Marketing Director, adjunct professors, and Director of the Workforce Development Center. These individuals attended and participated in brainstorming at industry advisory board meetings held quarterly. They did not have a specific function or leadership role.

Industry representatives more often participated as individuals, rather than as a representative of their company. Only one industry representative who consented to an interview specified that he was primarily a representative of his firm, rather than as an individual. He could not contribute much information to the study, because he could not share information about progress on initiatives or communication until formal documentation had been agreed upon between the company and the college. Two other active participants from this company were present and actively communicated at board 
meetings, but were not given permission from their company to participate in the study. All other industry representatives viewed participation as a professional networking opportunity or a community service. One industry representative stated, "I was very clear with the college that my participation was voluntary and not representative of my company." Another industry representative described their position on the industry advisory board in relation to their company, "From my company, I can do whatever I want in my free time as long as I get my job done. We don't have any formal policies about our philanthropic engagements, which is what this would fall under." One of the co-chairs described how he viewed his participation on the industry advisory board and his relationship with his company:

I told them that I was volunteering in this capacity. I let them know when I have a meeting and I attend it. There is no dictatorship about how I use my time or what I can and cannot do. If there is a career fair and our organization wants to be a part of it, I can do it. I've set up hiring events through the college as well. Because I'm a board member, I have access to people within the college that I can do that with. There is nothing that my company says or does that I have to do.

If the opportunity presented itself, the representatives see themselves as a liaison that can facilitate communication or projects for the college with their company. Most perceive their participation on the board as an opportunity to share industry information that can improve the pipeline of qualified workers to the industry.

The nature of the general board membership being a voluntary option creates a wide range of dedication to the industry advisory board among the participants. The type 
of commitment that individuals were willing and able to give varied among the membership from only attending general meetings on occasion to actively taking up projects and defined roles. This concept extended to the time commitment that the board members were willing to commit to the industry advisory board. One of the co-chairs stated, "I have volunteered quite a few times on different occasions for different things. I try to be as active as humanly possible." An industry representative, "I could probably do a little more, but I'm just so busy trying to build my business.” Another industry representative described his experience observing the industry advisory board members over several meetings:

There were consistent people who would show up and other people that would just come and go. It's the nature of the participation on this board. They show up when they can or they change jobs or their circumstance changes.

A new industry representative described her experience, "This was my first and only meeting that I have been to. Since talking to the Coordinator, they've had two meetings and I was out of town. This was the first one that I could get to.” A past committee chair described his participation, "Basically, I go to the meetings when I have time, make sure that I am there on time, listen to the presentations as they are being given and provide feedback as requested."

The board members most often stated that that they participated as their schedule allowed them to. However, they, also qualified that they continued their membership no matter the amount they contributed because of the value they could add based on their experience. One industry representative described his participation: 
I don't have a massive role. I'm really there just to engage and support the college around the idea of what people should be doing in terms of curriculum, marketing and internships. What subjects they should be teaching and because of my insight into IT trends, give my insight into what they might be interested in. It's limited to the meetings. I don't do a lot of extra work. I usually focus when I'm in the meeting to really engage with the people and I think that's what most of the people do apart from those who are a part of the college. We also try to get other people to go to it and we think that's pretty good.

The varied participation among the board members was recognized by the Coordinator, who described the group as an evolving collective of people. As part of her job description she stated, "I have to be able to adjust for the lack of continuity among members. This is why the committees and their goals have to remain constant." The varied commitment was observed at the three meetings during the study. At the two general meetings, approximately 25 people were in attendance. At both meetings were the six college administrators and the four industry leaders who took on leadership positions. The rest of the industry participants and college administration were a mix of new membership and others who had attended before. This observation was confirmed during the introductions where individuals were given the opportunity to say their name, company, and role on the board. At the marketing committee meeting, only a small fraction of the volunteers from the general membership were in attendance. The Dean, Coordinator, and Chairs of the industry advisory board, along with other related college 
administrative staff, such as the Director of Marketing were also in attendance. There were approximately 12 people in attendance at this meeting.

\section{Boundary Rules}

Boundary rules refer to how individuals have access to entering and exiting positions. This includes who has access, their process for eligibility, and how they can leave a position. Attributes and qualifications fit into this category. In this case study, there are two defined groups with different sets of boundary rules -- representatives from the community college and representatives from industry.

Community college representatives. Representatives from the community college often had previous work experience in private industry. The Dean placed a highvalue on hiring people with this work experience and stated, "The coordinators must have previous experience working with industry." He described that this work experience gave the coordinators a greater advantage of understanding the real-world applications the programs they created would have in the region and a head-start for knowing who to connect with in industry to create better programs. Because the Dean is the authority, this rule exists. The industry representatives did not explicitly state that they needed the Coordinator to have this experience, but some expressed value about the communications they had with the Coordinator about her background in the field. One industry representative's comments about her communication with the Coordinator is below.

It was kinda cool because she had come from a project manager background at a large IT company. She understood what the corporate world was looking for in terms of educational and technical talent and things of that sort. We had coffee and the rest was history. 
The Coordinator's background in the workforce made her relatable to the industry representatives. They perceived that she would be more understanding and receptive to their perspective of the IT industry.

Other community college representatives present in the meetings were there with the purpose of providing information and keeping the ideas and solutions on track with the resources and needs of the college. The Marketing Director was a good example of this concept. He was observed in attendance at each meeting where marketing was being was being addressed. He actively listened and provided answers to questions as they were asked. The Chair explained the presence of the Marketing Director, "The college's staff has to be a part of each committee. If a committee does not have a member of the college on it, they are going to come up with things that are not relevant or won't work." Having the appropriate staff present allowed for clarification of information as needed. It, also, symbolically suggested to the industry representatives that the college was taking the ideas mentioned in the room seriously. The community college representatives in charge of these areas were present and actively listening, which suggested to the industry representatives present that there would be follow-up actions as a result of their meetings.

Industry representatives. The only boundary rule relating to industry representatives on the advisory board was that they have some contributing knowledge regarding the IT program that the college and/or their company could benefit from. The Dean and Coordinator sought industry representatives that they perceived could add value to their program. The Dean stated, "Industry members are representing companies that are healthy and growing, so they need people and they know they are going to need people." Other members who were not directly recruited by the college expressed that 
they were referred to join by another member or from someone within their company. One industry representative stated:

I met with the Coordinator at a cyber-security dinner. We were both there, met, and had a fabulous conversation. She explained that they were getting the board up and going and bringing in various IT leaders from different companies in the community.

Another industry representative stated, "I became involved in my last job position. Because of the connections, I was involved with some specialty people who were already on the board." One of the co-chairs described how he became involved, "I was in a work meeting [at an IT staffing agency], where I met the Coordinator and another college representative. They informed us about the advisory committee and asked if I would like to be a part of it." Another industry representative stated, "The Chair referred us to join the advisory board, then everyone from our office decided to join us and it all kind of spiraled." While another industry representative described an interaction with her boss that led her to join, "My boss had a conflict one day and asked me to go and represent him. Because of my participation that day, I was invited to be a part of the board, which I accepted." Another industry representative explained that they realized they were uniquely qualified to help with a problem:

Another member told me I should talk to the Coordinator because they were running a veterans' program and were having difficulties. We're a veteran-owned company, so they thought we could help. Because I was able to successfully help them out, I got sucked in and the Coordinator invited me to join. 
While the college attempted to recruit people with backgrounds that they recognize could be a good fit for their board, they also did not attempt to control the membership. There were no rules that put stipulations on who could participate. All participants could invite any person that they perceived could contribute.

\section{Scope Rules}

When describing the rules in the research, scope rules are generally listed last, because they are defined as the rules that do not fit into any other category. It was intended that this section would be covered last for precisely that reason. However, the analysis of the case found that scope rules were used to set the tone for interactions between community college and industry representatives. To better understand the application of aggregation and information rules, scope rules will be covered first to understand the setting and tone in which decision-making and communication occur.

Gratitude, praise, and respect. The community college leadership focused their efforts on setting a positive tone to their communication with industry. Appreciating the time commitment made by volunteers, offering lunch, and prioritizing the meetings on their own calendar were done with the purpose of communicating the value they placed on having the industry advisory board. The Dean expressed this in several comments throughout our interview:

Because remember they don't get paid to be on the board. However, I would say make sure that you have really good food. That's very important. These are very important people that are giving you advice on the future of your programs. Treat them really good.

At a different point in our interview, he stated: 
If these industry advisory board members tell us to do $\mathrm{X}, \mathrm{Y}$, and $\mathrm{Z}$ and we do $\mathrm{A}, \mathrm{B}$, and $\mathrm{C}$, then after a short period of time, they are all going to quit. They're not going to tell you, they will just stop showing up. Correctly, they are going to say that my time is very valuable.

In addition, the Dean understood that even his presence at a meeting was a sign of respect to the industry members who committed their time. His presence at the meeting was a visible signal that the college valued the industry advisory board and the information it provided, "In terms of showing up as the Dean of this Division, it's critically important. If the Dean does not show up to an industry advisory council, then it's not serious." The respect and value that the Dean gave to the industry advisory board communicated to the college and industry representatives that there was legitimacy to the effects that the group could have on influencing the IT program.

As the person in charge of the execution and management of the board, the Coordinator supported the tone that was set by the Dean. To her, management of the board was guided by the rule: "make participation easy for members". This meant that she communicated gratitude and respect by acknowledging the time commitment members contributed, "I feel strongly about starting and ending meetings on time to be respectful of the time commitment of committee members." She purposely arranged for all meetings to take place on Friday afternoons where lunch was served to create a relaxed and friendly environment. She also always made sure that there was an agenda to give the meeting structure that was closely adhered to. This was an important gesture to balance the goals of the industry advisory board, while recognizing the time commitment industry was volunteering. The agenda always included an initial fifteen minutes 
dedicated to welcoming everyone who attends, by greeting everyone, always offering them a lunch or snack, and facilitating networking, and introductions.

These expressions of gratitude and value from the community college were noticed and appreciated frequently among the industry representatives throughout the interviews. One industry members noted, "After about an hour to 90 minutes, we'd be praised lavishly for our time and attention then be allowed to head on back to our day jobs." Another industry representative stated, "The Dean has always been very appreciative of any input that I can provide the Continuing Education program.” An additional example from an industry representative included, "You've got senior leaders that quite frankly would not participate if they didn't feel like they were being listened to. They [college representatives] are very actively listening." The tone of gratitude set by the Dean and Chair were appreciated by the members of the industry advisory board. They perceived the time and energy that they committed to the industry advisory board were considered of value to the college.

The Chairs of the industry advisory board were the most expressive about interpreting the Dean's presence at meetings and his communication as a commitment to the development and betterment of students and the college program. One co-chair stated, "You can really tell that the Dean really cares about what is going to be happening with their school." Another co-chair stated his perception of the gratitude and perceived commitment of the college:

It shows you that ACC is motivated, you know, they're winners. They're there to help the students. That's one of the things you'll notice about the 
Dean, he has a passion for the students... The Dean cares about his students. It's refreshing.

The co-chairs expressed that the Dean's and Coordinator's communicated commitment to the industry advisory board through their presence and conveyed gratitude played a role in their reasoning to volunteer as a leader. The gratitude from the Dean and Coordinator were not only perceived as interest in improving programs, but also a larger message about their commitment to students. This helped to convey to the co-chairs that their volunteer efforts as leaders on the board were a service to the students who were enrolled in the college.

Shared power. The last scope rule determined was the importance to the college of respecting the balance of power within the industry advisory board. As stated earlier, the Dean gives the final approval for any initiatives to move forward.

Legally, we're not expected to do anything. If the committee said we want you to do something that is totally outside of what we do or is illegal or just doesn't make sense to use at all, we're not legally bound to do that. However, his attitude and preference is to act as a facilitator and give power to the industry representatives. The Dean further elaborated the message that is intended to guide the relationship between himself, the other college staff, and the industry representatives, "It is the understanding that the board will eventually tell us what to do and we will do it. It is not that they will us what to do and we will do what we want." To accomplish this, the Dean actively promotes and advocates for the college administration to actively listen and act on the suggestions from board membership, even if they are not in full agreement with the board's suggestions or ideas. 
Whatever like that that they [industry representatives] come up with, and they vote on it or they agree, and we're [college representatives] listening, and we're taking notes, we're going to do it. We are not going to agree with $100 \%$ of what they say, but we are probably going to still do it, because we want this to be a long-term relationship.

This attitude and balance of power was expressed by the industry representatives over the course of interviews in several ways. One of the Chairs stated, "They never hinder us." A Committee Chair described the power that industry representatives are given to direct outcomes.

They haven't been really prescriptive about 'you have to do this' or 'you have to do that'. One thing I really enjoy about participating on this particular advisory board is that they did this because they want us to drive the conversation. I don't know if they would say the same thing or not, that they just sit back and watch it go or what. But they don't put any particular constraints us, saying 'you have to do something this way or that way'.

Another industry representative described the message he has received from the college about participation, "The expectation from the college is that I participate as much as possible."

The power that industry representatives had was also revealed in the individuals' description of how they opted to use their time as a part of the board. One industry member requested to be on the agenda at a general meeting to share an idea with all the representatives about creating a video to market the message that the college was 
attempting to send. The industry advisory board valued her presentation and decided to use this strategy as a marketing tool. This same member after sharing her idea through a presentation, decided not to participate in the video's creation. She decided her energy would be better spent finding internship placements for the students coming out of the IT program, "I didn't have a lot of responsibility in the creation of their [the college's] video. My focus right now is trying to identify opportunities for the college's interns to come and have a paid experience with the city."

Each of these quotes describe the industry representatives' perception of the power they have to make and affect changes to the IT program at the college. The college's leadership encourages industry representatives to take advantage of the power they are given. Industry representatives have the ability to assess their personal interest, knowledge, time, and/or skill set, then decide how they want to participate.

Aggregation and Information Rules

Aggregation and information rules were closely bound. Aggregation rules define whether one individual can make a decision or if the decision has to be made by some variation of the collective. Information rules define the flow of information. They give authorization for the participants to share information. This includes who they can share information with and how. It also describes the frequency and accuracy of the communication. The aggregation of decision-making and how information was shared primarily occurred in two action situations, the general meeting where everyone is invited to participate and committee meetings where only the committee members participate (see Figure 5). In both situations, participation was voluntary and the information that industry representatives shared and received was based on their own interest and 
commitment to the organization. In each of these action situations, a purpose or goal was made clear, the bulk of the time was dedicated to feedback and sharing information, and then next steps were identified.

A third action situation was briefly described by the co-chairs of the industry advisory board. A leadership meeting occasionally occurs where the chairs of the industry advisory board and the committees meet with the Coordinator and Dean (Figure 5). This meeting will be discussed briefly. However, this meeting was not observed as part of the study, because of its infrequent occurrence.

General Industry Advisory Board meetings. This meeting was the most highly structured and considered the primary space for volunteers to be active. Industry members spoke most about their participation in these meetings and the process related to it. Below is the most detailed description given by an industry representative.

How it works when you get into the general meeting is that we talk about what we talked about last time. But then they always have a very specific area that they are looking for feedback, like we're looking for feedback on our website, or we need to reengineer this curriculum, or we want to figure out how to do outreach better. They really make sure that the session is focused on that specific topic. Then they take us into breakouts where we talk in small groups or they've also just gone around the table and discussed it. They really are using that time effectively.

This description captures the main structure that provides the industry representatives direction as guided by the college, how they are able to actively participate by being placed into "breakout" groups of 5-8 people to brainstorm and discuss the directed topic. 
Following their breakout discussion, each group gives an informal presentation to the entire board about the highlights of their conversation or feedback. The Coordinator then gathers this feedback by collecting the notes written by the industry representatives and taking her own. Other industry representatives described this similar experience at different meetings that they attended.

Basically, it's get your drink, get your lunch, then listen to the topics, whatever the point of the day is. Then we break into our mini meetings and that was kind of the last piece. Or break out style sessions. Then come back and report on it.

Another industry representative explained their experience:

In our last meeting, they showed the internship video that had been put together and then they opened it up for us to break into groups, and collectively provide feedback. And then each of the groups shared their feedback and then from that feedback they define the next step.

In different words, each board member described a similar pattern of events. It was a routine that they were all familiar with and comfortable with using.

An agenda (see Figure 6) was the main tool used to communicate and create continuity for the participants. It gave the participants direction and information about the flow of the meeting and how and when they would participate. Figure 6 depicts a sample agenda for the general meeting. At the fifteen-minute mark, the intended topic of discussion or purpose for being there is announced by the Coordinator, along with a brief description of the issue at hand and the questions relating to it that they would like 
feedback regarding. The agenda highlighted the exact time table for how the meeting will progress and the information that they will cover to make sure all the necessary topics are Figure 6.

\begin{tabular}{|l|l|l|}
\hline $11: 00 \mathrm{am}$ & Welcome and Lunch & Dean \\
\hline $11: 10 \mathrm{am}$ & Introductions & All \\
\hline $11: 15 \mathrm{am}$ & Announcements and Updates & Dean and Coordinator \\
\hline $11: 45 \mathrm{am}$ & $\begin{array}{l}\text { Break Out to Discuss format of new } \\
\text { website and generate ideas to market } \\
\text { current classes }\end{array}$ & All \\
\hline $12: 15 \mathrm{pm}$ & Groups Report Out on Ideas & All \\
\hline $12: 45 \mathrm{pm}$ & Next Meeting and Next Steps & Coordinator \\
\hline $1: 00 \mathrm{pm}$ & Adjourn & All \\
\hline
\end{tabular}

included, maximizing the value of this time for the college. It was observed in both general industry advisory board meetings that the Coordinator followed this agenda as strictly as possible. She ended communication at the specific times listed to move on to the next topic and make sure that each received the appropriate time and attention. Industry representatives went along with the direction that the agenda and the Coordinator gave them easily. The agenda gave immediate direction to all participants, providing them with a time table, purpose, and instructions for when and how to participate. Two of the Chairs of the industry advisory board described the importance of the agenda. One Chair stated, "Once we get to the meeting, things are already in motion and we just have to stick to the schedule... When the board members get there, they have continuity." Another said, "In each meeting, we have an objective of what they are going to try and cover. It's pretty well defined with specific meeting notes, our agenda, and we follow through on the agenda."

The agenda was a particularly successful tool because of the varying commitment of the industry advisory board members and the nature of the board to be open to new 
members. It gave new members and those who had lapsed in their commitment continuity and information about what to expect in the progress of the meeting. One industry representative expressed that the agenda helped to guide her participation, "They have designed it in a way to give all attendees a chance to give input as well as opportunities to participate. When they have an agenda, it's a flexible agenda." Another industry representative noted how she used the agenda as a signal.

So I asked them if I could be on the agenda at the general meeting. What I wanted to do at that meeting was to show them the video that we had made of our high school internship program as something that they might want to consider to use as a marketing tool. I emailed the Coordinator. I shared with her what I wanted to do. And she just put me on the agenda. From there I joined the internship subcommittee.

The industry representative was interested in giving a presentation that was pertinent to the board. To be granted the appropriate amount of time to share information, she knew she had to be included on the agenda prior to the meeting. Access and permission was granted quickly and easily through communication with the Coordinator.

The last aspect of information and aggregation rules in the general meeting was the scheduling of the next meeting. At the meeting, it was observed that the Coordinator announced a proposed date and time for the next meeting and gave everyone an opportunity to determine if it worked for their calendar. The Coordinator described the importance of this gesture in our interview, "I always have events and future meetings for the industry advisory board on the calendar, so the industry representatives always have us on their calendar. They can't forget about volunteering with us." In addition, the 
coordinator also utilizes email about a week prior to make sure that the members are reminded to join them. This practice was appreciated by the industry representatives. Typically, when we wrap up the meeting, we talk about when the next one is going to be so a good majority of us can attend for that, define the location for that and typically also outline the topics that we are actually going to talk about. That gives me a chance to think about it as that quarter goes by. Or sometimes the Coordinator will reach out and ask a question. She's always great with the emails, 'thank you for meeting with us, here's what we discussed, here's when our next meeting is', so we can put it on our calendars. Then she'll follow up with us a week before and then a day before. She's making sure that, you know, we're busy executives that we're like children and need to be reminded multiple times because of how time slips by us.

However, there was a caveat to this advanced scheduling. Meetings were not held if a meaningful topic could not be covered. If information and discussion shared was not going to produce productive feedback, the meeting was postponed and rescheduled to respect the time and energy of all the participants who volunteer. Information about rescheduling and any other updates were communicated by email with the purpose clearly stated. Below is an email communication to the members of the board from the Coordinator regarding a meeting change from April $1^{\text {st }}$ to June $10^{\text {th }}$ to cover the necessary material:

The reason for the change on meeting date is because our Internship Committee Chair and Video Producer are working to create the marketing 
video which will focus on programs with internships. Our marketing folks cannot commit to have the video completed before the end of May so I am moving our meeting to June so that we can view the video, discuss a marketing campaign around the video and also hear some testimonials from students who have had internships that have led to jobs during our next meeting. I hope you understand and agree with the move and agenda for our next meeting. Again, I want to thank each and every one of you for your continued help and support. We are making progress and together we will do more good things for our students and community.

Thank you, thank you, thank you.

Email was used strategically by the college as the primary vehicle for informing people on the committee about general developments and other potential opportunities to volunteer their time. Other opportunities included professional networking opportunities and volunteering to observe graduates give their capstone presentations. The college did not use it to garner feedback or produce large amounts of communication. Industry representatives noted how the email communication they received from the college served a purpose of communicating simple information. Information that required discussion in greater depth primarily occurred at in-person meetings, but could also occur via other forms of technology. One industry representative stated her appreciation for the balance of face-to-face time and the use of technology to share information.

I certainly understand the value of email. It's great for tidbits or communicating scheduled events, etc... the college has been very 
responsive to that. As far as going back and forth, face to face time or a conference call makes a lot more sense, especially because of the city we are in. Traveling from one side of the city to the other can be challenging at times.... But to get back to your point. If I was to get 30 or 40 emails, I would just lose my mind, just call me, let's just talk this out. Filling up my inbox is just stressful to me. I do find the college to be communicative and responsive and I appreciate that.

A college representative, also, discussed the various forms of communication based on the type of information being shared. "Email is probably the main form of communication, just because it is very easy. But if we need to make a phone call, we'll make a phone call." The tailored form of communication based on the message and type of feedback that they hoped to receive aided the college in reminding the industry representatives about the volunteer opportunities available, without overwhelming them.

Committee Meetings. Committees exist to respond to specific concerns or goals that the college has determined to be a priority. Meetings are run by the Committee Chair who is a volunteer industry representative. Participants in the committee meetings, include the Dean, Coordinator, other relevant college administrators and staff who can add support, the Industry Advisory Board Chair, and industry representatives that have volunteered to be on the committee. These individuals make up the people who will influence the decision-making and outcomes that are produced by the group.

There are no rules to dictate the direction or structure of the committee meeting. They can be organized as the Committee Chair sees fit. This means they can be over email, in-person at any location, or requested to take place during a general meeting. The 
objective is to discuss the details of an idea, make priorities, and determine how to move forward. The Committee Chair determines the process and direction, but in order to move forward, they must have approval from the Dean and Coordinator.

During our interview, the Dean described the structure of the committee meetings as being an informal discussion of the details where the college actively tries to empower the industry representatives on the committees.

They [the committees] have been thinking about this quite a bit and have a plan. The goal of marketing for example is to get the word out. That sounds simple, but it's a very difficult process...There are maybe 100 ways to do that, so they discuss videos and this and that. I prefer to have them [industry representatives] start the conversation and have the conversation, and then they will ask a few questions, in regards to the college side, and I hope to have an answer or have the college team respond appropriately and honestly, and then hopefully we can act on those things. It's an informal, friendly meeting where we discuss the goals we set and where we are related to that committee. The Chair will also be here and he may have more topics that he wants to talk about. And that's great.

The Marketing Committee was observed as part of the study. It was held on the college campus as an informal open discussion on a Friday afternoon with lunch served. The Committee Chair gave a presentation on an idea for marketing. The presentation was then discussed openly between the industry and college representatives. Individuals from both posed questions and offered answers as best they could. Next steps were then defined by 
the Chair of the Marketing Committee and the Dean based on the communication and information shared in the meeting. The Committee Chair was given support by the Dean and other college representatives to move forward with an idea he proposed to the group. Next, the Chair gave a timeline for when the next meeting should be so he could offer more information.

While the Marketing Committee meeting appeared very similar to a general meeting, the Internship Committee meeting took a different form. The Internship Committee Chair determined that the meetings regarding the creation of a video could be managed via email and another video technology. When they initially took on the project they used a video technology to discuss the project in person. Otherwise, email was primarily used to communicate specifics among the volunteers, such as scripts for the video it created. On occasion, the committee brought their conclusions to the general meetings for additional input and feedback from all of the industry advisory board's members.

While the actual structure of the marketing and internship committee meetings varied, it was the chairs of the committees that were in charge of determining the best course of action. It was, also, the chairs who were ultimately responsible for providing a final product to the Dean, Coordinator, and other college representatives. Observations of the marketing committee and interviews with participants from the internship committee pointed to a great deal of opportunities for communication. Committee chairs offered the industry and college representatives chances to communicate and influence the final product. In both situations, the committee chair created a forum for industry representatives to offer feedback in-person or via e-mail. The committee chair then lead 
and made final decisions on special projects that have been determined as the solution to the concern identified by the college. However, this leadership and general power is given to the committee chair by the Dean and Coordinator based on their determination of the appropriateness of the idea.

Leadership Meeting. The leadership meetings are the Dean, Coordinator, other relevant college administration and the Industry Advisory Board Chair and committee chairs. The only rule associated with this was that the leadership of the Industry Advisory Board from both the college and industry must be able to have access to each other to be on the same page about the direction and purpose of the board. This meeting was described as occurring about once a year at the request of the Chair of the Industry Advisory Board. The purpose is to understand the general direction of the Industry Advisory Board and determine if the college is getting the type of help and feedback that it is seeking. It is an opportunity to discuss improvement, direction, and transitions, so that the advisory board is helpful and useful tool for the college. Because the leadership meetings occur infrequently, none were held during the timeframe of the study, and therefore, could not be observed. They were referred to during interviews with the Dean and Industry Advisory Board Chairs. The Dean describes these meetings as a part of the operation of the college.

We have meetings outside of the board meeting before and after and in between where we discuss many of the things that they have talked about. So the Coordinator and other relevant college administrators, because this stuff overlaps with their work, as well as marketing. We discuss this is what they said, where are we, what do we need to do next, by when... We 
have those conversations and sometimes we have them with the Chair of the board, and sometimes with the Chair of the Committee meetings.

One of the Industry Advisory Chairs described the usefulness of these meetings for guiding the direction of the board.

We get together with the Dean from time to time to discuss what's going on with the board and to be frank if the college is getting any value out of it. Because that's what it is all about. The college is paying for it, so they need to get value out of it and so do we. There has to be alignment. We get together with him to talk about what initiatives we should go after, what they need help with, and what makes sense...We try to figure that out. For this year, we knew it was the video. We were trying to get it done. For last year, it was evaluating all of their programs and how relevant they were to our job postings. So the board, that's what they do, they provide job postings, job profiles and it's just this back and forth. The leadership team, they facilitate the working sessions with the sub committees, not to dictate what they were going to do, but just to kinda provide direction. Because sometimes when you get a topic or you get an ask from the college, you don't really know where to start. So the people who volunteered are very strong leaders. They know what to do, what questions to ask and they know how to guide the discussion.

The Internship Committee Chair also described it as an opportunity to discuss the direction and relevance of the work they were doing for the college. 
Really the purpose there is to just kind of talk about what went on in the bigger meetings and the action items that came out of that. Where are we with regards to those action items? What help or assistance do we need from the college and their group to pull those things off and it gives each of the committee heads a chance to say, [Committee Chair], you're the head of marketing, what are you going to do to market it? How are you going to market it? There's going to be a pass off there. To just really discuss the interdependencies and how to do the pass offs on any of those assignments that we were working on.

One of the Co-Chairs for the Industry Advisory Board stated how he would be requesting another in the near future, because he felt direction for the board and clarity was needed again.

So this last time I told Maria it might be good for the senior leadership to get together one more time in the fourth quarter just to go through everything that was talked about. Just to develop a game plan and get more feedback, figure out where we need to go forward from here. This meeting, despite not having detailed information to report rules on, had significance in that it gave clarity and direction to the volunteers from industry. It gave them access to information that allowed them to play a supportive role in the development of the industry advisory board.

\section{Payoff Rules}

Payoff rules define the rewards or sanctions that are the result of decisions. Decisions and outcomes have costs and benefits to the participants for in the action 
situation. The action situation the participants enter is cyclical (See Figure 5). They are able to enter the action situation to influence outcomes, then they learn from this process, and adapt to maximize their rewards as individuals. To understand participation and outcomes, the costs and benefits to individuals for their participation has to be understood. The Dean discussed the cycle of decision-making and benefits that encourages industry representatives to participate and sets the stage for identifying the four payoff rules in this case study.

I want to make sure that everything that we do and everything that they [industry representatives] do also benefits them. Because if it doesn't benefit them, if we're [the college] just thinking about we, we, we, this group is going to disappear. So you need to make sure that everything you're doing is benefiting them and benefitting everybody and the students and the region. So the obvious benefits is that these members are representing companies are healthy and growing, so they need people and they know they are going to need people. So we're creating a pipeline of highly skilled people that they [industry representatives] are going to hire, so that will make them more money and that's going to make them happy. The college was aware that the industry advisory board had to be mutually beneficial if it was going to succeed. The industry representatives needed to receive some benefit for using their time and energy toward improving the college. The Dean, Coordinator, and members of the industry advisory board identified four payoff rules.

Alignment of goals. In the introduction and literature review of this paper, the demand for greater alignment between education and the workforce were discussed. 
Organizations invested in improving the quality of the U.S. workforce and education system to improve opportunities for students highlighted improvements and best practices that always included a reference to improving the pipeline between community college education offerings and regional workforce development (e.g. Symonds, Schwartz, \& Ferguson, 2011; Vandal, 2009). U.S. presidents also included community colleges consistently in their addresses as an important resource for creating greater economic opportunities for the nation and individuals (Katsinas, D’Amico, \& Friedel, 2012). There is an understanding that industry needs educational institutions to produce students that are highly qualified for current job openings. The Dean's description of the purpose for having an industry advisory board is accorded with the literature.

It's always evolving and hopefully you're evolving with it, because if you're not, you're going to be out of business soon. So how do you evolve your curriculum, how do you expand it to more areas? How do you bring in scholarship funding? How do you come up with great marketing ideas? How do you get help for marketing? How do you get advice for how to tweak individual courses and programs? How do you intern your students? That's critically important. In workforce, that's critical. If you can't find your students jobs, you'll be out of business very fast. If you can find your students internships and jobs, you will grow. So how do you do all of these things? It has to be an industry advisory council. It has to be. In any workforce or given industry area, you should have an industry council...It's a requirement. 
The Dean describes that the success of the students and the college's programs are contingent on their alignment with the needs of the regional workforce. Industry representatives, many of the them who have recruiter in their job title or descriptions, agree and described how they have benefited from working with the college to improve this alignment. Below is an industry representative who described the benefits he received as a member of the industry advisory board. In addition to describing the benefit of access to potential employees, he, also, made suggestions for improvement to the college, which was added to their curriculum.

I think what's really important about the committee is that virtually everybody who participates on the committee has influence on hiring people. I directly hire people who come out of that program as do the other senior leaders...My office brought in three companies and put them [students] through a round robin of interviews and I think 4 out of 5 of them got job offers following that. The participation goes further. My technical team sits in on their capstone projects and my lead project developers give them feedback. Frankly, we're looking for people to hire. We've gotten some great hires out of the program. We want to catch them quickly. It's a full cycle partnership. This is how we believe that they need to be trained by looking at the candidates. After they went through the first round of interviews, we told them [the college] that they needed to spend some time making sure that they [the students] know how to go through an interview. They [the college] incorporated that into the program as well. 
Other industry representatives agreed that the alignment was in their best interest as employers:

The major change comes from the fact that I'm an executive at my company, so I was able to set up the internship program. I regularly participate in graduation presentations for the students, so I get to see the talent and then figure out if that talent would be a benefit for my company to meet their internship requirements.

Another industry representative who worked for the city explained the benefit they receive:

We were intrigued by the college because it presented a real possibility that we could have people that were much closer to the point where we could hire them. Also in the early days, since the college seemed to have a number of programs that were both traditional degrees and certification programs that we might be able to take current city employees and run them through certification programs and help our employees move from let's say the water department to wherever else.

While another representative from a large technology firm in the city explained that they started hiring new employees after volunteering to observe student's presentations: I saw student presentations. The HR rep was looking to start an internship program. I really didn't know about the board's existence until the student presentations and he was asking me to rank the students on their technical ability, because I'm in IT. We went and that's where I met and hired our first intern. I was also looking to fill open positions. I, too, was looking for 
an IT quality assurance engineer. We hired another person that happened to be doing a presentation. I'm really impressed with the people coming through the program.

The industry advisory board gave regional employers a repository of potential candidates for job openings, which helps them to improve the quality of their business.

Participation Diminishes Without Change. The Dean initially explained that to make changes to improve the IT program, you need an industry advisory board. He further qualified this by saying that the college would not have industry representatives, if the college did not make changes based on industry's feedback.

In terms of giving the committee an overview of everything that we've done, I don't do it every meeting because I would drive them crazy. I do it once and awhile to give an update on this is when we first met a long time ago and this is what you said and this is what has happened. So that they remember that they said all of these things and hopefully most of them have gotten done or at least half. But they're taking you seriously. Because they're saying, 'We did say that and you did it. We all did it. This is worth my time. I'm excited. I'm happy to be volunteering with this.' They're thinking that in addition to the other benefits that they get. Now, if they say all these things and you aren't getting these things done, your credibility will decrease dramatically and eventually you won't have a committee. 
There was a consensus among the industry representatives that the Dean's perception that the college would receive sanctions, if they did not make changes based on the feedback was correct. One industry representative stated:

People will always ask you to fill a seat, but time is precious. If I'm going to spend my time, however long, it better be meaningful. I have the same time that everyone else does and once it's gone, I can't get it back. I want it to be worth my while, no matter how big or small.

One of the Chairs described that he felt positive about volunteering in this capacity because that he noticed the changes that the industry advisory board suggested being incorporated into the program.

I think one of the good things about this group. We're giving the suggestions and they're not immediately saying why it can't be done. They're listening to our suggestions, they're thinking about it, and they'll come back and say we were able to do this and this, but we just couldn't do this because of X or Y. But they aren't shutting down discussions, that's so easy to do, right, in an organization. You know, just turn around and say, 'Well that won't work.' They're really listening to the feedback. You know you got IT executives from the largest employers in the city sitting on the committee. If you do that, they're going to say, 'Well, I'm wasting my time. I'm going to use my time to do something else.

This aspect of a payoff rule is closely tied to the concept of shared power discussed earlier in the section regarding scope rules. The power held by the industry representatives to affect the outcomes and change is related to how they perceive the time 
they give to the industry advisory board. The most common response about why the industry representatives continued to participate was because they did not feel that their time was "being wasted". Instead, they felt that their opinions were valued and that they were actively making a difference.

Networking Opportunities. In addition to the purpose of the board, there are other short-term benefits to individuals and their businesses in the form of networking. The Dean acknowledged the importance of making the industry advisory board a professional event that benefits the industry representatives as professional individuals:

But if you're a board member at the community college, it gives you exposure to a lot of other people, you get to meet a lot of other people that are your peers, some of them might even be your competitors, but that's important. It also gives you credibility and who knows where that ends. You might end up working for one of the other companies. So there are a lot of benefits for them personally to be a part of the board. Because remember they don't get paid to be on the board.

The industry representatives did discuss how they benefitted from this aspect of their participation on the industry advisory board. One industry representative stated it directly and succinctly, "For me it's been a great networking event to meet other senior leaders." Others provided more depth:

Just as important as the candidate repository was the opportunity to network with other potential clients. As an agency recruiter, you're a third party to every company. Being able to create business development opportunities were the door to those. 
One of the committee chairs stated:

I have picked up a lot of good additional connections and business affiliations with people I didn't know before and people that I didn't know were prospective clients of mine. In that perspective, it's improved my client relationships with many of my existing clients.

One representative described the value that participation had granted them in greater detail:

I really wanted to meet people that maybe I could work with from the college point of view and a recruiting point of view. Funny enough, when we were speaking with the Chair of the Industry Advisory Board, we hadn't worked with his company before. Then he referred us to other managers and we won a project on the back of it and now we do some work for his company. We've actually gotten a lot of business with that company from this experience. Not necessarily because of the college, but because of our showing up and being active.

As described in more depth in position rules, industry representatives perceived their participation in a professional voluntary capacity. During the general meeting, it was observed that approximately ten minutes was given at the beginning of the meeting to the industry representatives to introduce themselves to the group. No other formal time was given for networking. However, the industry representatives were observed coming early and staying after the meeting to chat with one another.

Fulfilling as a civic commitment. The last payoff was the sense of civic duty that industry representatives perceived feeling as a result of their participation. The perception 
of giving back was closely tied to the college's reception of the feedback from industry representatives and the emphasis that was placed on changes benefiting students in the IT program. Civic service or "giving back" was the most commonly discussed theme with every individual interviewed. The Dean recognized how some saw the value that they were adding and stated, "It also gives them a sense of community involvement, giving back, and really helps their resume."

The Chair of the Industry Advisory Board connected how the Dean's communication and the changes that the industry board influenced facilitated the perception of participation as a community service:

I've been really surprised at how the college has handled the input of the board. Because as you saw with the video, I'm a little bit shocked that we're even there. I didn't expect for us to end up there in a year. It shows you that the college is motivated, you know, they're winners. They're there to help the students.

It was observed during the two general meetings open to all participants that the Dean spent some time showing examples of the changes that had taken place based on the feedback of the industry advisory board and explaining how these changes would benefit the students.

All of the industry representatives reiterated that they viewed their participation as a civic service throughout the study with different degrees of passion. One industry representative stated:

My motivation is that I want to do something for the community. I think community engagement is one of the important things and this is one of 
the things that I can do. So I see my role on the committee as being whatever is asked of me to take care of, I take care of.

While another industry representative described how participation on the industry advisory board was, also, about supporting her political beliefs.

"One of them is right now and for decades in this country, immigration reform issue...You can't restrict immigration laws and then say well need to save money so we're going to cut the education budget for the arts, teacher's salaries, etc... If you want to provide more job opportunities for US citizens, and cut down on immigration, you have to provide better educational opportunities...That's my motivation. It has to start here. Diversity and inclusion is so important in the workforce. We want to see more African Americans, Latinas, and females into engineering and STEM fields. Diversification of the workforce is so important." The degree of passion among the industry representatives varied, along with their reasons. However, it was a consistent and frequently discussed theme that the work on the board was being done to benefit students. Each of the industry representatives saw their participation as a civic engagement to support the community.

Partnership Outcomes

The second research question seeks to determine how the identified rules affect the outcomes of the partnership. The exact question is stated below.

- How do the identified rules affect the outcomes of the partnership?

There were three outcomes identified in the model. The first was the that the college was able to update and add to their curriculum to meet the needs of the IT sector within the 
region. Another was the creation of a marketing video. The last was an updated website geared towards students to make searching for relevant courses easier and more efficient. Each of the outcomes was based on a discussion prompted by the college at a general meeting. The highlights of the discussions were then brought to a committee meeting where they were discussed in greater depth and an action plan was established. The results of the action plan were then returned to the general meeting for critiques and celebration.

Updated and Added Curriculum \& Improved Website

The community college was able to add and update their curriculum based on a report from their curriculum committee. The curriculum committee was made up of a range of volunteers representing different organizations (including state government and small and large private companies) of the IT industry in the region. The industry volunteers wrote a report stating their findings and opinion on priorities based on discussions at two separate committee meetings. At the first meeting, only industry representatives were present. They determined that they needed a community college representative to join them to provide more background information and keep them oriented to the needs of the college. At the second committee meeting, an industry representative was present and provided this knowledge and the industry representatives were able to produce findings. The committee chair put their findings into a report that was given to the Dean and Coordinator of the community college. At the next general meeting, a presentation was given to all of the volunteers and community college representatives who participated on the Industry Advisory Board. 
The final report provided to the community college included a range of suggestions for improving curriculum, including courses specific to the demands of employers (i.e., cloud services and mobility, programming in Ruby, Python and Hadoop, ID management, penetration testing, salesforce, and improving soft skills and mentorship opportunities for students), removing courses that have lower demand from regional industry, changing the format of curriculum to boot camps for some courses, and updating the website to be easier to use. This report was written and delivered to the college in November 2015. The coordinator used the information to implement changes to the college's offerings. At the end of this study in October 2016, programs were added to the community college's offerings reflecting these suggestions. Amazon web services (cloud service) and mobile applications programs were added. Boot camps for specific programming applications were offered over the course of the year. In our interview, the coordinator specified that the implemented programs were purposely a reflection of the suggestions made by the curriculum committee and were in place because of availability of technology, resources, and instructors. It was the availability of resources and instructors that limited implementation of certain courses and programs. However, this led to a new conversation at the September 2016 general meeting about how to fill the seats for the new courses and programs that were offered. Despite the suggestions offered by the industry that the skills were in demand for employment, students were not registering for the courses.

As part of the final report given to the community college, the curriculum committee determined the community college's website was difficult to use and hard to understand. This suggestion came about as the committee utilized the website to 
determine the current course offerings and programs available. At the general meeting in September 2016, an updated, user-friendly version of the website was presented to the industry advisory board members. It was still behind a firewall with the intent to go live within a few months.

\section{Communication Efforts}

The marketing video was an initiative initially started with a prompt from the Coordinator and Dean. Their question for the industry advisory board was how can we market ourselves better to regional industry, so that they will have interest in giving our students internships and employment after they graduate. There were multiple results as a part of this prompt from the community college. The largest and most obvious was a marketing video. One industry member asked to give a presentation during the general session about how she had managed an internship program and marketed its success through a video. A marketing committee was created and decided they would commit to the creation of the video. The chair of the marketing committee made sure the video was created, by writing the script and working with community college staff through the video's completion. In the response to the first question, the Dean had mentioned two things that were integral to the video's creation. The first was that he was dedicated to supporting the initiatives of the committee. The other was that he wanted the committee to have power in the creation of results. Even though this was not the direction that the community college had intended with this prompt, they were willing to take risks and let the industry members move forward with their ideas.

Another smaller, less visible, response occurred as a result of the prompt. Industry advisory board members, who did not participate on the committees, still heard the 
message. Rather than participate in the creation of an advertisement, they returned to their companies and thought about how a community college graduate could fit into their organization. They then began to work within their organizations to create internship positions or attend presentations on student work with the intention of filling positions that were open within their organization.

\section{Informal Public Relations}

The industry advisory board is a form of public relations that gave regional industry leaders the opportunity to look at the internal work of the community college. It increased awareness of the programs that were offered, along with the quality. In addition, it improved the public image of the school and its graduates. Industry leadership from IT companies, from large to small organizations stated that they had hired at least one graduate as a result of their participation on the board.

Summary

In chapter four the findings from the study were laid out. The rules that governed the successful partnership between industry and a community college to improve an IT program were identified. They were organized (Figure 5) to show their role in the partnership and described in-depth throughout the rest of the chapter. The purpose of this was to understand the group dynamic that led to productive outcomes.

The purpose of Chapter five is to discuss these findings within the context of the framework and literature review to posit theory. First, chapter five will revisit the framework and some of the relevant literature to provide the reader context for the findings. Next, the limitations of the study will be readdressed. Last, the findings will be discussed within the context of the framework, literature, and limitations. 


\section{CHAPTER V \\ CONCLUSIONS}

Chapter five is dedicated to the conclusions of the case study. This chapter offers the researcher the opportunity to explain how the findings were supported or unsupported by the previous literature and research that had been conducted prior to the study. This purpose of this case study was to look in-depth at a successful community college and industry partnership to understand the organizational dynamics that helped it produce productive outcomes. To achieve this, this chapter will first revisit the institutional analysis and development framework. Then it will revisit some of the relevant research related to collaboration and the limitations of the study. Revisiting these aspects of the previous chapters will give readers and future researchers a better sense of how the findings from this study fit into their own experience and the greater body of research on partnerships between community colleges and industry. Last, the findings will be discussed within this context.

\section{Revisiting the Purpose of the Study}

The United States is at a disadvantage in the vocational and technical training of the workforce and at continually upskilling workers to meet the progressing needs of industry (Schwab et al., 2014). Globalization, advances in technology, among other factors were cited earlier in this paper that have contributed to the rapidly changing demands of industry (Friedman, 2005). Education has adapted slowly to these increasing demands, because of its own complex factors, including a fragmented and unaligned system of preparation for the workforce (Gray \& Herr, 1998; Kuchinke, 2002) and 
debates on how education best serves the public good (Chambers \& GoPaul, 2008; Hebel, 2014; Labaree, 1997).

Solutions to remedy this disconnect tend to be best applied at a regional scale, because it allows for development of specialization meant to accommodate unique characteristics of the businesses and citizens (Porter, 2000). Community colleges have often been cited as an obvious resource to bridge this gap because of their unique purpose of serving the individuals' and regional economic needs (Government Accountability Office, 2008; Leigh \& Blakely, 2013; Mellow \& Heelan, 2015; Skinner, Sanders, \& Beresford, 2004; Zinser \& Lawrenz, 2004). The most reiterated idea to bring community colleges and industry together are through partnerships with the goal of improving the workforce development pipeline and enhancing the innovative nature of industry (ACT, 2011; Lamos, Simon, Waits, Fulton, \& Bird, 2010; Soares, 2010; Vandal, 2009). While this is a great idea, collaboration is difficult, with about 50\% failing (Doz, 1996).

The purpose of this study was to observe a community college and industry partnership that had been successful in collaborating with industry to achieve positive results for its students and industry partners. This qualitative work was not going to solve the issue at hand. With the guidance of the literature on collaboration and the IAD framework as a lens for observing the behavior of institutions, however, it was intended that this study contribute to other qualitative works observing community college and industry partnerships, understand the application of collaboration literature, and begin to determine best practices for collaboration between community colleges and industry partnerships through a rigorous series of studies. 


\section{Revisiting the Framework}

The IAD framework utilized in this study was chosen because of its use in understanding the components that make up an institution. It also specifies how to begin the process of understanding institutions. It is suggested that the analysis of institutions should begin with identifying rules that the participants use to choose their actions in a decision-making scenario to determine how outcomes are produced. This framework gives the researcher a plan for studying individuals as its unit level because people as individuals define how they will organize to shape the behaviors, choices, and outcomes of an institution. The rules (both formal and informal) individuals identify how this governance structure within institutions occurs. How the rules intertwine was depicted in the literature review (Figure 4). Individuals, their specific roles, resources, the environment or context of their institution along with the rules that govern this context converge to determine outcomes. This framework was ideal for researching the complexity of how a community college and industry partnership operated successfully. As it helped to identify and sort the variables associated with collaboration. In addition, it defined the research questions in the study which were based on identifying the rules that governed the partnership between the community college and industry. Through the methods defined in the methodology chapter, the rules of the community college and industry partnership were identified within the defined categories of the IAD framework (Figure 5). The process of their identification and their application are discussed in greater depth proceeding Figure 4.

This study utilized the IAD framework as the lens for best observing the partnership between community colleges and industry. For the purposes of this study, it 
was assumed that the IAD framework is correct in its application of observing how complex factors affect one another to create outcomes that in turn form institutions. As such, there was no intention for this study to further develop the framework itself.

\section{Collaboration Literature}

The previous research done to specifically understand partnerships between community colleges and industry have been minimal. However, the literature that looks at how people work together has a great deal more depth (e.g. Amey, Eddy \& Campbell, 2010; Austin, 2000; Copa \& Ammentorp, 1998; Hord, 1986; Kezar, 2005; Mattessich \& Monsey, 1992; Mohr \& Spekman, 1994; Ostrom, 1990; Romzek, Leroux, \& Blackmar, 2012). Previous literature has defined cooperation and collaboration as being on a spectrum based on the amount of overlapping, invested, or shared resources contributed, rather than interchangeable terms (Hord, 1986). Cooperation involves the fewest amount of resources. Individuals get together to discuss an issue, share their knowledge and opinions, making limited other investments than time. A highly collaborative relationship will have a great deal more shared resources. Institutions may pool large sums of money, equipment, and people to achieve a common goal. In addition, eleven themes were identified in collaboration literature that contribute to the success of outcomes, environmental factors, membership characteristics, structure, communication, purpose, resources, leadership, rewards, incremental time, conflict resolutions, and sanctions. Rather than just identify the rules through the case study methodology as suggested by the IAD framework, they also should be examined through the lens of previous collaboration research. This allows for the determination of stronger theoretical 
propositions in the long-term. These will be discussed in greater depth within this chapter as the applicability of the rules are discussed.

\section{Applicability of the Rules}

The community college and industry partnership selected because of its success in working with industry representatives to achieve goals. There are several unique aspects to the culture of the city that supports the partnership. The partnership exists within a fast-growing city that places a high value on networking and community outreach as a part of its culture. There is a great deal of potential industry partners who are naturally inclined to be involved with schools and community development.

The literature that discusses community college and industry partnerships directly has primarily focused on context. It generally describes the demand for a particular set of skills due to regional industry and a community college that has agreed to assist in closing the gap. People who represent the community college, industry, and government come together and begin to discuss a plan for addressing the issue at hand. Because case studies are constrained by time, there is limited information about how these partnerships progress and develop over time to effectively meet the needs of the workforce. Due to the way this case study was approached, by looking specifically at variables that are specific to collaboration through a framework that has been designed to capture how organizations govern themselves with the unit of measurement being the individual, there was a great deal of detailed information garnered to understand the governance system that allows the partnership to operate successfully. 


\section{Participants}

In literature specific to community college and industry partnerships, stakeholders are an important facet. Representatives and leadership from the community college, industry, and government come together (e.g. Caton \& Mistriner, 2016; Sharfman, Gray, and Yan, 1991). In one paper, that describes how partnerships between outside organizations and community colleges should work together, it suggests that anyone being affected by the program should be invited to attend and shape the partnership (Copa \& Amentorp, 1998).

This study looked at a successful partnership that had been established and in operation for over a year. A more detailed look at the participants were identified. The community college placed a high value on hiring staff that had previous experience working in the field. The Dean felt that his staff would be more responsive to the needs of industry, if they had previous work experience within it. Industry representatives either had technical experience in the field or played a significant role in hiring people within the field. Representatives from industry either had the ability to hire new employees at their own organizations or were a part of a recruitment firm that assisted IT industries in finding potential employees. The value of who participated in the partnership was focused on the individuals that had practical abilities and knowledge to respond to the needs of the organizations.

\section{Scope Rules}

The identified rules within the scope category related strongly to the themes of membership characteristics. The concept of membership characteristics was highly discussed throughout general collaboration literature, those specific to higher education, 
and other collaborative models, with respect, commitment, and trustworthiness among participants being some of the most frequent themes (Amey, Eddy \& Campbell, 2010; Copa \& Ammentorp, 1998; Hord, 1986; Kezar, 2005; Mattessich, Murray-Close, \& Monsey, 2001; Mohr \& Spekman, 1994; Ostrom, 1990; Romzek, Leroux, \& Blackmar, 2012). These were certainly characteristics that existed among the participants, however, within this case, gratitude and appreciation were pointed out more frequently.

The literature does not discuss the concepts of gratitude and appreciation in relation to collaboration. It is possible that these characteristics are unique to community college and industry partnerships because of the philanthropic nature of participation. The community college relied on the varying degrees of commitment from individuals who saw their involvement as a volunteer effort. To continue to keep their volunteers active, the community college leadership, primarily the Dean and Coordinator, actively made efforts to show their appreciation by providing food, holding the meeting at a generally convenient time for most people, and often saying the words, "thank you." In addition, the Dean of the IT program always made an effort to be present at the meetings as a sign of respect to the volunteers who had also committed their time. The industry representatives often made note of the efforts made by the college to make them feel like their time was appreciated.

\section{Action Situation}

The literature does not explain the governance system or practical ways that participants have communicated in a community college and industry partnership. The primary unique finding was the pattern of discussion among the participants. Discussion topics and purpose were directed by the community college's Dean and Coordinator. 
However, the bulk of the time was given to the industry representatives to share their knowledge and experience. The industry representatives were, also, given active leadership responsibilities to create and shape the outcomes of the industry advisory board. The community college placed a great deal of importance on the involvement of the industry representatives in the creation of the outcomes produced.

\section{Payoff Rules}

The payoff rules are specific to the collaboration literature themes of rewards and conflict resolution or sanctions. All participants in a collaboration must benefit from working together. If participants are not able to benefit from the collaboration, they will likely dissolve the partnership. Within workforce development literature, the need for aligning the workforce and education has been discussed. Recommendations have often been made for industry and educational institutions to work together in order to improve the quality of the workforce (ACT, 2011; Lamos, Simon, Waits, Fulton, \& Bird, 2010; Soares, 2010; Vandal, 2009). This understanding of purpose has been standard for why industry and community colleges would use their resources to collaborate.

Two unexpected rules were identified in this study related to the payoff category. Industry representatives consistently referred to the philanthropic aspect of the industry advisory board. They felt their efforts would improve work opportunities for the unemployed or underemployed in the region. For themselves, they were able to identify this as a networking opportunity to meet their peers.

The last rule was the most crucial. If industry representatives did not see change related to their contribution, they would cease to participate. The community college had to show accountability for taking advantage of the participants' time. The changes the 
community college acted on did have to be large, quick, or sweeping, but they did have to show that they were listening and willing to act on the suggestions. The community college was aware of this stipulation and took multiple steps that appeared throughout the other rule categories to ensure that change based on industry's suggestions were made. The importance that the Dean placed on attending the meeting, and encouraging other administrators to participate, was an example of being dedicated to the college's improvement. Industry representatives could see that they had access to people with power in the college giving them a greater chance to have a purposeful impact. In addition, the college shared its power by asking industry to take charge of various projects. Each of these gave the industry representatives assurance that the time they invested in the college was not wasted.

\section{Assessing the Outcomes}

The assessment of outcomes as a part of this study was relevant to determine that the goals of the industry advisory board were achieved and if they were achieved in a way that the community college found productive. The goals for any community college and industry partnership will vary to different degrees due to a multitude of variables, including the type of programming, the degree program, the needs of the stakeholders, and the available resources. There were three outcomes noted as successfully achieved by the industry advisory board, a video marketing initiative, a user-friendly website, and updated programming to meet the needs of regional industry. There were no stated goals identified throughout the observations and interviews that did not go fulfilled.

\section{User-friendly Website}


An updated user-friendly website was a suggestion of the industry representatives to the community college in response to the college requesting more information about how they could improve their programming. Although, this was a side note about improving programming the critique was noted by the college's Dean and Coordinator. The goal required a great deal of resources from the community college side. This meant that there was an increased responsibility for the college to exercise their leadership and show steps to industry stakeholders that they were moving forward with a response based on the critique. The creation of the user-friendly website was considered a success by both the industry representatives and community college.

\section{Marketing Video}

On the other hand, a marketing video was suggested by the industry representatives in response to the college's prompt for suggestions on how to improve internship and work opportunities for their students. The marketing video was suggested to include various representatives from regional companies who have benefited from employing graduates from the IT programs. Although the Dean and Coordinator were surprised by the suggestion, they encouraged the industry members to move forward with their idea and offered resources in support of it. This particular idea required high investment from industry representatives, who wrote, scheduled, and appeared in the video. In this instance, the industry representatives opted to commit their own resources to the success of the initiative. Both the industry and community college representatives were happy with the final results. 


\section{Updated Programming}

The success of creating programming with an industry advisory board was only a moderate success at the close of this study. The updated programming had some greater complications because of the nature of an industry advisory board. Industry advisory board representatives are meant to represent the industry sector in a variety of capacities. This means that individuals have a range of knowledge and experience. The industry representatives are primarily acting as individuals using their resources in an extracurricular volunteer capacity. This means that the information they share may not directly translate to a job pipeline or interest from students into entering the suggested new programs. In this instance, the industry representatives could provide information on trends or assess and hire students based on the college's existing programs. Multiple industry representatives mentioned starting internship programs for students within their current organizations and hiring graduates, as a result of their participation as an industry representative. However, in terms of starting new programs and coursework, the college's Coordinator was frustrated. The type of feedback a volunteer industry advisory board offered required a great deal of legwork and investment on her part to create programs that had about a $50 \%$ chance of failure, if students did not opt in. The process required a great deal of "throwing things at a wall to see what sticks."

\section{Informal Public Relations}

In addition to the formal outcomes that were created as part of the goals of the community college and industry partnership, there were some important intangible outcomes that were made, including increasing public awareness, increasing positive perceptions regarding the quality of candidates, and incrementally increasing the number 
of available job openings and internships available to graduates. Increasing the number of job and internship openings was a tangible goal that the community college and industry advisory board had set for themselves. To achieve their goal, they created a marketing video to highlight the quality of their graduates. However, several of the industry leaders admitted that because of their involvement on the advisory board and participating in capstone projects, they invited several potential candidates in for interviews for entrylevel positions or for hiring. They were able to do this because of their leadership role within their companies but did not report it to the community college in an official capacity. All of the industry representatives who participated in the study walked away feeling positive about the community college and its graduates. By asking industry to share their thoughts and responding to them, they created a positive public relations effort that improved their relationship with the local IT industry.

\section{Implications for Future Research}

This case study is an important first step into understanding the nature of collaboration between community colleges and industry. Greater detail was identified in what allows a community college and industry partnership to achieve its goals. The rules identified were supported by broader literature in the field of collaboration giving greater trustworthiness to the findings. However, this was only one case study that looked at a successful industry advisory board relationship with a community college. The community college observed in this study was fortunate to be in a fast-growing city that placed a high value on networking as a part of its culture. This setting is unique. Community colleges in a rural setting would be an important comparison, as would a failing industry advisory board. These could provide more insight into which variables 
are universal versus unique. Additional case studies of partnerships are needed to explore the dynamics further so that theoretical propositions could be established through a metaanalysis of cases that can confirm that the identified details in this case could be generalized to other cases.

Updated programming for community colleges to meet the needs of a region is a relevant goal among industry advisory boards. In this case, there was limited effectiveness. However, this result could be for a mix of reasons, such as potential students not being aware of the availability of these courses, general lack of interest in the courses despite there being openings in the community, or the courses were not as relevant as communicated at the board meetings. Future case studies could provide more insight into how other colleges have gone about improving this process.

In addition, exploring more collaborative forms of community college and industry partnerships might be able to provide greater insight. Higher collaborative partnerships mean there is a greater form of investment between industry and the community college that may shift dynamics, but could, potentially, improve information sharing and communication. The type of information shared, as well as, greater understanding of the types of resources shared, would be integral into understanding how community colleges and industry can work together in the future.

Implications for Practice

The rich description is intended for those who administer other community college and industry partnerships to determine what is applicable to their own institutional system. This study was also intended to help inform theoretical propositions 
about how to improve best practices for community college and industry partnerships that can be tested further in the future.

The greater detail identified in the findings regarding involvement of appropriate stakeholders, distribution of power, high communication, and the effect of seeing the outcomes were integral to the success of this industry advisory board. The initial input into the success of the partnership is a list of stakeholders that have relevant experience and knowledge within the community college or industry that can help to inform the development of an IT program (depicted in Figure 5). Each of the people involved have reason to want the improvement of the college's programming and have a background that can help the college achieve that. Almost all of the rest of the rules in the model (Figure 5) contributed to the frequency and quality of the communication patterns. The structure of the partnership gave industry representatives opportunities to participate to their own degree, by volunteering to become highly involved in specific tasks or mildly by brainstorming when they had the availability. The scope rules were primarily intended to bolster the individuals who volunteered, so they would feel appreciated and encouraged to continue their service and contribution. When the community college had to take responsibility for a task that was communicated during a meeting by the industry representatives, they voluntarily held themselves accountable to following through and communicating their progress to the board (i.e. improving the website to make it userfriendly). This high level of communication gave everyone a sense of reward for their participation. The community collee was able to improve their programming, increase the number of students hired following graduation, and improve their marketing efforts to regional businesses. Industry representatives expressed a feeling of reward from their 
participation, either through their civic service or because they had a higher quality pool of applicants to hire.

$$
\text { Implications for Policy }
$$

The case study was performed on a large community college with a regional impact. They were supported by a state grant. The President's and Dean's messaging to the community were an important part of the success and establishment of the industry advisory board. Both leaders actively expressed support to the regional business community and encourage their administrators, teachers, and staff to do the same. Having leadership communicate the need to work with industry is an important aspect of what drove the community college teachers, administration, and staff towards working together. Responding to industry responsibly was a part of their job.

In addition, the state grant required that the community college work with regional industry when creating its programming. It did not state how or to what degree the college was required to work with industry. This was an effective policy. It set the standard for the community college to have a relationship with industry but was flexible in the school's approach. This allowed the community college to follow through with their relationships with industry as it applied to their scenario. 


\section{REFERENCES}

Acemoglu, D. (2009) Introduction to modern economic growth. Princeton: Princeton University Press.

Acemoglu, D. \& Autor, D. (2010). Skills, tasks and technologies: Implications for employment and earnings. In Orley Ashenfelter \& David E. Card (Eds.) Handbook of Labor Economics, Volume 4. Amsterdam: Elsevier.

ACT. (2011). Breaking new ground: Building a national workforce skills credentialing system. Iowa City, IA.

Agrawal, A., Alssid, J. L., Bird, K., Goldberg, M., Hess, S., Jacobs, J., Jenkins, D., Joseph, G., Kazis, R., King-Simms, S., Laprade, N., Long, S., Maduro, M., Petty, J., McClenney, K., McKeehan, P., McKenney, J., Mendoza, I., Meyer, A., Pfeiffer, M., Poppe, N., Rubin, J., Snyder, D., Taylor, J., \& Warford, L. (2007). Career pathways as a systematic framework: Rethinking education for student success in college and careers. Phoenix, AZ: League for Innovation in the Community College.

Allison, M. \& Kaye, J. (2005). Strategic planning for nonprofit organizations: A practical guide and workbook. Hoboken, NJ: Wiley.

Alter C., \& Hage, J. (1993). Organizations working together. Newbury Park, CA: Sage. Amey, M. J., Eddy, P. L., \& Campbell, T. G. (2010). Crossing boundaries creating community college partnerships to promote educational transitions. Community College Review, 37(4), 333-347. 
Amey, M. J., Eddy, P. L., \& Ozaki, C. C. (2007). Demands for partnership and collaboration in higher education: A model. New Directions for Community Colleges, 139, 5-14.

Anderson, J. C., Hakansson, H., \& Johanson, J. (1994). Dyadic business relationships within a business network context. Journal of Marketing, 58(4), 1-15.

Ansell, C. \& Gash, A. (2007). Collaborative governance in theory and practice. Journal of Public Administration Research and Theory, 18, 543-571.

Appleton J.V. (1995) Analysing qualitative interview data: Addressing issues of validity and reliability. Journal of Advanced Nursing (22).

Arbo, P. and P. Benneworth (2007). Understanding the regional contribution of higher education institutions: A literature review. OECD Education Working Papers, No. 9, OECD Publishing, Paris. Retrieved from http://dx.doi.org/10.1787/161208155312

Austin, J. E. (2000). Strategic collaboration between nonprofits and business. Nonprofit and Voluntary Sector Quarterly, 29(1), 69-97.

Autor, D. H., Levy, F. \& Murname, R. J. (2003). The skill content of recent technological change: An empirical exploration. The Quarterly Journal of Economics, 118(4), 1279- 1333

Axelrod, R. (1984). The evolution of cooperation. New York, NY: Basic Books.

Barnard, C. I. (1938). The Functions of the Executive. Cambridge, MA: Harvard University Press.

Becker, G. S. (1976). The Economic Approach to Human Behavior. Chicago: University of Chicago Press. 
Becker, H. S. (1998). Tricks of the trade: How to think about your research while you're doing it. Chicago, IL: University of Chicago Press.

Berger, C. R., \& Calabrese, R. J. (1975). Some explorations in initial interaction and beyond: Toward a developmental theory of interpersonal communication. Human Communication Research, 1(2), 99-112.

Boyne, G. A. (2002). Public and private management: What's the difference? Journal of Management Studies, 39(1).

Brady, H. E., Collier, D., \& Seawright, J. (2004). Refocusing the discussion of methodology. In H. E. Brady \& D. Collier (Eds.) Rethinking Social Inquiry: Diverse tools, shared standards. Lanham, MD: Rowman \& Littlefield.

Bresnahan, T. F., Brynjolfsson, E. \& Hitt, L. M. (2002). Information technology, workplace organization, and the demand for skilled labor: Firm-level evidence. The Quarterly Journal of Economics, 117(1), 339-376.

Brumbach, M., Conner, S., \& Van Nostran, D. (2009). Special insert: Community colleges thriving under the stimulus package. In Federal funding to two-year colleges report 2008-2009. Silver Springs, MD: Council for Resource Development.

Brynjolfsson, E., \& McAfee, A. (2012). Race against the machine: How the digital revolution is accelerating innovation, driving productivity, and irreversibly transforming employment and the economy. Lexington, MA: Digital Frontier Press.

Buchanan, J. M., \& Tullock, G. (1962). The calculus of consent. Ann Arbor, MI: University of Michigan. 
Burke Johnson, R. \& Onwuegbuzie, A. J. (2004). Mixed methods research: A research paradigm whose time has come. Educational Researcher, 33(14). DOI: $10.3102 / 0013189 \times 033007014$

Cahen-Salvador, E. G. (1926). La situation materielle et morale des fonctionnaires. Revue politique et parlementaire, 319. In Merton, R. K. (1957). Beauraucratic Structure and Personality. New York, NY: Free Press.

Cain, M.S. (1999). The community college in the twenty-first century: A systems approach. Lanham, MD: University Press of America.

Capelli, P. (2012). Why good people can't get jobs: The skills gap and what companies can do about it. Philadelphia, PA: Wharton Digital Press.

Carnevale, A. P., Jayasundera, T., \& Gulish, A. (2016). America’s divided recovery: College haves \& have nots. Washington, D.C.: Center on Education and the Workforce, Georgetown University.

Carnevale, A. P., Smith, N., Stone, III, J., R., Kotamraju, P., Steuernagel, B., \& Green, K. A. (2011). Career clusters: Forecasting demand for high school through college jobs, 2008-2018. Washington, D.C.: Center on Education and the Workforce, Georgetown University.

Carnevale, A. P, Smith, N., \& Strohl, J. (2010). Help wanted: Projections of jobs and education requirements through 2018. Washington, D.C.: Center on Education and the Workforce, Georgetown University.

Carnevale, A. P., Smith, N., \& Strohl, J. (2013). Recovery: Job growth and education requirements through 2020. Washington, D.C.: Center on Education and the Workforce, Georgetown University. 
Caton, J. \& Mistriner, M., (2016). Leading change: A case study of leadership practices from the development of the Niagara County Community College Culinary Institute. Community College Journal of Research and Practice, 40(7), 615-624.

Chamber, T. \& Gopaul, B. (2008). Decoding the public good of higher education. Journal of Higher Education Outreach and Engagement, 12(4)

Clinton, W. J. (1998). Address before a joint session of Congress on the State of the Union. In Public Papers of the Presidents of the United States: Vol: 1. Washington, DC: U.S. Government Printing Office.

Coase, R. (1937). The nature of the firm. Economica, 4(16), 386-405.

Cohen, A. M., \& Brawer, F. B. \& Kisker, C. B. (2014). The American community college ( $6^{\text {th }}$ ed.) San Francisco, CA: Jossey-Bass.

Collier, D., Seawright, J., \& Munck, G. L. (2004). The quest for standards: King, Keohane, and Verba's Designing Social Inquiry. In H. E. Brady \& D. Collier (Eds). Rethinking Social Inquiry: Diverse tools, shared standards. Lanham, MD: Rowman \& Littlefield.

Cook, K. S. \& Emerson, R. M. (1978). Power, equity and commitment in exchange networks. American Sociological Review, 43(5), 721-739.

Copa, G. H., \& Ammentorp, W. (1998). New designs for the two-year institutions of higher education. Berkeley: University of California, National Center for Research in Vocational Education.

Crawford, S. E. \& Ostrom, E. (1995). A grammar of institutions. The American Political Science Review, 89(3), 582-600. 
Creswell, J. W. (2013). Qualitative inquiry \& research design: choosing among five approaches $\left(3^{\text {rd }} \mathrm{ed}\right)$. Thousand Oaks, CA: Sage.

Culver-Dockins, N. (2012). An analysis of the collaborations between the California Workforce Investment Boards and the California community colleges (California State University, Fresno; Ed.D.). Retrieved from ProQuest (doc. ID: 1034456024)

Cutcliffe, J. R. \& McKenna, H. P. (1999). Establishing the credibility of qualitative research findings: The plot thickens. Journal of Advanced Nursing, 30(2), 374380.

Cyert, R. M. \& March, J. G. (1959). A behavioral theory of organizational objectives. In Haire, M. Modern Organization Theory. New York, NY: Wiley.

Daft, R. L. \& Lengel, R. H. (1984). Information richness: A new approach to managerial behavior and organizational design. Research in Organizational Behavior, 6, 191233.

DiMaggio, P. J., \& Powell, W. W. (1983). The iron cage revisited: Institutional isomorphism and collective rationality in the organizational field. American Sociological Review, 48, 147-160.

DiMattina, C., Alagaraja, M., Stone, III, J. R. (2013, February). Building regional HRD strategy: A qualitative case study of a community college and industry partnership. Paper presented at the Academy of Human Resource Development, Conference of the Americas, Washington, DC.

Doz, Y. (1996). The evolution of cooperation in strategic alliances: initial conditions or learning processes? Strategic Management Journal, 17: 55-58.

Drucker, P. (1993). Post-capitalist society. New York, NY: Harper Collins. 
Dyer, J. H., \& Singh, H. (1998). The relational view: cooperative strategy and sources of inter-organizational competitive advantage. Academy of Management Review, 24(4) 660-679

Fayol, H. (1916). General and industrial management. In Shafritz, J. M., Ott, J. S., \& Jang, Y. S. (eds.) Classics of Organization Theory $\left(7^{\text {th }}\right.$ ed). Boston, MA: Wadsworth.

Fiebleman, J. K. (1968). Disorder. In P. G. Kuntz. The Concept of Order. Seattle: Grinnell College.

Fitzpatrick, L. (July 20, 2009). Can community colleges save the U.S. economy? Time. Retrieved from http://content.time.com/time/magazine/article/0,9171,1909623,00.html

Fombrun, C. (1986). Structural dynamics within and between organizations. Administrative Science Quarterly, 31, 403-421

Friedman, M. (1953). Essays in positive economics. Chicago: University of Chicago Press.

Friedman, T. L., (2005). The world is flat: A brief history of the twenty-first century. New York: Farrar, Straus and Giroux.

Frederickson, H. G. (1991). Toward a theory of public administration. Administration \& Society, 22(4), 395-417.

Fulk, J., \& Boyd, B. (1991). Emerging theories of communication in organizations. Journal of Management, 17(2), 407-446.

Gary, B. (1989). Collaborating: Finding common ground for multi-party problems. San Francisco: Jossey-Bass. 
Goodman, M., Finnegan, R., Mohaadjer, L., Krenzke, T., \& Hogan, J. (2013). Literacy, numeracy, and problem solving in technology rich environments among U.S. adults: Results from the Program for the International Assessment of Adult Competencies 2012. National Center for Education Statistics, U.S. Department of Education.

Government Accountability Office. (2008, May). Workforce development: Community colleges and one-stop centers collaborate to meet $21^{\text {st }}$ century workforce needs. (Report \# GAO-08-547) Washington, D.C.

Gray, K. (1997). Seeking a 'tie that binds': Integrating training \& development/human resource development and teacher preparation. Journal of Industrial Teacher Education, 34(4) 80-86.

Gray, K. C. \& Herr, E. L. (1998). Workforce education: The basics. Boston, Massachusetts: Allyn and Bacon.

Gulick, L. (1937). Notes on the theory of organization. Papers on the Science of Administration. Institute of Public Administration, 3-13.

Guscina, A. (2008). Impact of macroeconomic, political, and institutional factors on the structure of government debt in emerging market countries. IMF Working Paper, WP/08/205, International Monetary Fund.

Hall, R. E., \& Jones, C. I. (1999). Why do some countries produce so much more output per worker than others? Quarterly Journal of Economics 114, 83--116.

Hamilton, V. (2012). Career pathway and cluster skill development: Promising models from the United States. OECD Local Economic and Employment Development 
(LEED) Working Papers, 2012/14, OECD Publishing. http://dx.doi.org/10.1787/5k94g1 s6f7td-en

Hays, D. G. \& Singh, A. A. (2012). Qualitative inquiry in clinical and educational settings. New York City: The Guilford Press.

Hayter, R. (1997). The dynamics of industrial location: The factory, the firm, and the production system. West Sussex, England: John Wiley \& Sons.

Hebel, S. (2014, March 2). From public good to private good: How higher education got to a tipping point. The Chronicle of Higher Education. Retrieved from http://chronicle.com/article/From-Public-Good-to-Private/145061

Hebel, S., Schmidt, P., \& Selingo, J. (2002, January 11). States face year of famine after decade of plenty: 36 legislatures must deal with deficits, and higher education may be a lower priority. The Chronicle of Higher Education, 48(18), A20.

Hoachlander, G., Sikora, A. C. \& Horn, L. (2003). Community college students: Goals, academic preparation, and outcomes. Washington, DC: U.S Department of Education, National Center for Education Statistics.

Holzer, H. (2010). Is the Middle of the U.S. Job Market Really Disappearing? A Comment on the Polarization Hypothesis. Center for American Progress. Retrieved from https://www.americanprogress.org/issues/labor/report/2010/05/13/7843/is-themiddle-of-the-u-s-job-market-really-disappearing/

Hord, S. M. (1986). A synthesis of research on organizational collaboration. Educational Leadership, 43(5), 22-26. 
Hudson, D. (2015, January 8). The president proposes to make community college free for responsible students for 2 years. Washington, D. C.: The White House Blog. Retrieved from https://www.whitehouse.gov/blog/2015/01/08/president-proposesmake-community-college-free-responsible-students-2-years

Imperial, M. T. (1999). Institutional analysis and ecosystem-based management: The institutional analysis and development framework. Environmental Management, 24(4), 449-465.

Information Technology Association of America. (2002). Jobs, skills, and the continuing demand for IT workers. Community College Journal, 73(2), 32-35.

International Labour Office. (2011). A skilled workforce for strong, sustainable and balanced growth: A G20 training strategy. Geneva, Switzerland.

Jackson, K. L., \& Glass, J. C., Jr. (2000). Emerging trends and critical issues affecting private fund-raising among community colleges. Community College Journal of Research and Practice, 24(9), 729-744.

Jacob, R. L, \& Hawley, J. D. (2009). The emergence of 'workforce development': Definition, conceptual boundaries and implications. In MacLean, R., \& Wilson, D. (eds.). International Handbook of Education for the Changing World of Work. Netherlands: Springer Science+Business Media.

Kanter, R. M. (1994). Collaborative advantage: The art of alliances. Harvard Business Review, 72, 96-108.

Katsinas, S. G., D’Amico, M. M., \& Friedel, J. N. (2012). Workforce training in a recovering economy: Perceptions of state community college leaders. Tuscaloosa, AL: University of Alabama, University of Alabama Education Policy Center. 
Kearns, K. P. (2000). Private sector strategies for social sector success: The guide to strategy and planning for public and nonprofit success. Jossey-Bass: San Francisco

Kezar, A. (2005). Redesigning for collaboration within higher education institutions: An exploration into the developmental process. Research in Higher Education, 46(7), 831-860. doi: 10.1007/s11162-004-6227-5

Kisker, C. B. \& Carducci, R. (2003). Community college partnerships with the private sector - organizational contexts and models for successful collaboration. UCLA Community College Review, 31(3).

Kline, W.B. (2008). Developing and submitting credible qualitative manuscripts. Counselor Education and Supervision, 47(4), 210-217.

Kolb, K. A. (1984). Experiential learning: experience as the source of learning and development. Englewood Cliffs, NJ: Prentice Hall.

Kuchinke, K. P. (2002). Strengthening ties between career-technical education and human resource development. Journal of Vocational Education Research, 27(2), 179-196.

Labaree, D. F. (1997). Public goods, private goods: The American struggle over educational goals. American Educational Research Journal, 34(1), 39-81.

Lamos, E., Simon M., Waits, M. J., Fulton, B., \& Bird, K. (2010). A sharper focus on technical workers how to educate and train for the global economy. Washington, D.C.: National Governors' Association Center for Best Practices. Retrieved from http://www.nga.org/files/live/sites/NGA/files/pdf/1007TECHNICALWORKERS. PDF 
Lederman, D. (2009, February 25). College for all. Inside Higher Ed. Retrieved from https://www.insidehighered.com/news/2009/02/25/obama

Leigh, E. J. \& Blakely, N. G. (2013). Planning local economic development: Theory and practice. Thousand Oaks, California: Sage Publications, Inc.

Lipset, S. M., Trow, M. A. \& Coleman, J.S. (1956) Union democracy: the internal politics of the International Typographical Union. New York: Free Press.

Logan, R.K., \& Stokes, L.W. (2004). Collaborative to compete: Driving profitability into knowledge economy. Toronto: Wiley.

Madhok, A. \& Tallman, S. B. (1998). Resources, transactions and rents: Managing value through interfirm collaborative relationships. Organization Science, 9(3), 326339.

Mankiw, N. G. (2014). Principles of microeconomics ( $7^{\text {th }}$ ed.). Mason, Ohio: Southwestern Cengage Learning.

Mankiw, N. G., Romer, D. \& Weil, D. (1992). A contribution to the empirics of economic growth. Quarterly Journal of Economics, CVII, 407-438.

ManpowerGroup. (2011). Talent shortage 2011 survey results. Retrieved from http://files.shareholder.com/downloads/MAN/1932906611x0x469531/7f71c882c104-449b-9642-af56b66c1e6d/2011_Talent_Shortage_Survey_US.pdf

ManpowerGroup. (2012). 2012 Talent shortage survey research results. Retrieved from http://www.manpowergroup.us/campaigns/talent-shortage2012/pdf/2012_Talent_Shortage_Survey_Results_US_FINALFINAL.pdf 
ManpowerGroup. (2016). Manpower employment outlook survey: United States.

Retrieved from http://manpowergroup.us/meos/2016/Q2-docs/meos-q2-2016report.pdf.

Manyika, J., Lund, S., Auguste, B., \& Ramaswamy, S. (2012). Help wanted: The future of work in advanced economies. London: McKinsey Global Institute.

Martin, F. (1989). Common-pool resources and collective action: A bibliography. Bloomington: Indiana University, Workshop in Political Theory and Policy Analysis.

Mattessich, P. W., Murray-Close, M., \& Monsey, B. R. (2001). Collaboration: What makes it work. A review of research literature on factors influencing successful collaboration (2nd ed.). Saint Paul, MN: Fieldstone Alliance.

McGinnis, M. D. (2011). An introduction to IAD and the language of the Ostrom Workshop: A simple guide to a complex framework. Policy Studies Journal, 39(1).

Mellow, G. O. \& Heelan, C. M. (2015) Minding the dream: The process and practice of the American community college. Lanham, MD: Rowman \& Littlefield.

Merton, R. K. (1957). Bureaucratic structure and personality. In Social Theory and Social Structure. New York: Free Press.

Meyer, J. W., Rowan, B. (1977). Institutionalized organizations: Formal structure as myth and ceremony. American Journal of Sociology, 83, 340-363.

Miles, M. B. \& Huberman, A. M. (1984). Qualitative data analysis: A sourcebook of new methods. Sage: Beverly Hills, CA. 
Mintzberg, H. (1983). Power in and around organizations. Englewood Cliffs, NJ: Prentice-Hall.

Mohr, J. \& Spekman, R. (1994). Characteristics of partnership success: Partnership attributes, communication behaviour, and conflict resolution techniques. Strategic Management Journal, 15, 135-152

Moltz, D. (2011). 'Triage' funding for community colleges. Inside Higher Ed. Retrieved from http://www.insidehighered.com/news/2011/03/31/state_budgets_and_community _college_funding

Morgan, D. L. (2007). Paradigms lost and pragmatism regained: Methodological implications of combining qualitative and quantitative methods. Journal of Mixed Methods Research, 1(1), 48-76. DOI: 10.1177/2345678906292462

Munck, G. L. (2004) Tools for qualitative research. In H. E. Brady \& D. Collier (eds). Rethinking Social Inquiry: Diverse tools, shared standards. Lanham, MD.: Rowman \& Littlefield Publishers, Inc.

Murphy, J. P. (1990). Pragmatism: From Pierce to Davidson. Boulder, CO: Westview Press.

National Association of Manufacturers. (2005). 2005 Skills gap report: A survey of the American manufacturing workforce. Washington, D.C.: National Association of Manufacturers, Center for Workforce Success and Deloitte Consulting LLP.

National Governors' Association Center for Best Practices. (2010). A sharper focus on technical workers: How to Educate and train for the global economy. Retrieved from 
http://www.nga.org/files/live/sites/NGA/files/pdf/1007TECHNICALWORKERS. PDF

North, D. C. (1986). New institutional economics. Journal of Institutional and Theoretical Economics, 142, 230-237.

North, D. C. (1993). New Institutional Economics and Development. Economic History, EconWPA. Retrieved from http://www2.econ.iastate.edu/tesfatsi/NewInstE.North.pdf

Obama, B. H. (2009). Remarks by the President on the American Graduation Initiative. Washington, DC: The White House, Office of the Press Secretary.

Ostrom, E. (1986). An agenda for the study of institutions. Public Choice, 48, 3-25.

Ostrom, E. (1990). Governing the commons: The evolution of institutions for collective action. Cambridge, UK: Cambridge University Press.

Ostrom, E. (1992). Crafting institutions for self-governing irrigation systems. San Francisco: Institute for Contemporary Studies.

Ostrom, E. (1998). A behavioral approach to the rational choice theory of collective action presidential address, American Political Science Association, 1997. American Political Science Review, 92(1).

Ostrom, E. (2005). Understanding institutional diversity. Princeton, NJ: Princeton University Press.

Ostrom, E. (2010). Institutional analysis and development: Elements of the framework in historical perspective. In C. Crothers. (Ed.) Historical developments and theoretical approaches in sociology, Volume II. Oxford, UK: UNESCO \& Encyclopedia of Life Support Systems. 
Ostrom, E., Gardner, E. \& Walker, J. (1994). Rules, games, and common-pool resources. Ann Arbor, MI: University of Michigan Press.

Ostrom, V. \& Ostrom, E. (1977). Public goods and public choices. In E. S. Savas (ed.) Alternatives for Delivering Public Services: Toward Improved Performance, 749. Boulder, CO: Westview.

Ostrom, E., Schroeder, L. and Wynne, S. (1993). Institutional incentives and sustainable development: Infrastructure policies in perspective. Boulder, Co: Westview Press.

O’Toole, J. \& Lawler, E. E. (2006). The new American workplace. New York: Palgrave Macmillan.

Partnership for 21st Century Skills. (2008). 21st century skills, education \& competitiveness: A resource and policy and guide. Tuscon, AZ.

Patton, M. Q. (1990). Qualitative evaluation and research methods. Newbury Park, CA: Sage.

Pfeffer, J. \& Salancik, G. R. (2003). The external control of organizations. New York: Harper \& Row.

Polski, M. M. \& Ostrom, E. (1999). An institutional framework for policy analysis and design. Retrieved from http://mason.gmu.edu/ mpolski/documents/PolskiOstromIAD.pdf

Porter, M. E. (2000). Location, competition, and economic development: Local clusters in a global economy. Economic Development Quarterly, 14(1), 15-34.

Poteete, A. R., Janssen, M. A., \& Ostrom, E. (2005). Working together: Collective action, the commons, and multiple methods in practice. Princeton, NJ: Princeton University Press. 
Pramuk, J., Domm, P., \& Breuninger, K. (Aug. 2017). Trump abruptly ends manufacturing council after CEOs disband strategic and policy forum. $C N B C$. Retrieved from https://www.cnbc.com/2017/08/16/trump-abruptly-endsmanufacturing-council-after-ceos-disband-strategy-and-policy-forum.html

Rainey, H. G., \& Bozeman, B. (2000). Comparing public and private organizations: Empirical research and the power of the a priori. Journal of Public Administration Research and Theory, 10(2), 447-469.

Rapoport, A. \& Chammah, A. M. (1965). Prisoner's dilemma. Ann Arbor: University of Michigan Press.

Rescher, N. (1977). Methodological pragmatism: A systems-theoretic approach to the theory of knowledge. New York City: New York University Press.

Reinsch, N. L. (2001). Business performance: communication is a compound, not a mixture. Vital Speeches of the Day, 67(6).

Richardson, R. C., Jr. (1975). Reforming community college governance. New Directions for Community Colleges. San Francisco: Josey-Bass.

Richardson, R. C., Blocker, C. E., \& Bender, L. W. (1972). Governance for the two-year college. Englewood cliffs, NJ: Prentice-Hall.

Richardson, R. \& Martinez, M. (2009). Policy and performance in American higher education: An examination of cases across state systems. Baltimore: The Johns Hopkins University Press.

Robson, C. (1993). Real world research: A resource for social scientists and practitioner researchers. West Sussex: John Wiley \& Sons Ltd. 
Roe, M. J. \& Siegel, J. I. (2011). Political instability: Effects on financial development, roots in the severity of economic inequality. Journal of Comparative Economics, 39(3), 279-309.

Romzek, B.S., Leroux, K., \& Blackmar, J.M. (2012) A preliminary theory of informal accountability among network organizational participants. Public Administration and Review, 71(3). 442-453

Rose, K., Schuck, B., Twyford, D., \& Bergman, M. (2015). Skunked: An integrative review exploring the consequences of the dysfunctional leader and implications for those employees who work for them. Human Resource Development Review, 14(1), 64-90.

Rugaber, C. S. (February 2017). US factory CEOs to Trump: Jobs exist; skills don't. Associated Press.

Schwab, K., Sala-i-Martin, X., \& Greenhill, R. (2011). The global competitiveness report 2011-2012. Geneva, Switzerland: World Economic Forum.

Schwab, K., Sala-i-Martin, X., \& Eide, E. B., \& Blanke, J. (2014). The global competitiveness report 2014-2015. Geneva, Switzerland: World Economic Forum.

Selznick, P. (1948). Foundations of the theory of organization. American Sociological Review, 13, 25-35.

Shafritz, J. M., Ott, J. S., \& Jang, Y. S. (2011). Classics of organization theory. Boston, MA: Wadsworth. 
Sharfman, M. P., Gray, B., \& Yan, A. (1991). The context of interorganizational collaboration in the garment industry: An institutional perspective. Journal of Applied Behavioral Science, 27(2), 181-208.

Shaw, J. S. (2010). Education—a bad public good? The Independent Review: A Journal of Political Economy, 15(2).

Shear, M. D. \& de Vise, D. (2009, 15 July). Obama Announces Community College Plan. The Washington Post. Retrieved from http://www.washingtonpost.com/wpdyn/content/article/2009/07/14/AR20090714 00819.html

Shimanoff, S. B. (1980). Communication rules: Theory and research. Beverly Hills, CA: Sage Publications.

Singh, J. V., Tucker, D.J., \& House, R. J. (1986). Organizational legitimacy and the liability of newness. Administrative Science Quarterly, 31, 171-193.

Skinner, D. Saunders, M. \& Beresford, R. (2004). Towards a shared understanding of skills shortages: Differing perceptions of training and development needs. Education \& Training, 46(4).

Skyrms, B. (2003). The stag hunt and the evolution of social structure. Cambridge University Press.

Smith, A. (1776). Wealth of nations. In C. J. Bullock. The Harvard classics. New York: P.F. Collier \& Son.

Soares, L. (2010). The power of the education-industry partnership: Fostering innovation in collaboration between community colleges and businesses. Washington, D.C.: Center for American Progress. 
Stake, R. (1994). Case studies. In N. K. Denzin \& Y. S. Lincoln (Eds.), Handbook of qualitative research. Thousand Oaks, CA: Sage Publications.

Stamps, D. (1995). Community colleges go corporate. Training, 32(12), 36-43.

Symonds, W. C., Schwartz, R. \& Ferguson, R. F. (2011). Pathways to prosperity: Meeting the challenge of preparing young Americans for the 21 st century. Cambridge, MA: Pathways to Prosperity Project, Harvard University Graduate School of Education.

Talisse, R. B. \& Aikin, S. F. (2011). The pragmatism reader: From Pierce through the present. Princeton, NJ: Princeton University Press.

Taylor, F. W. (1916). Principles of scientific management. Bulletin of the Taylor Society. In Shafritz, J. M., Ott, J. S., \& Jang, Y. S. (eds.) Classics of organization theory $7^{\text {th }}$ ed. Boston: Wadsworth.

Treib, H. B. \& Falkner, G. (2007). Modes of governance: Towards a conceptual clarification. Journal of European Public Policy 14(1), 1-20

Trist, E. L. (1983). Referent organizations and the development of interorganizational domains. Human Relations, 36, 247-268.

U. S. Bureau of Labor Statistics. (2012). Employment projections: 2010-2020 Summary. Retrieved from http://www.bls.gov/news.release/ecopro.nr0.htm.

U.S. Bureau of Labor Statistics. (2016). Which industries need workers? Exploring differences in labor market activity. Monthly Labor Review. Washington, D.C. Retrieved from http://www.bls.gov/opub/mlr/2016/article/which-industries-need$\underline{\text { workers-exploring-differences-in-labor-market- }}$ 
activity.htm?utm_source=Labor+Market+Data\&utm_campaign=BLSData\&utm $\underline{\text { medium=email }}$

U.S. Department of Education, Office of Vocational and Adult Education. (2012). Integrating industry-driven competencies in education and training through employer engagement. Washington, D.C.: Community College Virtual Symposium.

U.S. Department of Labor. (2009). $O * N E T$ : Beyond information intelligence. Washington, D. C.

U.S. Department of Labor. (2011) Trade adjustment assistance community college and career training grant program. Washington, D.C. Retrieved from https://doleta.gov/taaccet/

U.S. Department of Labor, Employment and Training Administration. (2009). Trade adjustment assistance community college and career training grants program. Washington, D.C. Retrieved from http://www.doleta.gov/taaccet/

Vaisey, S. (2006). Education and its discontents: Overqualification in America, 19722002. Social Forces, 85(2), 835-864.

Vajjhala, S. (2013). Building sustainable cities: New models for public-private partnerships. Bloomington: Indiana University, Workshop in Political Theory and Policy Analysis.

Vandal, B. (2009). Revving the education engine: Effectively aligning education, workforce and economic development policy. Denver, CO: Education Commission of the United States. 
Warford, L., \& Flynn, W. J. (2000). New game, new rules: The workforce development challenge. Leadership Abstract, 13(2), 1-4.

The White House, Office of the Press Secretary. (2013, April). Fact sheet:

Administration partners with industry to get service members credentialed for high-demand jobs. Retrieved from http://www.whitehouse.gov/the-pressoffice/2013/04/29/fact-sheet-administration-partners-industry-get-servicemembers-credenti

The White House, Office of the Press Secretary. (2017, February). Remarks by President Trump in Meeting with Manufacturing CEOs. Retrieved from https://www.whitehouse.gov/the-press-office/2017/02/23/remarks-presidenttrump-meeting-manufacturing-ceos

Williamson, O.E. (1973). Markets and Hierarchies: Some Elementary Considerations. The American Economic Review, 63 (2), May 1973, 316-325.

Williamson, O.E. (1985). The Economic Institutions of Capitalism: Firms, Market, Relational Contracting. New York, Free Press.

Yellen, J. L. "Current conditions and the outlook for the U.S. economy." The World Affairs Council of Philadelphia, 6 June, 2016, Philadelphia, Pennsylvania.

Yin, R. K. (2014). Case study research: Design and methods. Thousand Oaks, CA: Sage.

Yin. R. K. \& Davis, D. (2007). Adding new dimensions to case study evaluations: The case of evaluating comprehensive reforms. In. G. Julnes \& D. J. Rog (Eds.), Informing federal policies for evaluation methodology. San Francisco: JosseyBass. 
Zinser, R. \& Lawrenz, F. (2004). New roles to meet industry needs: A new look at the advanced technological education program. Journal of Vocational Education research, 29(2), 85-100. 


\section{APPENDICES}

\section{Appendix A. Observation Protocol}

Two meetings between the community college leadership and the industry representatives will be observed and recorded.

First step: Identify the people in the room and their titles.

Second step: Notes will focus on who speaks and the frequency of the discussion. In addition, any decisions/actions/next steps that are agreed to be taken on in the room, as well as who takes charge of the course of action will be noted.

Third: Recordings will be transcribed and analyzed or any additional rules that may discussed in the meeting.

Fourth: Meeting minutes will be collected to triangulate accuracy of observations. 


\section{Appendix B. Unstructured Interview Guide}

- What is your title?

- How did you come to define your role in the collaborative partnership?

- How did the community college help you to define your role?

- How does this work in relationship with your company?

- What has guided you most in how you define your role and participation in the collaboration?

- What is your role in the collaborative partnership?

- I heard you state/saw your email where you communicated [opinion/need for change/etc.,]. How does that communication fit your role?

- How did you decide that the email/voice was the right way to communicate your message?

- What do you perceive the expectations from your company/community college are?

- What does your regular participation look like? If this had daily activities, what would they be?

- How does this collaboration work operationally within your company?

- How did these activities come to be? What made them the normal operation?

- Who else do you perceive contributes to the collaboration?

- How are you effectively serving the community/students?

- College policy limits the role of industry to only performing X\&Y. How do you interpret this?

- How has this informed your participation and role?

- How have challenges or challenging opinions been handled? 


\section{Appendix C. Provisional List of Codes for Identified Rule Types}

Pos - Position rules define the authorized actions of the participants. Example positions are president, parent, or manager.

Bou - Boundary rules define the rules for entering and exiting positions. More specifically, the rules define who has access to a position, the process for determining eligibility for entering or leaving a position, and how the individual may leave the position. It includes the attributes or qualifications an individual must have to obtain the position.

Ch - Choice rules specify what a participant in a position has the choice of doing in a decision-making process based on the deontic component of the rules.

Agg - Aggregation rules define whether a single participant can make a decision or if the decision has to be made by some variation of the collective.

Info - Information rules define the flow of information. They give authorization for the participants to share information about the structure and current events. It also describes the frequency and accuracy of the communication.

Pay - Payoff rules define the rewards or sanctions that are the result of decisions. Sco - Scope rules encompass all other rules that cannot be defined in these other 


\title{
CURRICULUM VITAE
}

\author{
Cara DiMattina-Ryan \\ 608 Cottonwood Creek, Dripping Springs, TX, 78620
}

(347) 819-2974

Caradi84@gmail.com

\section{PUBLICATIONS}

Stone, J.R. II, \& DiMattina-Ryan, C. (2015). College \& career ready mathematics.

Louisville, KY: National Research Center for Career \& Technical Education.

Jean-Marie, G., \& DiMattina-Ryan, C., (2015). Educational attainment across the global context: complexities, turbulence, and possibilities. In Comparative international perspectives on education and social change in developing countries and indigenous peoples in developed countries. Charlotte, NC: Information Age Publishing,inc

DiMattina-Ryan, C., \& Ferris, L. Taking charge of your career path: A future trend of the workforce. (2013, March). In Techniques: Connecting Education and Careers

DiMattina-Ryan, C., Alagaraja, M., \& Stone II, J. R. (2013) Building regional HRD strategy: A qualitative case study of a community college and industry partnership. Presented at the Academy of Human Resource Development, Washington, DC.

DiMattina-Ryan, C. (2009, October). Haiti's economic growth initiative and CTE. In Techniques: Connecting Education and Careers.

\section{EXPERIENCE}

ASSOCIATION FOR CAREER AND TECHNICAL EDUCATION (ACTE)

Alexandria, VA

A non-profit advocating for career and technical education

Dissemination Coordinator (October 2008-Present)

- Work directly with the Communication Director at the National Research Center for Career and Technical Education (NRCCTE)

- Communicate research produced by the NRCCTE to about 30,000 teachers and administrators in the career and technical education (CTE) industry and to leaders in the Department of Education

- Coordinate and implement logistics for the production of NRCCTE products, such as research reports and webcasts

- Oversee a budget of $\$ 600,000$

- Represent the NRCCTE at education conferences throughout the year

- Coordinate and promote the ACTE Excellence Awards, honoring individual teachers and administrators who excel in the career and technical education industry

HOUSING INTERNATIONAL ORGANIZATION (HIO), INCORPORATED New York City, NY 
A start-up real estate brokerage firm that used one-third of its profits to aid development projects globally

Mass Communication Specialist (February 2008 - May 2008)

- Promoted the core business and its non-profit projects by networking with United Nations officials

- Designed websites and marketing materials that successfully attracted an increased amount of business to the firm

\section{MACMILLAN COMMUNICATIONS}

New York City, NY

Boutique public relations firm specializing in investor relations and law services Assistant Account Executive (June 2007 - March 2008)

- Assisted in the launch of several different financial products, by coordinating events held at venues such as the New York Stock Exchange and aggressively pitching media that garnered press in major financial publications

- Followed trends in the media to pitch products and financial advisors to reporters at key moments to gain recognition in feature articles that appeared in national magazines, including Kiplinger's Personal Finance and Investor's Business Daily

- Coordinated media tours for CEO's and other experts

- Developed relationships with reporters at major daily print media, trade publications and television programs

MWW GROUP

East Rutherford, NJ

Mid-size PR agency

Consumer Affairs Intern (January 2007- May 2007)

- Wrote pitches for Samsung's consumer affairs division and secured placement in Family Circle and USA Today

- Supported Volkswagen's lifestyle team in coordinating entertainment for an event prior to the New York Auto Show

\section{TIME MAGAZINE, EUROPEAN EDITION}

London, UK

Public Affairs Intern (September 2005 - December 2005)

- Wrote country-specific press releases to media outlets throughout Europe, the Middle East and Africa encouraging continued readership and the use of TIME as a source of reference

- Directly involved in the process of planning and coordinating the Awards Ceremony for Time's European Heroes

- Coordinated small corporate events and parties

\section{EDUCATION}

WILLIAM PATERSON UNIVERSITY

Wayne, NJ

Bachelor of Arts, Communication

May 2007 
- Concentration in Journalism / Public Relations GPA 3.479

- Minor in Political Science 